UNIVERSIDADE DE SÃO PAULO

FACULDADE DE SAÚDE PÚBLICA

\title{
UMA CONTRIBUIÇÃO À CIÊNCIA PÓS-NORMAL: APLICAÇÕES E DESAFIOS DA AMPLIAÇÃO DA COMUNIDADE DE PARES EM CONTEXTOS SOCIOAMBIENTAIS E DE SAÚDE
}

\section{LEANDRO LUIZ GIATTI}

Tese apresentada ao concurso para obtenção do título de Livre-docente junto à Faculdade de Saúde Pública da Universidade de São Paulo.

Departamento de Saúde Ambiental. Área: Planejamento, Política e Gestão Ambiental. Especialidade: Planejamento em Saúde Ambiental.

São Paulo 



\title{
UMA CONTRIBUIÇÃO À CIÊNCIA PÓS-NORMAL: APLICAÇÕES E DESAFIOS DA AMPLIAÇÃO DA COMUNIDADE DE PARES EM CONTEXTOS SOCIOAMBIENTAIS E DE SAÚDE
}

\author{
LEANDRO LUIZ GIATTI
}

Tese apresentada ao concurso para obtenção do título de Livre-docente junto à Faculdade de Saúde Pública da Universidade de São Paulo.

Departamento de Saúde Ambiental. Área: Planejamento, Política e Gestão Ambiental. Especialidade: Planejamento em Saúde Ambiental.

São Paulo 
É expressamente proibida a comercialização deste documento, tanto na sua forma impressa como eletrônica. Sua reprodução total ou parcial é permitida exclusivamente para fins acadêmicos e científicos, desde que na reprodução figure a identificação do autor, título, instituição e ano de publicação da tese. 
À todos os afetados pela tragédia de Santa Maria. 



\section{AGRADECIMENTOS}

Meus sinceros agradecimentos aos Professores Aristides Almeida Rocha e Maria Cecília Focesi Pelicioni, mestres e coordenadores de importantes projetos em que participei.

Á minha querida família: Luciane Viero Mutti, Henrique Mutti Giatti e Bibiana Mutti Giatti, pela paciência e estímulo.

À Renata Ferraz de Toledo, com quem venho compartilhando algumas das ideias fundamentais para essa tese e por ter feito uma dedicada revisão no manuscrito. À Ricardo Agum, pelos debates interessantes sobre o tema. E ao Prof. Pedro R. Jacobi, colega experiente e entusiasta de novos desafios, na pessoa de quem agradeço aos colegas que no ano de 2012 contribuíram em discussões do grupo de estudos sobre ciência pós-normal.

Ás minhas colegas de departamento, sempre presentes, que vêm constantemente recebendo meu entusiasmo, compartilhando leituras e discutindo importantes ideias sobre meu trabalho, são elas: Maria do Carmo de Oliveira Dória, Silvana Audrá Cutolo e Solange Martone Rocha.

Ao grande colega Carlos Machado de Freitas, que sempre me oportuniza grande aprendizado.

Aos professores Arlindo Philippi Jr., Wanda Maria Risso Günther, Rodolfo Andrade de Gouveia Vilela e Maria Tereza Pepe Razzolini, colegas de departamento com quem tenho compartilhado ideais e projetos.

Aos estudantes de pós-graduação sob minha orientação que vem contribuindo com interessantes debates, enriquecendo e motivando meu trabalho. Dentre estes menção à importante colaboração de Natasha Ceretti Maria, na busca de bibliografias e apoio na formatação de trechos do manuscrito.

À Henriette Scholtze pela dedicada revisão. À Adilson M. Godoy pelo companheirismo e colaboração na elaboração de figuras.

À instituições de fomento que contribuem ou contribuíram com projetos de pesquisa elementares enquanto bases para este texto: FAPESP (processo 2010-20899-0); Fundação Nacional de Saúde (convênio FUNASA/USP 513/04); e Fundação de Amparo à Pesquisa do Estado do Amazonas (Desenvolvimento Científico Regional, Edital MCT/CNPq/FAPEAM № 018/2004). 



\section{RESUMO}

GIATTI, L. L. Uma contribuição à ciência pós-normal: Aplicações e desafios da ampliação da comunidade de pares em contextos socioambientais e de saúde [tese de livre-docência]. São Paulo: Faculdade de Saúde Pública/USP; 2013.

Questões socioambientais de elevada influência na saúde humana vêm se correspondendo intensamente com as transições e dilemas contemporâneos, inclusive no que diz respeito à ciência clássica, por sua forma de respaldar as decisões políticas. Esse contexto vem demandando a participação dos sujeitos dos riscos na produção e controle de qualidade de saberes, assim como nos processos de governança mediante à crescente escala de incertezas e disputas em jogo. Tendo como ponto de partida uma experiência em pesquisa participativa em terra indígena na Amazônia brasileira esta tese propõe uma crítica avaliação de diferentes aspectos de projetos de pesquisa e intervenção com foco em contextos socioambientais e de saúde. Associando-se com os pressupostos da ciência pós-normal, faz-se uma classificação de artigos selecionados em revisão sistemática sobre o tema, categorizando aspectos de aplicação de instrumentos participativos, escala de abordagem e funcionalidade das experiências descritas. Dentre 170 artigos selecionados, apenas 10 representaram o mais elevado grau de participação dialógica por meio da combinação cíclica de instrumentos e foco em fenômenos emergentes. Os demais desempenharam condições bastante exitosas de participação, porém, não representaram uma perspectiva de sustentabilidade, pois não dialogaram com prospectiva de cenários futuros e/ou não proveram meios de conexão por dinâmicas globais-locais, indutoras da constante reprodução dos riscos. Por meio do panorama possibilitado pela revisão bibliográfica foi possível identificar que um novo paradigma das relações ciência, sociedade e política está apenas se iniciando.

Descritores: ciência pós-normal, comunidade ampliada de pares, pesquisa participativa, saúde ambiental, saúde pública. 



\section{ABSTRACT}

GIATTI, L. L. A contribution to the post-normal science. Applications and challenges for the extended peer community in socio-environmental and health contexts [associate professorship thesis]. São Paulo: Faculdade de Saúde Pública/USP; 2013.

Socio-environmental issues of high impact on human health are attuning intensely to contemporary transitions and dilemmas, also in respect of the classic science, in ways of backing political decisions. This context asks for the participation of the subjects of risks in the production and control of the quality of knowledge, as well as in the processes of governance by means of the increasing scale of uncertainties and decision stakes. As a starting point there is this experience in participatory research in indigenous land, in the Brazilian Amazon, which is being used in this thesis as a critical evaluation of different aspects of research and intervention projects, focusing on socioenvironmental and health contexts. Conjoining the presuppositions of the post-normal science, a classification of selected articles, through a systematic review on the theme, was made, categorizing aspects of the application of participatory instruments, scales of approach and functionality of the described experiences. Among the 170 selected articles, only 10 represented de highest grade of participatory dialogic by means of cyclic combinations of instruments and focus on emerging phenomena. All the others performed very successful participations, although not representing a perspective of sustainability, once they didn't converse with prospective future scenarios and/or didn't offer means of connection by global-local dynamics, which are constant inductors of risk reproduction. By means of the panorama offered by the bibliographic review, it was possible to identify that a new paradigm of relations between science, society and politics is just beginning.

Keywords: post-normal science, extended peer community, community-based participatory research, environmental health, public health. 



\section{ÍNDICE}

1. Apresentação - Antecedentes, subsídios e objetivos 1

2. Introdução - Questões contemporâneas e ciência Pós-normal 9

3. A demanda dialógica nos contextos socioambientais e de saúde 15

3.1. Desafios nas questões socioambientais e de saúde humana 15

3.2. Incertezas e fenômenos emergentes 24

3.3. Ampliação da comunidade de pares 28

4. Lições e desafios identificados em uma experiência de pesquisa participativa de base comunitária em terra indígena $\quad 36$

4.1. Conceitos relevantes sobre participação 36

4.2. A combinação cíclica de instrumentos em abordagem de pesquisa-ação 38

4.3. Desafios para a ampliação da comunidade de pares: demarcando categorias de análise $\quad 48$

5. Uma revisão sistemática de literatura sobre pesquisa participativa e ampliação de comunidade de pares em contextos socioambientais e de saúde $\quad 55$

5.1. Método de revisão sistemática 55

5.1.1. Hipóteses e perguntas da revisão sistemática $\quad 57$

5.1.2. Busca de evidências 59

5.1.3. Análise crítica e classificação dos artigos incluídos 63

5.2. Resultados e discussão da revisão sistemática de literatura 63

5.2.1. - Classificação e análise das publicações quanto aos instrumentos participativos dialógicos 69

5.2.2. - Classificação e análise das publicações quanto à escala territorial de abrangência das intervenções 75

5.2.3. Classificação e análise das publicações quanto a funcionalidade 80

5.2.4. Análise integrada e distribuição geográfica das pesquisas 89

6. Considerações finais 102

7. Referências 105

8. Anexo - Lista completa de referências utilizadas em revisão sistemática 


\section{Lista de figuras}

Figura 1 - Sobreposição riscos ambientais em diferentes grupos populacionais 17

Figura 2 - Estrutura conceitual de interação entre bem-estar humano, serviços dos ecossistemas e forças motrizes diretas e indiretas de mudanças nos ecossistemas 21

Figura 3 - Fluxograma metodológico de etapas de revisão sistemática $\quad 57$

Figura 4 - Aplicação do diagrama de ciência pós-normal sobre a classificação de artigos selecionados em revisão sistemática 94

Lista de gráficos

Gráfico 1 - Evolução temporal por ano de publicação de artigos selecionados em revisão sistemática $\quad 69$

Gráfico 2 - Distribuição de artigos selecionados em categorias segundo aplicação de instrumentos participativos 71

Gráfico 3 - Distribuição de artigos selecionados em categorias segundo classificação por escala de abordagem $\quad 77$

Gráfico 4. Distribuição de artigos selecionados em categorias segundo classificação por funcionalidade $\quad 82$

Gráfico 5 - Relação entre artigos quanto à aplicação de instrumentos e funcionalidade $\quad 91$

Gráfico 6 - Distribuição das intervenções relatadas em estudos selecionados através dos cinco continentes $\quad 97$ 


\section{Lista de quadros}

Quadro 1 - Publicações e projetos de pesquisa de participação do autor que constituem subsídios e motivação à elaboração desta tese

Quadro 2 - Alguns agravos significativamente atribuíveis a fatores ambientais e carga ambiental na causalidade $\quad 18$

Quadro 3 - Alguns instrumentos aplicados em pesquisa-ação, contribuição na participação e classificação por tipo de feedback provido, lauaretê, 2005 - 2008

Quadro 4 - Dimensões e categorias de análise para processos participativos e promoção da ampliação de comunidade de pares $\quad 52$

Quadro 5 - Critérios de inclusão e exclusão para artigos em revisão sistemática de literatura de pesquisas e intervenções participativas em contextos socioambientais e de saúde 62

Quadro 6 - Relação de periódicos com apenas um artigo selecionado em revisão sistemática $\quad 67$

Lista de tabelas

Tabela 1 - Periódicos com dois ou mais artigos selecionados em revisão sistemática $\quad 66$

Tabela 2 - Inter-relações entre as categorias de classificação aplicadas para artigos selecionados em revisão sistemática 90

Tabela 3 - Países com dois ou mais artigos classificados por apresentarem intervenção em seu território 99 



\section{Apresentação - Antecedentes, subsídios e objetivos}

A motivação para a composição desta tese reside na trajetória de pesquisa e docência do autor, remontando ao curso de doutorado em Saúde Pública na Faculdade de Saúde Pública da Universidade de São Paulo. Na respectiva pesquisa, o autor, acompanhado de colaboradores e de seu orientador, o Prof. Aristides Almeida Rocha, publicaram um artigo na Revista de Saúde Pública (GIATTI et al. 2004) em que se explorou aspectos inerentes à percepção dos sujeitos mediante a problemas de saneamento básico.

Mas uma experiência definitivamente recondutora do interesse deste pesquisador foi a participação em um projeto de pesquisa ocorrido entre 2005 e 2008 em terra indígena na região do Alto rio Negro, Estado do Amazonas. Como ponto forte destaca-se o primeiro contato com a metodologia de pesquisa-ação, tendo como foco a questão da inexistência de infraestrutura em saneamento básico, e a continuidade de hábitos e práticas sanitárias não correspondentes com a realidade do local, que se constituía como um núcleo de feições urbanas.

O interesse na pesquisa participativa, mais especificamente no envolvimento colaborativo de sujeitos e pesquisadores, buscando soluções compatíveis com a realidade, a utilização de diversos instrumentos de pesquisa, a possibilidade de um aprofundamento em aspectos socioculturais e a imersão na complexidade necessária à resolução dos problemas, são fatores que contribuíram com o interesse em sucessivas revisões bibliográficas sobre temas correspondentes. Além disso, o correr do tempo e as publicações inerentes permitiram realizar constantes reflexões sobre contextos socioambientais e de saúde e a necessidade da inclusão dos sujeitos para a promoção da saúde.

Um avanço especial decorreu do contato com publicações no campo da ciência pós-normal, na leitura de artigos de Silvio Funtowicz e Jerome Ravetz, incorporados em citações no decorrer do texto desta tese. Mas a experiência de 
pesquisa participativa que se mencionou teve algumas características que a distanciavam muito do referencial da ciência pós-normal, destacando-se: A pesquisa foi realizada em uma escala local, em uma comunidade indígena; E o tema de pesquisa e intervenção se constituía como um assunto que não contava, aparentemente, com questões científicas a serem superadas.

Ou seja, havia certa distância do contexto em terra indígena para alguns pressupostos de Funtowicz e Ravetz (1993), como no que diz respeito às incertezas científicas que necessitam uma mediação da sociedade quanto ao controle da qualidade do processo de subsídio às políticas públicas. Mas, a partir de 2008, em colaboração em equipe de pesquisa com o pesquisador Carlos Machado de Freitas, da Escola Nacional de Saúde Pública da Fundação Oswaldo Cruz - ENSP/FIOCRUZ, um novo horizonte de investigação proveu importante contribuição para melhor dialogar com a ciência pós-normal. Trata-se de um projeto sobre indicadores de sustentabilidade ambiental e de saúde para a cidade de Manaus, em que se previa a ampliação da comunidade de pares (Funtowicz e Ravetz 1993; 1997) no processo de gestão intersetorial para aquela cidade.

O desafio de uma abordagem participativa no âmbito de uma grande cidade, implicando em dialogar com aspectos inerentes ao seu território e sendo Manaus a maior cidade da região Pan-Amazônica, possibilitou dois diferentes caminhos com uma interessante intersecção: Primeiramente, foi cogitado em como ampliar um processo participativo utilizando a experiência em uma comunidade indígena, para a escala de uma grande cidade; Em segundo momento, houve o questionamento de como encontrar correspondência e representatividade a partir do que o diálogo com gestores na escala urbana deveria se conectar com as escalas menores como bairros ou comunidades, pois é nesse nível que se constituem os contextos de vulnerabilidade.

No encontro entre os questionamentos entre escalas de abordagem, foi possível situar amplas correspondências entre uma pesquisa participativa de base comunitária com os pressupostos da ciência pós-normal. Sendo a proposta de Funtowicz e Ravetz interpretada como bastante arrojada, desafiadora e 
correspondente aos dilemas de nossa contemporaneidade, é justamente quanto às correspondências com as premissas da ciência pós-normal, suas aplicações e desafios que esta tese trata.

A seguir apresenta-se o Quadro 1 em que se encontra uma síntese de elementos relevantes na produção e na participação de pesquisas por parte do autor, considerando-se o tema em foco. Neste, ressalta-se experiências interdisciplinares, aprendizagem colaborativa entre pesquisadores e sujeitos, a valorização da subjetividade dos atores sociais envolvidos com os riscos e, por fim, a perspectiva de ampliação de abordagens participativas incorporando gestores públicos e representantes da sociedade civil.

Quadro 1 - Publicações e projetos de pesquisa de participação do autor que constituem subsídios e motivação à elaboração desta tese.

Artigo: Condições de saneamento básico em Iporanga, Estado de São Paulo. Revista de saúde pública (GIATTI et al. 2004). Como um componente da pesquisa de doutorado do autor, este texto dialoga com questões de saneamento básico e a importância da percepção dos sujeitos quanto aos problemas inerentes, como as consequências à saúde.

Projeto de Pesquisa: Pesquisa-Ação no distrito de lauaretê do município de São Gabriel da Cachoeira: proposta de melhorias sanitárias e de hábitos. Coordenadores: Maria Cecília Focesi Pelicioni e Aristides Almeida Rocha. Financiamento da Fundação Nacional de Saúde (convênio FUNASA/USP 513/04). Vigência 2005-2007. Complementado por fomento da Fundação de Amparo à Pesquisa do Estado do Amazonas, edital MCT/CNPq/FAPEAM № 018/2004, com objetivo no estudo de saúde ambiental em lauaretê e vigência estendida até 2009.

Artigo: Comunidade indígena na Amazônia: metodologia da pesquisa-ação em educação ambiental (TOLEDO et al. 2006). Traz uma importante contribuição metodológica e crítica 
quanto à aplicação de múltiplos instrumentos de forma integrada em um processo de pesquisa-ação.

Artigo: Condições sanitárias e socioambientais em lauaretê, área indígena em São Gabriel da Cachoeira/AM (GIATTI et al. 2007). Descreve um diagnóstico participativo sobre aspectos socioambientais, com foco na precariedade do saneamento básico. Ressalta o envolvimento dos sujeitos e um processo de retroalimentação na combinação de questionamentos e aplicação de instrumentos participativos e outros complementares característicos de ciência clássica, como análise de qualidade de água.

Artigo: Reflexões sobre água de abastecimento e saúde pública: um estudo de caso na Amazônia Brasileira (GIATTI 2007). Uma importante contribuição quanto a uma análise integrada do problema de abastecimento público de água em uma pequena cidade no interior do Amazonas. Envolve aspectos demográficos, étnicos/antropológicos, logísticos e avaliação de qualidade de água disponível para abastecimento público.

Projeto: Abordagem ecossistêmica para o desenvolvimento de indicadores e cenários de sustentabilidade ambiental e de saúde na cidade de Manaus / AM. Coordenação de Carlos Machado de Freitas, ENSP/FIOCRUZ, vice-coordenação: Leandro L. Giatti. Financiamento: Edital Fiocruz/Vice-Presidência de Pesquisa e de Serviços de Referência e Meio Ambiente 01/2007 - "Cidades Saudáveis: Saúde, Ambiente e Desenvolvimento". Vigência 2008 a 2011. Este projeto possibilitou a motivação para se planejar uma abordagem participativa em escala ampliada, efetuada por meio de um seminário interdisciplinar tratando de condições e tendências em sustentabilidade e saúde, em Manaus. O referido seminário ocorreu em junho de 2011 e teve uma metodologia de discussões sobre produtos da pesquisa, envolvendo apresentações e debates com gestores públicos de distintos setores, além de acadêmicos e representantes da sociedade civil.

Livro: Enfoques ecossistêmicos em saúde - Perspectivas para sua adoção no Brasil e em países da América Latina (FREITAS et al. 2009). Consta de produto da realização de um seminário na sede do Instituto Leônidas e Maria Deane, Fiocruz/Amazônia, em Manaus no mês de dezembro de 2008. O seminário foi organizado por Leandro Giatti e 
colaboradores, contou com a participação de pesquisadores da Fiocruz e de colaboradores da Organização Pan-americana de Saúde, em que foram abordados enfoques ecossistemas em saúde, incorporando amplos processos de colaboração acadêmica com atores sociais.

Artigo: Urbanidade rural, território e sustentabilidade: relações de contato em uma comunidade indígena no noroeste amazônico (TOLEDO et al. 2009). Aborda aspectos interdisciplinares da caracterização do território que influenciam nas dinâmicas de urbanização e na saúde da população.

Artigo: Indicadores de sustentabilidade ambiental e de saúde na Amazônia Legal, Brasil (FREITAS e GIATTI 2009).

Livro: Sustentabilidade ambiental e de saúde na Amazônia Legal, Brasil: Uma análise através de indicadores (FREITAS e GIATTI 2010).

Estas duas produções se acoplam ao projeto de pesquisa referente a Manaus e fornecem um importante subsídio para a compreensão desta cidade no contexto territorial em termos de ambiente e saúde. A abordagem com indicadores vem se constituindo, na produção deste autor, como um importante instrumento para viabilizar o diálogo com gestores em escala ampliada de participação de atores sociais na governança ambiental e da saúde.

Artigo: Exposição à água contaminada: percepções e práticas em um bairro de Manaus / Estado do Amazonas, Brasil (GIATTI et al. 2010). Sob uma metodologia descritiva de rota de exposição à contaminantes via água de consumo em área ocupada por população de baixa renda, este artigo incorpora as percepções dos sujeitos sobre a questão e demonstra juízos equivocados e a insuficiente compreensão dos riscos de efeitos à saúde provenientes de exposições em longo prazo.

Artigo: Desafios da Promoção da Saúde em diferentes contextos amazônicos (TOLEDO et al. 2010).

Capítulo de livro: Access to water for human consumption and aspects of public health in 
the Brazilian Amazon (GIATTI e CUTOLO 2012a)

Artigo: Acesso à água para consumo humano e aspectos de saúde pública na Amazônia Legal Brasileira (GIATTI e CUTOLO 2012b).

Essas três produções exploram, sob a perspectiva da promoção da saúde, como questões interdisciplinares se combinam gerando um quadro de difícil equacionamento quanto a provimento de água para populações na Amazônia.

Projeto: Indicadores de sustentabilidade ambiental e de saúde para a Região Metropolitana de São Paulo - Uma abordagem ecossistêmica para estudo em distintos níveis holárquicos. Coordenação Leandro Luiz Giatti. Financiamento FAPESP (proc.2010.20899-0), vigência 2011 - atual. Com enfoque metodológico similar ao da pesquisa acima citada sobre a cidade de Manaus, este projeto também se propõe à promoção de uma abordagem participativa com gestores, acadêmicos e sociedade civil. Além disso, se identifica em termos de inovação com uma análise de indicadores em distintos níveis de organização, referentes à metrópole e seus municípios componentes.

Artigo: Mobilização social em saúde e saneamento em processo de pesquisa-ação em uma comunidade indígena no noroeste amazônico. (TOLEDO et al. 2012). Explora a trajetória do processo de mobilização social e empoderamento na comunidade indígena de lauaretê. Descreve avanços, desafios e instrumentos de elevado poder de participação social.

Artigo: Agenda 21 e Governança (JACOBI et al. 2012). Por meio de uma revisão da produção de teses e dissertações dentre programas de pós-graduação da USP desde 1992, este artigo explora os avanços na incorporação de agenda 21 e Governança, subsidiando discussões na ocasião da realização da Rio+20. O artigo está incorporado no dossiê Sustentabilidade da Revista Estudos Avançados/USP.

Capitulo de livro: Uma interface necessária entre pesquisa em Saúde Ambiental e Promoção da Saúde. (GIATTI et al. 2012). Aborda questões ambientais e de saúde pela necessidade de produção de saberes colaborativos a partir de inciativas do meio acadêmico, envolvendo os sujeitos dos riscos, constituindo um processo de advocacia em 
saúde e subsidiando a sociedade na busca de superar injustiças ambientais.

Capítulo de livro no prelo: Giatti LL. A emergência de um novo paradigma nas relações de pesquisa, participação e intervenção para problemas socioambientais e de saúde. In: Toledo RF, Jacobi PR. A pesquisa-ação na interface saúde, educação e ambiente: princípios, desafios e experiências interdisciplinares. Aceito para publicação pela editora Annablume, previsto para publicação em 2013.

Artigo submetido em agosto de 2012 (em avaliação no periódico Health Promotion Internacional): Toledo RF, Giatti LL. Participation in action research: health and environment in an Amazon indigenous land.

Observação: com relação publicações realizadas as informações bibliográficas completas constam nas referências, item 7 desta tese.

Fonte: elaborado pelo autor.

Esta tese tem como objetivo propor uma crítica avaliação de diferentes aspectos de projetos de pesquisa e intervenção com foco em contextos socioambientais e de saúde. É também objetivo constituir um panorama sobre pesquisas nesse tema dialogando com a proposta de ciência pós-normal, especialmente no que diz respeito à ampliação da comunidade de pares, como um novo paradigma das inter-relações entre ciência, sociedade e políticas públicas.

Para isso, parte-se de reflexões sobre uma abordagem participativa para problemas de saneamento básico em terra indígena na Amazônia Brasileira, avançando em questionamentos pertinentes à aplicação de instrumentos dialéticos, escalas de promoção de intervenções e diálogo e, também, aspectos da funcionalidade de pesquisas e intervenções em uma revisão bibliográfica sistemática.

As interpretações e críticas quanto ao panorama de pesquisas e intervenções participativas tratadas nessa tese, bem como a possibilidade de se 
estabelecer categorias de análise sobre as referidas abordagens, conecta-se com a atuação do autor nas linhas de pesquisa: Política, Planejamento e Gestão Ambiental do Programa de Pós-Graduação em Saúde Pública; e Gestão Ambiental e Sustentabilidade Urbana, do Programa de Pós-Graduação Mestrado Profissional em Ambiente, Saúde e Sustentabilidade, ambos programas da Faculdade de Saúde Pública da Universidade de São Paulo. 


\section{Introdução - Questões contemporâneas e ciência Pós-normal}

Intensas mudanças vêm se fazendo presentes em nosso tempo. De modo marcante e conduzindo as relações do ser humano com os meios de produção e os ecossistemas, destaca-se a atual transição do período industrial para o período do risco da modernidade. Esse processo indesejado, despercebido e que entrega malefícios de modo compulsivo se distancia amplamente do projeto da modernidade, manifestando-se na forma de efeitos colaterais (BECK 1997).

Em forte associação com esse contexto Giddens (2000) assinala que as mais importantes revoluções de nosso tempo são a globalização, transformações na vida pessoal e no nosso relacionamento com a natureza. Esses processos atuam de forma conjunta e assim devem ser operados por novas alternativas quanto a governança que combinem criatividade e democracia a partir de uma nova orientação que tenha a flexibilidade de mesclar atitudes positivas superando conflitos anteriormente exacerbados entre posturas de governo social democráticas ou neoliberais. Fatos recentes na história política vêm mostrando uma nova amálgama entre essas antigas correntes dicotômicas. Como exemplo disso interesses individuais deixam de ser uma heresia dentre socialdemocratas, políticas de socialização de benefícios públicos passam a fazer parte da agenda de grupos neoliberais, questões ecológicas passam a ser focais em sociais democracias, sendo que anteriormente estes grupos abonavam o sacrifício da natureza em prol do desenvolvimento e da redução das desigualdades de classe.

Essas situações que vem a ocorrer de forma muito intensa a partir das décadas de 1970 e 1980 também têm suas condições atreladas a uma intensa reestruturação econômica com novas experiências nos domínios da organização industrial e da vida social. Isso ocorre notadamente em compasso com a consagração do processo de acumulação flexível, com a fluidez do capital, dos investimentos e dos sistemas de produção. Com essa nova configuração exacerbam-se e reproduzem-se em maior velocidade mudanças nos padrões do desenvolvimento desigual. Ao passo 
em que indústrias migram de modo assustadoramente rápido para locais até então completamente subdesenvolvidos, também cresce rapidamente o chamado setor de serviços, especialmente nas antigas regiões industrializadas (HARVEY 2009).

Dinâmicas tão acentuadas e emergentes tiveram o efeito de ampliar profundas desigualdades, incluindo o que concerne à combinação de exclusão social com a exposição de grupos de excluídos aos piores riscos ambientais inerentes à dinâmica devorante e acelerada que se institui. Isso se combinou com a acentuação de processos de urbanização e a consagração da insustentabilidade urbana. Especialmente nos países em desenvolvimento que se submeteram à rápida industrialização associada com uma urbanização desprovida de investimentos sociais com dinâmica compatível, constituíram-se grandes bolsões de pobreza onde a falta de saneamento básico, por exemplo, se combinou com os riscos advindos da industrialização inconsequente, como no caso de acidentes industriais ampliados (MARTINEZ-ALLIER 2007; SANTOS 2009a; PORTO e FREITAS 2003).

Exercendo elevada motricidade nas situações acima relatadas, a globalização, embora seja um processo bastante anterior, tem seu fortalecimento no período da segunda metade do século XX, portanto. Frente a este contexto, deve-se considerar que embora seja cada vez mais relevante o papel dos governos reguladores, característica da socialdemocracia, torna-se necessário contestar o protecionismo econômico e cultural típico dos posicionamentos de extrema-esquerda. Por outro lado, deve-se buscar ponderação entre o atrativo poder de desenvolvimento oferecido pelo livre mercado e as possibilidades destrutivas sociais e culturais que este também agrega. Quanto a isso as imposições governamentais não são adequadas, pois a autoridade no período contemporâneo só se constitui na democracia.

Esse pré-requisito se faz nas surpreendentes transformações da individualidade que vem consagrando maiores conexões dos indivíduos com os problemas globais, por exemplo, em relação às crises ambientais. Os indivíduos percebem a degradação ecológica global conjuntamente com a destruição das florestas nas proximidades de seus domicílios ou com a preocupação por estarem consumindo ovos de galinha contaminados por elementos tóxicos no café da manhã. 
$\mathrm{Na}$ sociedade de risco, o reconhecimento da imprevisibilidade das ameaças oriundas do desenvolvimento técnico industrial exige autorreflexão. Aflorando o autoconceito da sociedade de risco, a sociedade torna-se reflexiva, o que implica em que ela se torne um tema e um problema para si mesma. A liberdade para a atual socialdemocracia deve significar autonomia de ação e isso demanda o envolvimento da comunidade social mais ampla nos processos de governança (BECK 1997; GIDDENS 2000).

Mas todas essas mudanças nos sistemas sociais, políticos, econômicos, na globalização e, em conjunto, nas consequências da modernidade não ocorreram de modo isolado deixando o meio científico intocado. Pois, se em vez de a modernidade entregar pleno controle de um desenvolvimento equilibrado abarcando natureza e sociedade com benesses, ela trouxe instabilidade, desigualdade, risco e despreparo em termos de respostas à altura dos problemas. Com isso deflagrou-se uma marcante crise na ciência, pois foi na consagração do positivismo científico que se enalteceu 0 projeto da modernidade e se constituiu a sociedade industrial. Categoricamente, o paradigma dominante da chamada ciência moderna ou clássica se instituiu a partir do século XIX, preparando as bases para importantes avanços desde o início do século $X X$, todavia, caracterizando um processo de híper especialização dos saberes e fragmentação dos objetos de estudo (ALVARENGA et al. 2011).

Com relação aos questionamentos destes modelos científicos e por ocasião dos esforços para o estabelecimento de um princípio da complexidade, Morin (2010;p.31) afirma que "o princípio de explicação da ciência clássica tendia a reduzir o conhecível ao manipulável. Hoje, há que se insistir fortemente na utilidade de um conhecimento que possa servir à reflexão, meditação, discussão, incorporação por todos, cada um no seu saber, na sua experiência, na sua vida..."

A partir de uma perspectiva ética, frente aos dilemas científicos da híper especialização e das dificuldades de se estabelecer modelos explicativos interdisciplinares que sejam capazes de apreender as múltiplas facetas dos problemas que afetam a humanidade e o ambiente, Boaventura de Souza Santos, pensador da Universidade de Coimbra, propõe interações mais intensas entre o meio científico e a sociedade. Nesse sentido, afirma que "A ciência pós-moderna, ao se sensocomunizar, 
não despreza o conhecimento que produz tecnologia, mas entende que, tal como o conhecimento deve se traduzir em autoconhecimento, o desenvolvimento [das ciências] deve traduzir-se em sabedoria de vida" (SANTOS 2009b; p.91).

Para este autor, os problemas complexos que não tem encontrado resolução por meio de pesquisas disciplinares só podem ter devido encaminhamento mediante ao dialogo com o senso comum e a devolução a se proceder do meio científico para a sociedade, permitindo a complementariedade dos saberes. Ao mesmo tempo, espera-se com isso ampla difusão deste conhecimento, que a partir de então passa a ter maior poder para a resolutividade dos dilemas da atualidade. Na verdade, este processo pode ser entendido como uma proposta de democratização para que a ciência possa ser passível de apropriação pela sociedade.

Mas dentro da perspectiva da ciência clássica, o controle da qualidade dos saberes é restrito à comunidade de pares acadêmicos, confinando a legitimidade $\mathrm{e}$ o reconhecimento de novas teorias e atestando as certezas condutoras das decisões para a vida da sociedade em geral (KUHN 2009). Quanto a isso, Morin (2010) adiciona críticas à estrutura organizacional dessas comunidades de pares acadêmicos, onde, segundo este autor, prevalecem elites de mandarinato e sindicalismo constituídas por cientistas de elevado prestígio e que ocupam altos postos como dirigentes de investigação. Essas elites operam intensamente de modo corporativo, interferindo, por exemplo, no desenho e aplicação de políticas de ciência e tecnologia.

É justamente nos contextos de elevadas incertezas, cujas consequências são exacerbadas pela atual crise da modernidade, que Funtowicz e Ravetz (1993) questionam de modo veemente, que o controle da qualidade crítica da ciência, no que diz respeito a subsídios para processos políticos, não pode permanecer restrito à comunidade de pares acadêmicos. Pois é emergente a crise nos modelos de ciência, diante da incapacidade de prover explicações para situações complexas e fenômenos emergentes, com valores controvertidos e riscos de elevadas consequências que demandam ações urgentes. Pois para esses autores, diante de incertezas sistêmicas, prevalece elevado grau de juízo de valor e ignorância no processo de a comunidade científica subsidiar os processos políticos. 
Situações de incertezas sistêmicas serão mais bem tratadas e exemplificadas no capítulo 3 desta tese, com a descrição de configurações que se convencionou denominar neste texto como contextos socioambientais e de saúde. Mas, retomando o relacionamento da comunidade de pares acadêmicos com políticas de elevado grau de disputa sob as limitações preditivas e explicativas inerentes, tem-se a considerar a quebra de um importante dogma: de que a ciência é neutra.

Van den Hove (2007) afirma que ciência e política não são categorias exclusivas e herméticas. Relativamente a isso há quatro domínios de forte interseção, possibilitando a identificação de um elevado grau de permeabilidade do meio acadêmico quanto a processos políticos; são eles: $1^{\circ}$ ) 0 processo de escolha de prioridades de pesquisa e desenho de possíveis soluções é fortemente polarizado no que diz respeito a decisões políticas; $2^{\circ}$ ) o processo de financiamento e fomento à pesquisa que é determinado em contextos de arenas políticas; $3^{\circ}$ ) a validação e acreditação de qualidade de pesquisa, como no estabelecimento de métricas; e $4^{\circ}$ ) um elevado grau de influência política no controle do processo de educação e capacitação científica.

Diante desta conjuntura, coloca-se em primeira instância a necessidade da superação dos limites disciplinares da ciência clássica, de acordo com a proposta de promover estudos interdisciplinares, que compartilhem de uma axiomática comum, dentro de grupos de disciplinas conexas que se integram a partir de conceitos, epistemologia, terminologia e metodologia (ALVARENGA et al. 2011), dirigindo seu foco para problemas complexos como os relacionados aos contextos socioambientais e de saúde. Em segunda instância para avanços diante dos dilemas tratados, e como principal enfoque desta tese, adota-se a proposição da ampliação da comunidade de pares como encaminhamento plausível para as questões que, de um lado se elevam em termos de incertezas, imprecisões e ignorância, ao passo que também se elevam as disputas em jogo (FUNTOWICZ e RAVETZ 1993).

Isso corresponde à proposta de uma ciência pós-normal, que consiste de uma técnica de resolução de problemas complexos. A prática de ciência pós-normal não vem oferecer respostas precisas às incertezas, pois estas sempre existirão. $\mathrm{Na}$ 
realidade, os pressupostos em questão oferecem possibilidades de difusão de saberes, amplo reconhecimento de riscos e incertezas inerentes, estabelecendo meios para, por exemplo, serem constituídas medidas adaptativas ou capazes de minimizar os riscos (FUNTOWICZ e RAVETZ 1997).

A proposta da comunidade ampliada de pares vem subsidiar processos de governança, palavra conceito que, embora recente, é amplamente difundida, refletindo a incorporação de atores não estatais em uma nova forma de governar, basicamente, de um modo não hierárquico e com ampla participação dos mais distintos atores e partes interessadas na formulação e implementação de políticas públicas (JACOBI e SINISGALLI 2012). Para Ravetz (2004) a proposta da ciência pós-normal enquanto bases conceituais e subsídios para o estabelecimento da governança, especialmente em condições de necessária postura precaucionária, legitima um princípio democrático quanto aos mais emblemáticos dilemas que interferem no campo das relações sociedade, ambiente e saúde. 


\section{A demanda dialógica nos contextos socioambientais e de saúde}

\subsection{Desafios nas questões socioambientais e de saúde humana.}

No sentido da elevada importância dos riscos ambientais para as populações humanas, um trabalho realizado por Smith e Ezzati (2005), com base no banco de dados da OMS sobre carga global de doenças, aborda criticamente a clássica descrição de transição epidemiológica. Com base em dados providos por inúmeros países, em se aplicando a carga total de riscos per capita, corrigidos proporcionalmente pela distribuição etária das populações, estes pesquisadores demonstram que morbi/mortalidade decaem proporcionalmente para doenças infecciosas ou crônicas ao passo em que os países se desenvolvem. Frente a essa tendência, apontam um equívoco ao se atribuir a maior importância para as doenças crônicas dentre os habitantes de países desenvolvidos, pois tais países, na verdade, possuem maiores proporções de idosos e estes, consequentemente, sofrem mais de doenças crônicas. Mediante essa leitura crítica, os autores demonstram de que modo, a partir da lógica do desenvolvimento econômico e social, ocorre na verdade, uma transição da relevância de distintas categorias de fatores de risco ambientais, classificados por meio de diferentes abrangências:

i. Fatores de risco associados à dinâmica do domicílio, do local de moradia, como os relacionados à pobreza, à precariedade de condições sanitárias e à subnutrição;

ii. Fatores de risco relacionados às mudanças ambientais no âmbito da comunidade, associados ao desenvolvimento industrial, aos serviços urbanos e às fronteiras agrícolas. Estes seriam os riscos associados à modernidade, onde também figuram os riscos ocupacionais. Adiciona-se, inclusive, que as pessoas que vivem nos locais mais desfavorecidos também possuem os piores empregos; 
iii. Fatores de risco associáveis aos fenômenos de amplitude global, como a degradação dos ecossistemas e de seus serviços de suporte à vida e às mudanças climáticas, sobretudo.

Como a carga total de doenças decai em países desenvolvidos, também os fatores de risco ambientais declinam em todas as categorias, inclusive, notadamente, quanto aos riscos ambientais globais. Dentre os países em desenvolvimento, estes frequentemente mantém grande carga em termos de riscos ambientais e, mediante as desigualdades intra-regionais, podem ter a configuração em que determinadas parcelas da população (como os moradores de favelas) sofram a sobreposição de riscos ambientais do domicílio, fortemente associados a doenças infecciosas (doenças diarreicas, infecções respiratórias agudas, malária, dengue, etc.), com riscos ambientais da comunidade. Também, as populações de países em desenvolvimento são mais vulneráveis às consequências dos riscos ambientais globais, como em caso de catástrofes naturais atribuíveis às mudanças climáticas (SMITH e EZZATI 2005). Essa situação de sobreposição de fatores de risco ambientais é bem aplicável para a situação de saúde no Brasil, segundo Franco Netto et al. (2009), na Figura 1.

Com relação à importância de fatores ambientais que atuam em menor ou maior peso enquanto determinantes de várias doenças, apresentamos o Quadro 2, produzido a partir de um estudo de carga ambiental de doenças da Organização Mundial da Saúde (PRÜSS-ÜSTÜN \& CORVALÁN 2006), que consiste de amplo levantamento bibliográfico no campo da epidemiologia ambiental, além da realização de consulta a mais de 100 especialistas de reconhecimento internacional. Nesse quadro, podemos visualizar distintos agravos e a estimativa da carga ambiental, que se constitui do peso percentual dos fatores ambientais na causalidade de cada agravo. A contribuição dessa classificação vai além da simples atribuição de um peso para os fatores ambientais, tornando possível, também, analisar a sobreposição de tipos distintos de fatores de risco que incidem sobre determinados grupos populacionais, contribuindo para a compreensão da situação da saúde, como em distintos países. 
Figura 1 - Sobreposição riscos ambientais em diferentes grupos populacionais.

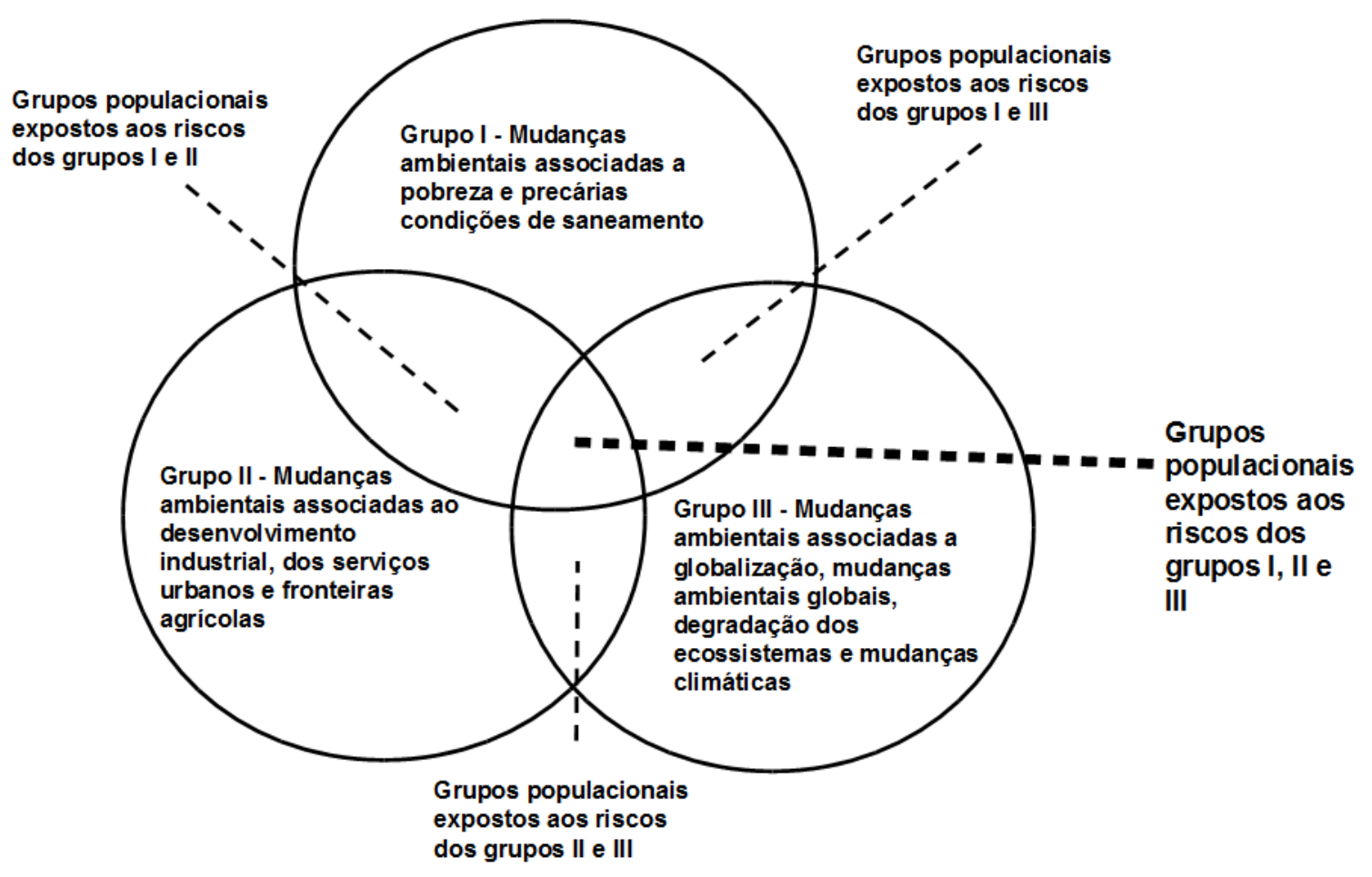

Fonte: Franco-Netto et. al. 2009.

O estudo da carga ambiental de doenças subsidia um ensaio realizado por Prüss-Üstün et al. (2008), que mostra como países comparáveis pela grandeza de produto interno bruto per capita, podem apresentar diferentes contextos epidemiológicos em termos de doenças com elevada carga de fatores ambientais (PRÜSS-ÜSTÜN e CORVALÁN, 2006). Ou seja, demonstra-se que com a mesma faixa de renda per capita é possível ter distintas situações em termos de carga ambiental de doença sobre a população de distintas nações.

De fato, mediante os modelos de desenvolvimento e a busca constante de recursos para prover as necessidades das populações, os inerentes processos impactantes nos ecossistemas e em seus serviços vêm sendo devidamente reconhecidos em amplas cadeias de causas e consequências com os mais distintos desdobramentos. Essa abordagem se consagra com a realização do Millenium Ecosystem Assessment (MEA, 2005), esforço de pesquisa promovido pelas Nações 
Unidas em cooperação multilateral, que explora de modo sistêmico como a interferência antrópica na busca de qualidade de vida e recursos interfere nas forças motrizes diretas e indiretas, que por sua vez, vem a comprometer a própria saúde e qualidade de vida dos humanos, em processo de retroalimentação (Figura 2).

Quadro 2 - Alguns agravos significativamente atribuíveis a fatores ambientais e carga ambiental na causalidade.

\begin{tabular}{|c|c|}
\hline Agravo & Carga ambiental e fatores ambientais relevantes na causalidade. \\
\hline $\begin{array}{l}\text { Infecções } \\
\text { Respiratórias - Vias }\end{array}$ & $42 \%$ - média para países em desenvolvimento \\
\hline Aéreas Inferiores & $25 \%$ - média para países em desenvolvimento \\
\hline $\begin{array}{l}\text { Infecções } \\
\text { Respiratórias - Vias } \\
\text { Aéreas Superiores e } \\
\text { Otites }\end{array}$ & $\begin{array}{l}\text { fatores: o principal fator associado é o da poluição em ambientes } \\
\text { fechados, como o uso de combustíveis sólidos para aquecimento e } \\
\text { cocção e fumo; também são relevantes a poluição atmosférica e } \\
\text { outros fatores domésticos, como a transmissão de doenças } \\
\text { infecciosas. }\end{array}$ \\
\hline Doenças Diarreicas & $\begin{array}{l}\text { 88\% - água potável, saneamento básico e hábitos de higiene, estes } \\
\text { últimos considerados particularmente enquanto inserção dos humanos } \\
\text { e suas práticas em ambientes com condições sanitárias precárias. }\end{array}$ \\
\hline Malária & $\begin{array}{l}\text { 64\% (para o Continente Americano) - mudanças ambientais } \\
\text { antrópicas, associadas a falta de sistemas de drenagem, que } \\
\text { interferem nos criadouros dos mosquitos transmissores do gênero } \\
\text { Anopheles. }\end{array}$ \\
\hline Leishmaniose & $\begin{array}{l}\text { 12\% para América Latina - interferência no equilíbrio ecológico que, } \\
\text { por situação de proximidade, expõem humanos a picadas de } \\
\text { mosquitos vetores acarretando a transmissão da doença que } \\
\text { frequentemente está restrita a ciclos silvestres. }\end{array}$ \\
\hline Dengue & $\begin{array}{l}\text { 95\% - depósitos de água a céu aberto; indevido manejo de água, } \\
\text { sobretudo em arredores de domicílios, constituindo facilidades para a }\end{array}$ \\
\hline
\end{tabular}




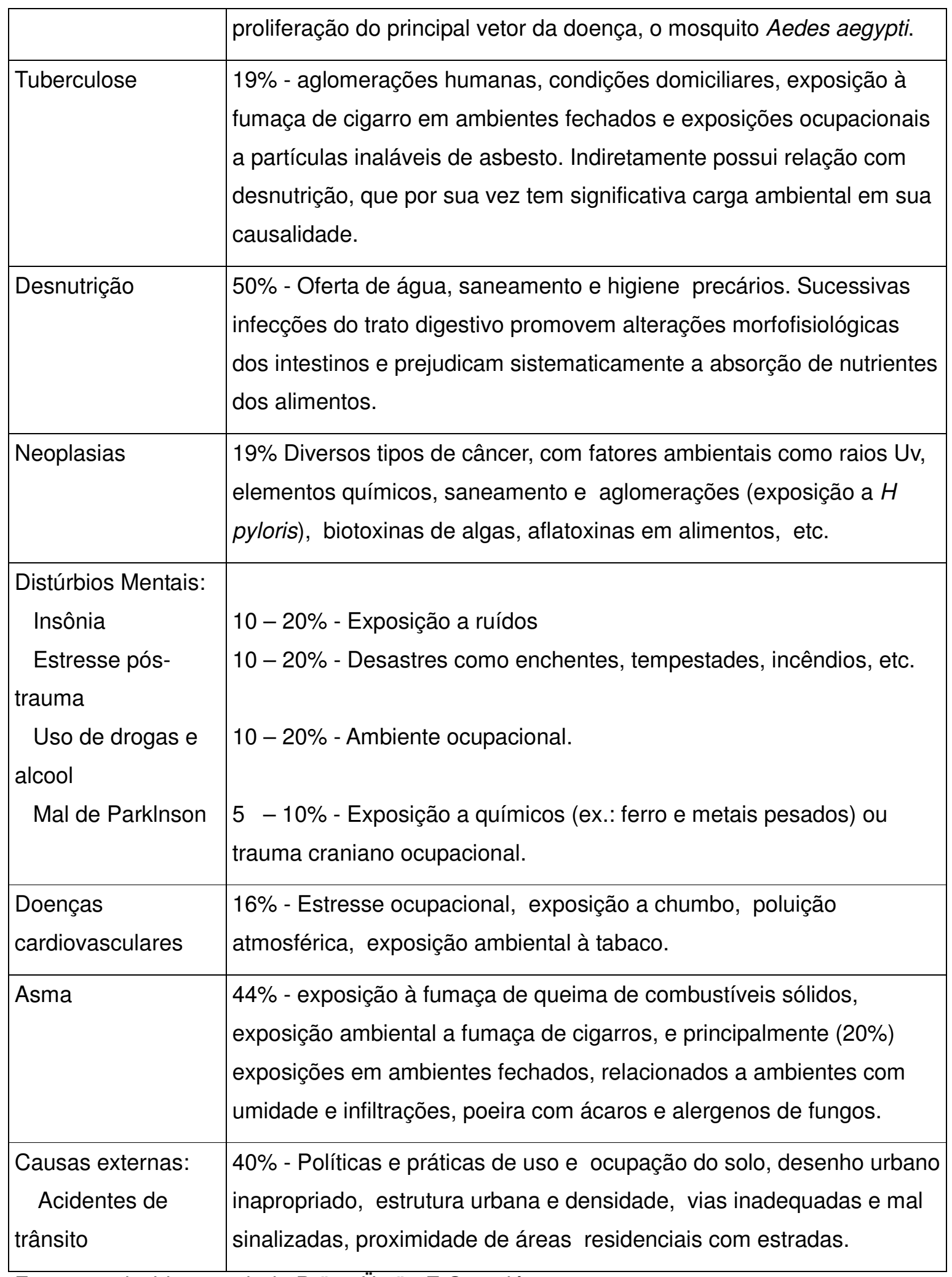

Fonte: produzido a partir de Prüss-Üstün E Corvalán 2006. 
Pressupõe-se, portanto, que alguns aspectos da situação de saúde de determinados grupos populacionais podem ser mais bem compreendidos mediante os modos de intervenção nos ecossistemas e em seus serviços, pois os desdobramentos dessas dinâmicas podem ser variáveis em escalas espaciais e temporais:

- $\quad$ Efeitos diretos, que têm como exemplos alterações físicas do meio em situações como a perda de estabilidade climática e aumento de mortalidade em ocorrência e exacerbação de ilhas de calor em áreas urbanas. Efeitos de uma causalidade são geralmente localizados e ocorrem imediatamente ou em curto prazo;

- Efeitos mediados - alterações em cadeias causais de doenças, como em distúrbios nos ecossistemas que venham a permitir maior proliferação de insetos vetores de doenças. Estes se ampliam em escala espacial e temporal, atingindo maior número de pessoas, afetando grupos adstritos a cidades, bio-regiões, bacias hidrográfica. Em escala espacial são característicos de gerar consequências em médio prazo;

- Efeitos modulados - situações em que os problemas ambientais interferem e/ou exacerbam outros problemas ou riscos sistêmicos à saúde, como no caso de ocorrências de secas, prejuízos à agricultura, crise econômica e subnutrição, ou situações de desastres naturais que podem se associar a precário saneamento e ampliar consequências atingindo significativas parcelas da população, especialmente os mais pobres, que frequentemente são os grupos expostos à sobreposição de distintos fatores e que possuem menores possibilidades de se protegerem. Em termos espaciais são ainda mais ampliados, podendo afetar países e se prolongar por décadas no que diz respeito à escala temporal. 
Figura 2 - Estrutura conceitual de interação entre bem-estar humano, serviços dos ecossistemas e forças motrizes diretas e indiretas de mudanças nos ecossistemas.

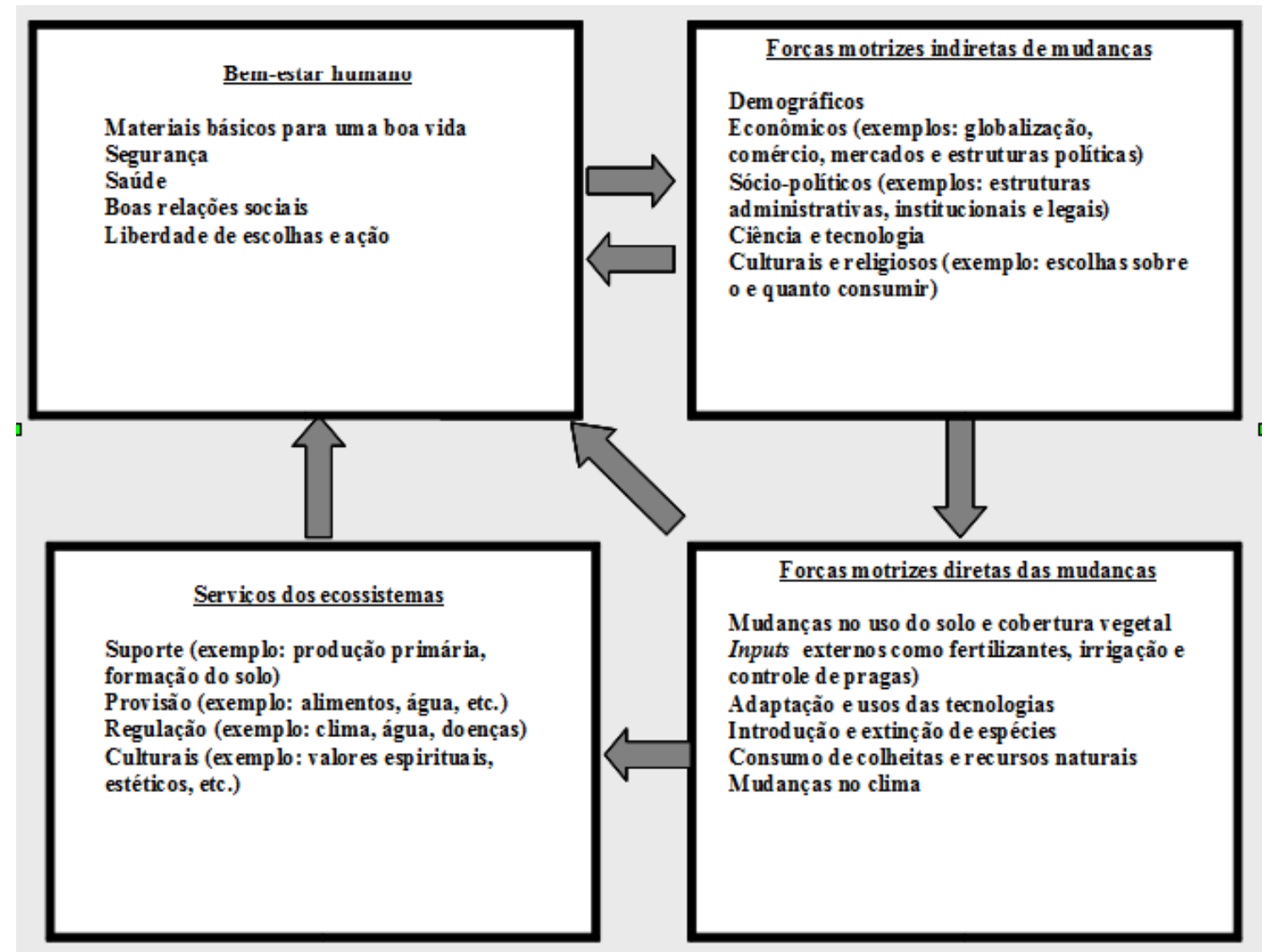

Fonte: MEA, 2005.

Essas possibilidades podem corroborar com quadros críticos, devido à combinação de distintos efeitos nas diferentes escalas espaciais e temporais, e suas consequências podem superar a capacidade de resposta e de adaptação das sociedades, levando a profundas crises e rupturas nos sistemas socioambientais, também gerando ou exacerbando conflitos, migrações, epidemias, grandes mortalidades e, de um modo geral, consequências ampliadas e sistêmicas dos problemas ambientais (HALES et al. 2004).

Além da sobreposição de fatores de risco condicionados pela relação do 
ser humano com os ecossistemas, considera-se que mesmo em se tratando de grupos de agravo de causalidade isolada e razoavelmente conhecida, como doenças transmissíveis ou intoxicações, prevalecem alguns dilemas quanto a efeitos à saúde humana. Por exemplo, apesar de haver vasto acúmulo e conhecimento sobre mecanismos de transmissão de doenças infecciosas e também de toxicologia para inúmeras substâncias conhecidas, a comprovação da relação causa e efeito para exposições ambientais é frequentemente permeada por séries de outros fatores condicionantes, como os determinantes sociais da saúde, que interferem em distintos graus constituindo a complexidade do processo saúde-doença.

Como exemplo destas situações de multifatorialidade, pode-se elencar pré-disposição genética, nutrição, sedentarismo e exposição a outros elementos tóxicos que possam potencializar riscos. Especificamente, para as situações em que ocorrem exposições prolongadas a doses relativamente baixas de substâncias tóxicas, a probabilidade de ocorrência de manifestações crônicas à saúde, que decorre majoritariamente em longo prazo, passa a demandar estudos bastante específicos em termos de desenhos de pesquisa epidemiológica, os quais são, geralmente, dispendiosos e requerem períodos de execução relativamente longos (CÂMARA e TAMBELINI. 2003).

Nessa analogia, o monitoramento de níveis de poluentes lançados nos ambientes é muito custoso e testes retrospectivos são impossíveis. Estas dinâmicas prevalecem sob a ordem de uma economia industrial que vem operando na lógica de que todas as inovações são seguras até que se provem perigosas, de modo condizente com o princípio clássico da prevenção. Quando efeitos nos humanos são descobertos, eles frequentemente são em longo prazo e mascarados por outras causas. Processos de sinergia entre poluentes ou outros fatores de risco muitas vezes são desconhecidos e dificilmente comprovados pelos critérios de uma ciência baseada em testes laboratoriais.

A combinação de variados fatores adiciona complexidade ao contexto como na combinação de exposição à poluição atmosférica, exposição a elementos tóxicos ou radiações, riscos de desastres tecnológicos, hábitos sedentários em 
ambientes urbanos, vulnerabilidade social, etc. Nessas circunstâncias também coexistem interesses corporativos como industrial, regulatório e profissional, que muitas vezes dão suporte ao não reconhecimento dos efeitos. Consagram-se assim, inevitavelmente, elevados graus de incertezas para com os efeitos dessas dinâmicas nos seres humanos, configurando valores em disputa (entre populações expostas e poluidores, por exemplo), apostas elevadas e a necessidade de decisões urgentes, em uma perfeita demanda de ciência pós-normal. (RAVETZ 2004).

De fato, na gênese de inúmeros problemas de saúde associados a questões ambientais tem-se como motricidade a busca pelo desenvolvimento econômico e social predominantes, acarretando agravantes no âmbito das incertezas quanto à ocorrência de doenças (BECK 2008). Por meio de processos que se relacionam espacialmente sob uma dinâmica global-local, configuram-se situações que submetem grupos socialmente excluídos, especialmente em países em desenvolvimento, à maiores exposições ambientais oriundas das externalidades dos processos produtivos e dos padrões exacerbados de consumo, que por sua vez, são substancialmente concentrados em países desenvolvidos. Essas relações assimétricas, com ampliação de profundas desigualdades, inclusive quanto aos fatores de risco ambientais, denominam-se de injustiças ambientais (PORTO 2007; MARTINEZ-ALLIER 2007).

Na impactação direta dos ecossistemas e seus serviços, pode-se ilustrar que urbanização, construção de estradas e de represas de hidroelétricas, desmatamento e avanço de fronteira agrícola são ações que têm de modo muito intenso, interferido na emergência e reemergência de doenças infecciosas como dengue, malária, febre amarela, leishmaniose tegumentar americana, doenças diarreicas causadas por distintos tipos de patógenos e demais doenças como viroses transmitidas por artrópodes (PATZ et al. 2004). Ao passo que essas mesmas mudanças conectadas à modernidade, industrialização, urbanização e estilos de vida condicionam também exposições a substâncias tóxicas, riscos de desastres tecnológicos, riscos ocupacionais, etc. (RAVETZ 2004). 


\subsection{Incertezas e fenômenos emergentes}

Há que se considerar significativas lacunas no entendimento da ampliação das consequências de determinados fenômenos emergentes, como desastres e epidemias relacionadas a problemas ambientais. De Marchi e Ravetz (1999) relatam dois casos relevantes. O primeiro, relacionado ao acidente de Seveso, na Itália, em 1976, onde um vazamento de uma indústria química expôs à contaminantes, inclusive dioxinas, a população das imediações, e por negligência dos responsáveis a situação teve sua divulgação postergada, prolongando a exposição, porém à parte de manifestações agudas registradas, não foram reconhecidas vítimas a longo prazo, como por ocorrência de câncer, que se esperaria da exposição, em uma situação típica de negligência de desdobramentos em médio e longo prazos.

O segundo caso relatado, trata da síndrome da 'Vaca Louca', em que, na Europa, houve intensa crise de opinião pública sobre o modo como se alimentavam animais. Ocorre que as rações utilizadas continham subprodutos de abate animal, tornando herbívoros em canibais, e possibilitando a veiculação de um patógeno de grande potencial em termos de mortalidade, inclusive humana. Por ocasião, não houve grandes prejuízos diretos em humanos, mas outras dimensões do problema afetaram profundamente a governança. Para os dois casos, os autores questionam os prejuízos ampliados, como no caso do impacto do temor sofrido pela sociedade, a questão da opinião pública, a necessidade de maior transparência quanto a riscos, a interferência negativa na governança e outras. Além, é claro, da iminência de catástrofes que poderiam ter ocorrido.

Questões de destaque na atualidade sobre elevados graus de incerteza podem ser portadores de fenômenos emergentes de elevada magnitude sobre os sistemas socioambientais, interferindo bruscamente e superando a capacidade de resiliência desses sistemas de modo a gerar profundas crises e rupturas. Ressalta-se que as condições de mais auto grau de incertezas estão frequentemente associadas a um elevado peso de conflitos e interesses quanto às decisões em jogo (KAY et al. 1999; FUNTOVICZ e RAVETZ 1993). Na sequência, são brevemente tratados três tópicos de relevância quanto às incertezas e possibilidade de severos impactos nos 
sistemas socioambientais:

- As mudanças climáticas globais - já foram evidenciadas por sua elevada importância nos contextos de sobreposição de fatores de risco ambientais (SMITH e EZZATI 2005). Mas é necessário refletir com relação ao elevado grau de incertezas e limitações quanto a modelos preditivos, situações crescentemente reconhecidas, inclusive, no âmbito do Intergovernmental Panel on Climate Change - IPCC (HA-DUONG et al. 2007). Se os prognósticos em escala global podem variar, prevalecem também desafios para a aplicabilidade regional dos mesmos, de modo a se prover gestores e sociedade com subsídios para elaborar as devidas medidas adaptativas e planos de redução de riscos. $E$ as consequências regionais destes processos globais manifestadas por meio de variabilidade climática, como a exacerbação de eventos extremos, têm muito a interferir e impactar profundamente nos sistemas socioambientais, tanto de modo direto, como mediado ou modulado (HALES e col. 2004);

- $\quad$ A utilização de transgênicos na agricultura - produtos agrícolas geneticamente modificados não vêm sendo contidos apesar das incertezas sistêmicas vinculadas à sua produção e consumo, como possíveis contaminações genéticas dos ecossistemas e riscos associados ao consumo. Os dilemas em torno dos transgênicos são característicos de situações com elevado grau de conflito de interesses (DE MARCHI e RAVETZ 1999). No Brasil, como no restante do mundo o tema é extremamente polêmico e intensamente polarizado entre duas correntes. As manifestações a favor dos transgênicos possuem um respaldo científico tipicamente positivista, com riscos reconhecíveis somente com a comprovação de relações causais. Adiciona-se que são posturas hegemônicas de mercado, assumindo a perspectiva de desenvolvimento econômico que esses produtos agrícolas podem oferecer (GUIVANT 2004); 
- A utilização de nanotecnologia - nano produtos vêm sendo comercializados amplamente em um mercado mundial que cresce de modo promissor e significativamente a cada ano. $O$ quadro conceitual sistematicamente aplicado para a avaliação de riscos oferecidos pelos nano materiais é elaborado por químicos e prevalece sob lógica quantitativa. A ampla necessidade de testes que seriam necessários para as mais variadas modalidades de risco dentre um sortimento crescente de materiais que vão sendo desenvolvidos para serem comercializados, cria uma situação difícil em que gestores se deparam com a insuficiência de informações para as mais prudentes decisões. Quanto a esse contexto, Grieger et al. (2010) propõem uma nova forma para a tomada de decisões, que deve combinar técnicas tradicionais (como identificação de riscos e avaliação de exposições) com amplos aspectos sociais, econômicos e culturais, contando também com a análise de especialistas, fomentando um modelo de governança adaptativa dos riscos.

Somam-se a essas questões bastante atuais os problemas já mais bem conhecidos, mas que continuam a constituir agenda no campo dos fenômenos emergentes, como acidentes industriais ampliados. Novamente, chama-se a atenção para os riscos diferenciais que ocorrem em países em desenvolvimento. Porto e Freitas (2003) demonstram, sob a perspectiva da vulnerabilidade, que desastres causados pelo homem ou pela própria natureza podem produzir diferentes efeitos quando ocorrem enquanto riscos similares sobre distintas populações ou países. Os autores assinalam as fragilidades que se conjugam nos campos sociais e institucionais de países em processo de industrialização, tendo como referência alguns dos maiores acidentes químicos da história que ocorreram todos em 1984:

- $\quad$ No Brasil, Vila Socó (508 óbitos);

- $\quad$ No México, San Juan Ixhuatepec (550 óbitos);

- $\quad$ E na Índia, Bhopal (com estimativas entre 1.800 e 20.000 óbitos, 
embora o registro oficial contabilize 2.500).

As três situações tiveram como pano de fundo um histórico de rápido e desordenado desenvolvimento entre 1960 e 1980, com ampla indução pelo Estado, endividamento, intensa e descontrolada urbanização acompanhada de grandes migrações de regiões pobres para centros urbanos em processo de rápida industrialização. Esses elementos acrescentaram significativa vulnerabilidade social aos acidentes relatados, em comparação com acidentes químicos anteriores, como o ocorrido em Seveso (FREITAS e PORTO 1995).

Tanto os riscos tecnológicos como acidentes químicos ou mesmo a exposição a poluentes, desastres naturais e emergência e reemergência de doenças infecciosas são consequências das mudanças nos ecossistemas e seus serviços que tendem a ser mais severas para com populações mais vulneráveis. Um bom modo de ilustrar quanto a essa afirmativa consiste de breve análise sobre o processo de mudanças climáticas, este por sua vez, não tende a trazer novos problemas, mas sim, exacerbar os já existentes.

As consequências das mudanças climáticas são mais avassaladoras para aqueles que: ocupam áreas de risco como sujeitas a inundações ou encostas; não possuem condições de moradia adequada e saneamento ambiental; estão sujeitos à insegurança alimentar; possuem precária atenção à saúde; e, frequentemente, não têm à sua disposição planos emergenciais de elevada capacidade de resposta. Um estudo realizado por Matulja (2012) sobre capacidade adaptativa à eventos extremos realizado no município de São Sebastião, litoral Norte do Estado de São Paulo, demonstra a precariedade de dados e indicadores que possam demonstrar a real situação de vulnerabilidade à chuvas intensas e deslizamentos de terras. O contexto de estudo são áreas de encostas da Serra do Mar, originalmente domínio de florestas tropicais do bioma Mata Atlântica, com rápido crescimento populacional motivado por intensas migrações, constituindo população de baixo poder aquisitivo, onde benefícios necessários de infraestrutura, como saneamento básico incluindo obras de drenagem, não são ofertados e não se ampliam sob a mesma dinâmica da ocupação humana. 
Em um levantamento sobre as desigualdades mundiais na ocorrência de agravos relacionados às mudanças climáticas nas últimas duas décadas (morbidade por malária, desnutrição e mortes associadas a enchentes e inundações), Patz et al. (2007) mostram claramente que os maiores óbices se concentram majoritariamente no continente Africano, na Índia e na América do Sul. Todavia, os principais responsáveis pela emissão de carbono, apontado como o principal causador da elevação da temperatura, são países desenvolvidos do hemisfério Norte.

\subsection{Ampliação da comunidade de pares}

Sob esse amplo contexto de questões socioambientais e de saúde ressalta-se a necessidade de superação do princípio clássico da prevenção, o qual se constitui com base em causalidades conhecidas, comprovadas. Diante de incertezas inerentes à multiplicidade de fatores e à complexidade das relações homem e ambiente, soma-se, ao necessário processo de prevenção primária, a proposição de uma ciência e prática da precaução (FREITAS e PORTO 2006), que seja capaz de lidar e orientar planos de ação diante de ocorrências inesperadas, para as quais prevalecem elevadas apostas em termos de magnitude de consequências, incertezas em fatos, controvérsias em valores e demandas por ações urgentes, emergenciais (RAVETZ 2004).

Para o estabelecimento de práticas em uma lógica precaucionaria, é preciso que a produção ampliada de saberes se associe à gestão, Ou seja, além do conhecimento científico e de suas especificidades, novos conhecimentos construídos no processo de apropriação por parte da sociedade devem ser incorporados na prática cotidiana, possibilitando maior engajamento político. Entretanto, a gestão ambiental e da saúde isoladamente já constitui um contexto bastante dificultoso, sobretudo por empecilhos para ações intersetoriais, bem como por obstáculos à gestão participativa.

Um agravante neste contexto é a pouca interlocução entre setor acadêmico, gestores e sociedade, tendo em vista que mesmo dentro da academia 
prevalecem limitações disciplinares que dificultam o entendimento sistêmico do ambiente e da saúde humana. Assim, de acordo com Funtowicz e Ravetz (1993; 1997) propõe-se que a ciência, como meio produtor de conhecimento essencial à humanidade, deve ser expandida para uma comunidade ampliada de pares, ou seja, não deve permanecer circunscrita apenas aos especialistas acadêmicos. A produção do saber deve incorporar os sujeitos passíveis de serem afetados pelos riscos ambientais, isso incluindo a população em geral e, obviamente, os gestores públicos, constituindo o que os citados autores propõem como elementos inerentes à ciência pós-normal.

Ampliar o diálogo necessário entre academia e sociedade, para problemas socioambientais e de saúde, não é desafio exclusivo de situações altamente complexas e/ou de incertezas vindouras com desdobramentos futuros. Determinados problemas tidos como comuns e até mesmo banalizados, mas que continuam a se reproduzir e impactar a qualidade de vida vem sendo compreendidos e geridos por meio de abordagens participativas, com o envolvimento dos sujeitos expostos aos riscos.

Reconhece-se, por exemplo, que em contextos de precário saneamento, onde populações não dispõem de esgotamento sanitário e de sistemas de abastecimento de água potável, os hábitos de higiene passam a ter um papel muito mais importante enquanto determinantes das doenças circunscritas (PRÜSS-ÜSTÜN e CORVALÁN 2006). À parte de ser uma situação bastante regular, principalmente no contexto da rápida urbanização dos países em desenvolvimento, a relação de precariedade em saneamento básico e hábitos de higiene sofre adição de complexidade em contextos locais quando soluções sanitárias se confrontam com aspectos antropológicos que remetem aos modos de valorar e perceber os problemas ambientais e de saúde e sua causalidade. Um exemplo contundente pode ser a maneira como indígenas interpretam o discurso sanitário de uma sociedade envolvente, sendo que o mesmo pode receber uma ressignificação pautada na lógica mítica, deslocando seu sentido original e comprometendo a possibilidade de resolução (GIATTI et al. 2007; GIATTI e CUTOLO, 2012b). 
A cadeia causal da dengue também pode trazer uma interessante ilustração. Essa doença transmitida em meio urbano pelo mosquito Aedes aegypti possui inúmeros fatores que interferem em sua dinâmica, tais como: infestação de vetores, competência vetorial, autoimunização da população a determinados sorotipos do vírus, etc. (CASTRO 2005). De modo geral, concebe-se que um elemento primordial para o controle desta arbovirose é a participação da população na supressão de criadouros do vetor, algo que só se obtém de forma duradoura quando a população se apropria quanto à importância de tomar medidas nesse sentido. Mas em primeira instância, o problema e suas causas devem ser apreendidos pela percepção dos sujeitos do risco.

GIATTI et al. (2010), realizaram um estudo na cidade de Manaus/Amazonas sobre a percepção de habitantes do bairro Novo Israel quanto ao fato de ocuparem área de aterramento de um antigo lixão que operou entre 1971 e 1986. Nessa vizinhança, procederam-se análises de qualidade da água de poços de lençóis superficiais e profundos (ROCHA e HORBE 2006). Estas águas que eram utilizadas inclusive para consumo humano, indicaram altos teores de contaminantes químicos, especialmente metais pesados. Apesar de o problema ambiental ser constatado, ainda entre 2007 e 2008 a população local continuava exposta aos contaminantes em razão do uso de água de poços, sendo constatados sérios equívocos quanto à percepção do problema ambiental e riscos à saúde entre a população local. Por exemplo, a população reconhecia que o lixão existente no local comprometia o ambiente, porém, não julgavam a água proveniente dos poços como ruim. Além disso, os habitantes também não vislumbravam relações de exposições prolongadas a tóxicos, com probabilidades de ocorrência de doenças crônicas.

As exposições e riscos relacionados a saneamento básico ou mesmo no caso de alguns contaminantes, como os metais pesados, não apresentam grandes desafios científicos. Os efeitos na saúde são incontestáveis, como na transmissão de doenças de ciclo fecal-oral, ou nos efeitos de intoxicação em curto ou médio prazo pela exposição ao chumbo. Mesmo assim, a questão da percepção dos sujeitos para o problema parece ser fundamental, adicionando complexidade a esses problemas, pois o modo como os riscos são percebidos implicam em comportamentos de proteção ou 
mesmo de aceitação da exposição.

Se a percepção é fundamental para problemas bem conhecidos, sua condição é ainda mais relevante nos processos permeados por incertezas quanto a relações de riscos aos ecossistemas e à saúde humana. GUIVANT (2006) faz um levantamento sobre pesquisas de percepção pública sobre ciência, com foco na questão dos transgênicos, realizadas nos Estados Unidos, Europa, Ásia e no Brasil. Sobre um amplo panorama dos variáveis e antagônicos resultados das pesquisas nesse campo, considera-se que elementos como a metodologia das pesquisas (com grandes diferenças entre as quantitativas e qualitativas) e o complexo leque de fatores sociais vão interferir nos resultados quanto a aceitação ou não desses produtos. Eventualmente, cidadãos podem se colocar a favor da produção e consumo de transgênicos, mesmo reconhecendo possuir pouco conhecimento científico sobre a questão. Isso se faz em uma condição que se reproduz onde a ciência permanece intocada, como em pesquisas de opinião na Ásia e no Brasil.

Nesse ponto, vale menção ao movimento de promoção da saúde, que "propõe a articulação de saberes técnicos e populares e a mobilização de seus recursos institucionais e comunitários, públicos e privados, para seu enfrentamento e resolução" dos problemas de saúde (BUSS 2000: p.165), recordando e frisando que a palavra-chave para esse processo é "empoderamento" dos sujeitos, a ser obtido por meio de intervenções continuadas e diálogo entre gestores e sociedade. Pelo processo de empoderamento os sujeitos ou organizações representativas da sociedade, por exemplo, se apropriam dos problemas em foco quanto à saúde, problemas estes que podem ter conexões e demandas em distintos setores da administração pública. Esses avanços podem ser considerados primordiais para que a sociedade venha a dialogar e intervir em prol de sua própria saúde, seja em medidas de abrangência local, como em atitudes de proteção individual, seja na participação e nos avanços de políticas públicas saudáveis, de caráter intersetorial.

A promoção da saúde pode ser considerada tangível na realização de processos participativos, onde determinadas iniciativas de intervenção e políticas públicas, de um modo geral, favoreçam o diálogo com distintos atores sociais. Para 
Jacobi et al. (2009) frente à conjuntura contemporânea de transformação de uma sociedade que não apenas é ameaçada, como também afetada por riscos socioambientais que se reproduzem e se renovam, emerge a necessidade de processos de aprendizagem social. Estes devem responder às demandas por sustentabilidade socioambiental por meio da construção colaborativa e compartilhamento de saberes, de modo a promover reflexões críticas e interdisciplinares sobre os problemas complexos da atualidade, possibilitando o diálogo coletivo entre atores envolvidos na gestão participativa, como voltada aos problemas ambientais.

A premissa norteadora desse paradigma é, portanto:

"o diálogo de saberes que permita construir espaços de fronteiras; formar um pensamento crítico, criativo e sintonizado com a necessidade de propor respostas para o futuro, capaz de analisar as complexas relações entre os processos naturais e sociais e de atuar no ambiente em uma perspectiva global, respeitando as diversidades socioculturais" (JACOBI et al. 2009: p.67).

Nota-se que os contextos socioambientais e de saúde problematizados e as necessidades de intervenções interdisciplinares, com o envolvimento de amplos atores da sociedade, contrapõem-se a abordagens baseadas em modelos explicativos baseados em linearidade causal e ações setorizadas, estas, insuficientes perante os dilemas da atualidade. Isso não significa que estudos de causalidade não são mais úteis. No entanto, assumindo a causalidade como algo muito relevante nesta discussão, considera-se abordá-la dentro de uma perspectiva sistêmica.

Em sistemas simples, verifica-se uma unidimensionalidade causal, algo que facilita, portanto, a compreensão de causas e efeitos nos fenômenos inerentes. A propósito, grande parte da ciência voltada para fatores de risco de doenças, se constitui de modo unidimensional, como se as cadeias determinantes fossem estritamente simples e lineares. Por outro lado, os sistemas complexos, como se pretende tratar, apresentam dois níveis diferentes de complexidade. O primeiro é de 
uma complexidade ordinária, característica de sistemas biológicos, onde há ausência de consciência. Nestes sistemas a complexidade pode ser estudada e descrita por elementos intrínsecos à teia alimentar, às relações entre as espécies, como predação, competição, resiliência, simbiose, etc.

O outro nível de complexidade identifica-se como emergente, ou complexidade reflexiva, típica de sistemas que envolvem os humanos. Neste caso, valores, crenças, processos educativos, informação, tecnologia, etc., vão desempenhar papéis muito importantes nas cadeias de causas dos mais distintos fenômenos. Podemos salientar que a subjetividade humana inerente adiciona complexidade e aumenta o grau de incertezas relacionadas à causalidade, trazendo novos elementos e possibilidades. Este nível de complexidade é característico, portanto, dos sistemas sociais, técnicos ou mistos (PORTO 2007; KAY et al. 1999).

A complexidade emergente ou reflexiva se constitui como o principal alvo dos questionamentos e proposições constantes no enunciado desta tese. É por meio da adição de complexidade provida pela subjetividade humana, que se propõe uma visão ampla e a necessidade de se estabelecer e/ou fortalecer o diálogo entre produção e aplicação de saberes, estimulando constantes trocas e, especialmente, a possibilidade de apropriação da ciência por parte da sociedade. Por outro lado, considera-se a possibilidade de o meio acadêmico tornar-se mais sensível, permeável e capaz de interagir de modo dinâmico com distintos saberes e condicionantes dos fenômenos socioambientais e de saúde. Observa-se que diante dos problemas ambientais e de saúde e no diálogo entre estas situações a partir do meio acadêmico com a sociedade e gestores em processos políticos, frequentemente o que prevalece é uma condição de profundas incertezas e ignorância. Nesses contextos também se sobressaem valores em disputa que influenciam as decisões científicas e políticas (RAVETZ 2004).

Cabe recordar que o modo clássico de produção e legitimação de saberes científicos, ocorre no âmbito da comunidade científica, de modo adstrito por meio da legitimação e reconhecimento dentre os pares acadêmicos. Qualquer novo conceito, abordagem ou metodologia, será reconhecido e adotado, ou não, mediante o 
crivo da comunidade profissional referente à especialidade científica em questão. Salienta-se que novas teorias podem sofrer grande resistência, por várias razões, tais como: os pares não estão prontos para absorvê-las; são muito incompatíveis com modelos e concepções vigentes; ou alteram severamente a estrutura hierárquica e política da comunidade de pares (KUHN 2009).

Voltando aos problemas socioambientais e de saúde, toma-se o exemplo de uma comunidade indígena com saneamento precário. Frente a isso, a solução simplista poderia ser: "vamos dar banheiros e rede de esgoto para eles". O referido direcionamento constituiria uma solução unilateral e verticalizada, com base em uma interpretação reducionista da realidade. Porém, vemos que a solução adequada requer muito mais do que infraestrutura ou algum manual que seja entregue de porta em porta. Além das dificuldades relacionadas ao meio físico para a implantação de melhorias (distância, isolamento espacial, custos), também é necessário promover o diálogo, construir novos saberes aplicáveis à realidade local. Considerando o caso de um grupo culturalmente diferenciado, há a demanda por abordar e interagir em um processo de ressignificação, que permita aos indígenas se apropriarem da lógica sanitária da sociedade envolvente, dentro de seu arcabouço cultural, compatível com a realidade e valores locais. É preciso promover a produção de conhecimento conjunto a ser aplicado e legitimado por essa lógica ampliada dos pares, que devemos obter com a ampla participação dos sujeitos, visando o empoderamento dos mesmos (GIATTI et al. 2007).

Traçando esse panorama de situações socioambientais e de saúde que se relacionam do global ao local, com condições de riscos que vão desde problemas elementares como precário saneamento básico até os mais elevados graus de incertezas que surgem a partir de novas tecnologias ou dos riscos de profundas mudanças nos ecossistemas, como no caso das mudanças climáticas, têm-se a registrar que nesta tese considera-se como um avanço elementar o processo de envolvimento dos sujeitos, de distintos atores sociais, principalmente os afetados pelos riscos. Desse modo, salienta-se que a ampliação da comunidade de pares proposta por Funtowicz e Ravetz (1993) é aqui aplicável a partir da relação do envolvimento dos sujeitos. Isto pode ocorrer para diagnóstico ou resolução de determinados problemas 
locais, ou na ampliação das discussões por diferentes níveis territoriais, envolvendo representações da sociedade e outros atores, como especialistas consultivos. 


\section{Lições e desafios identificados em uma experiência de pesquisa participativa de base comunitária em terra indígena}

\subsection{Conceitos relevantes sobre participação}

Tomando por base a complexidade socioambiental e de saúde e todos os desafios e incertezas associados, temos a considerar que é bastante contemporânea e pertinente a proposta de produção científica aliada à governança em que se promova o envolvimento de sujeitos no processo de interpretação, apropriação, produção de conhecimento conjunto e criação de estratégias e políticas para o enfrentamento e/ou solução dos mesmos (WALTNER-TOWES 2001; RAVETZ 2004).

Mediante a relevância e a perspectiva da aplicação de metodologias participativas sobre as situações socioambientais e de saúde na América Latina, Freitas et al. (2009) realizaram uma busca em importantes periódicos latinoamericanos de saúde pública ${ }^{1}$. Nesse levantamento, os autores selecionaram sete artigos publicados que envolviam participação direta do público ou da comunidade local, sendo que a participação procedida majoritariamente se restringia ao desenvolvimento de estratégias de prevenção pontuais e locais, com foco em ações educativas e aplicação de aparatos preventivos, como na proteção contra vetores de doenças. Apenas em três artigos foi verificada a participação inerente ao desenvolvimento metodológico das pesquisas, envolvendo os atores locais ativamente nos trabalhos.

Enfrentando a tarefa de definir participação, reconhecendo os percalços e a polissemia associada ao termo, List (2006) argumenta quanto a distintas formas de envolvimento de sujeitos, no sentido de que pode ser possível uma graduação de sete níveis de participação, partindo do passo 1 - cooptação manipulativa (manipulative co-

\footnotetext{
${ }^{1}$ Freitas e col (2009) realizaram levantamento contemplando os seguintes periódicos: Cadernos de Saúde Pública; Revista de Saúde Pública; Ciência \& Saúde Coletiva; Revista de Salud Publica e Revista Cubana de Salud Publica.
} 
option), passando pelo passo 6 - aprendizado interativo e colaborativo (interative colearning), até o passo 7 - auto-mobilização e empoderamento (self-mobilization and empowerment).

Para demonstrar um pouco da amplitude de processos envolvendo sujeitos dos riscos em pesquisas, primeiramente cita-se um estudo de percepção de risco de doença transmitida por vetor. A participação dos sujeitos é resumida a aplicação de grupos focais (ZIELINSKI-GUTIERREZ et al. 2006) onde, mesmo com o uso de um instrumento de natureza dialética, dependendo da forma como é aplicado, pode-se gerar uma participação apenas como um modo de aquisição de evidências.

Operando em maior profundidade no envolvimento dos atores sociais, apresenta-se um estudo que relaciona saúde, biodiversidade e recursos naturais realizado por Murray e Sánchez-Choy (2001), no qual se promove a participação colaborativa por uma variada gama de instrumentos, como: mapeamento comunitário da paisagem, desenho de transectos de saúde, histórias de vida, entrevistas com informantes chaves e outros. Neste segundo caso, é provável que o uso de distintos instrumentos em ciclos de intervenção, tenha permitido maior avanço no processo participativo, conforme níveis propostos por List (2006).

Vale ressaltar que, evidentemente, não se pretende com este comparativo afirmar que é possível mensurar que o nível de participação de sujeitos em uma pesquisa seja decorrente apenas da quantidade de instrumentos aplicados, e sim, salientar que o uso de instrumentos e estratégias com características diferentes pode favorecer o processo dialógico e participativo. Emprega-se nesse ponto o termo dialógico por esse ser um ideal para os processos participativos/colaborativos, pois tende-se à constituição de estruturas de poder em que relações assimétricas ocorrem, como na relação de pesquisadores com os sujeitos, estes últimos podem ser oprimidos ou inferiorizados. Todo um processo de interação e afetividade deve ser constituído para minimizar essa tendência, para que o diálogo ocorra de modo simétrico, justo, equilibrado (FREIRE 1987). Por outro lado, quando se classifica um instrumento de pesquisa e intervenção como dialético tem-se, simplesmente, a qualificação de que o mesmo permite dialogar e interagir entre saberes; melhor ainda, permite constituir 
saberem colaborativos.

Considerando a participação social como um pré-requisito e que pode haver distintos níveis de envolvimento dos sujeitos e produtos desse processo, buscase nessa seção de tese oportunizar uma orientação metodológica a partir do referencial da pesquisa-ação. Esta metodologia trata de um tipo de pesquisa colaborativa, com a obrigatoriedade do envolvimento dos sujeitos na busca da solução de determinados problemas interdisciplinares, onde por meio de uma reflexão constante sobre a ação, ocorre a investigação e promove-se aprendizagem coletiva (LEWIN 1946; CARR e KEMMIS 1986; BARBIER 2002). A opção pela pesquisa-ação não ocorre por esta apresentar qualquer algoritmo rígido para sua realização, pois nela não há predeterminação nesse sentido. Essa metodologia foi eleita pela possibilidade de se construir um processo dinâmico e interativo, mas com devido rigor científico em cada qual de suas etapas (THIOLLENT 2007; MORIN 2004).

\subsection{A combinação cíclica de instrumentos em abordagem de pesquisa-ação}

Esta seção baseia-se, portanto, em uma pesquisa-ação realizada entre 2005 e 2008 no Distrito de lauaretê, comunidade indígena situada à noroeste do estado do Amazonas, área de fronteira com a Colômbia, às margens do rio Uaupés, principal tributário da margem esquerda do alto rio Negro. Esta localidade enfrentava, na época da pesquisa, um processo de urbanização com sérios prejuízos ao ambiente e riscos à saúde mediante uma grave crise sanitária, sobretudo pela inexistência de serviços de água, esgotos, coleta e disposição de resíduos sólidos. Dentre a população de aproximadamente 2700 habitantes, constatou-se a manutenção de práticas sanitárias não condizentes com a aglomeração urbana que se consumava. Além de ser um problema sanitário bastante regular, a prevalência de saberes e práticas tradicionais indígenas, o pluriculturalismo, a continuidade da subsistência intensamente ligada aos sistemas naturais, a prevalência de uma lógica de urbanização indígena, o contato com a sociedade envolvente com seus postulados sobre saúde-doença, e a ressignificação destes preceitos sob a interpretação mitológica, são fatores reinantes 
no local (TOLEDO et al. 2009).

Por tratar-se de pesquisa envolvendo seres humanos e por ser realizada em terra indígena, contatos iniciais foram realizados com lideranças indígenas locais, em que foram apresentados os objetivos e a metodologia da pesquisa, além de critérios éticos compatíveis internacionalmente, como consentimento livre e esclarecido, participação voluntária, livre recusa à qualquer momento, encaminhamentos necessários para o caso de necessidade de tratamento de saúde e preservação do sigilo e da identidade dos participantes. Todo esse processo de contato inicial e a pesquisa em sua totalidade foram conduzidos com linguagem compatível ao nível de conhecimento dos sujeitos, sendo aplicado o português, uma vez que os indígenas locais são falantes desse idioma. Com base nos contatos iniciais foi solicitada a formalização do ingresso na terra indígena Alto Rio Negro - local de estudo -, que foi devidamente autorizado pela Fundação Nacional do Índio - FUNAI (processo 0480/04). Após isso, o projeto de pesquisa foi submetido, avaliado e teve parecer favorável do Conselho Nacional de Ética em Pesquisa - CONEP (registro 10.848), seguindo critérios da resolução CONEP - 196/1996.

Julga-se relevante o relato desta experiência, pois, convencionalmente, estudos sobre sociedades indígenas tratam de suas perspectivas e prioridades em linhas disciplinares tradicionais (STEPHENS et al. 2007), sendo que poucos exploram o potencial dos modos indígenas de compreender o mundo por meio de seu saber holístico, o qual é bastante oportuno diante dos atuais paradigmas científicos de superação de modelos positivistas-reducionistas para estudos de sistemas adaptativos complexos (BERKES e BERKES 2009).

No local referido, a precariedade sanitária foi a questão central da abordagem, em que foram associados e combinados distintos instrumentos dentro de uma lógica dialógica, compondo um fluxo metodológico em constante adaptação, legitimando o processo participativo. Desse modo, foi possível criar interação entre os problemas ambientais, as doenças a que os sujeitos mais estavam expostos em decorrência do contexto sanitário, os aspectos sociais e o pano de fundo cultural, além de também propiciar o intercâmbio com o grupo multidisciplinar de pesquisadores, 
interagindo em diagnósticos, respondendo a demandas e colaborando com a construção de saberes.

Os instrumentos em sua combinação de aplicações puderam ser posteriormente classificados por seu poder dialógico, com a capacidade de conduzir e direcionar a investigação e promover a participação dos sujeitos em um processo de retroalimentação. Desse modo, alguns instrumentos aplicados em ordem cronológica são apresentados e classificados no Quadro 3 enquanto produção de feedbacks dentro de duas categorias:

- Feedback direto/imediato: estimula a participação dos sujeitos em tempo real, pois oferece evidências enquanto resultados da pesquisa, ao mesmo tempo que contribui para a aprendizagem social e para adequações metodológicas - é o caso de instrumentos aplicados com envolvimento direto dos sujeitos, enquanto construções coletivas de pesquisadores-sujeitos. Também consideramos como dialéticos os instrumentos produtores desse tipo de feedback;

- Feedback indireto/não imediato: estimulam a participação dos sujeitos em um segundo momento, pois constituem instrumentos que não são executados em interações diretas pesquisadores-sujeitos, mas promovem retroalimentação por sua capacidade de preencher importantes lacunas que vão sendo identificadas no decorrer do processo de pesquisa e intervenção. São essencialmente demandas que emergem das interações diretas entre pesquisadores e sujeitos, e, com frequência são dirigidos a oferecer respostas precisas para dúvidas fundamentais do processo de pesquisa participativa. Nesse sentido, são convencionalmente constituídos de instrumentos e técnicas de pesquisas disciplinares, como mensurações, testes de hipóteses, inquéritos, etc. 
Quadro 3 - Alguns instrumentos aplicados em pesquisa-ação, contribuição na participação e classificação por tipo de feedback provido, lauaretê, 2005 - 2008.

\begin{tabular}{|c|c|}
\hline $\begin{array}{l}\text { INSTRUMENTO / } \\
\text { DESCRIÇÃO }\end{array}$ & $\begin{array}{c}\text { CONTRIBUIÇÃO AOS DESAFIOS DA PARTICIPAÇÃO E } \\
\text { CATEGORIAS DE FEEDBACK }\end{array}$ \\
\hline $\begin{array}{l}\text { MAPAS-FALANTES } \\
\text { representação gráfica } \\
\text { realizada pelos sujeitos, } \\
\text { sobre situação sanitária atual } \\
\text { e cenários futuros. } \\
\text { PAINEL COM FOTOS } \\
\text { adaptação de painel } \\
\text { integrado utilizando-se de } \\
\text { fotos feitas pelos sujeitos } \\
\text { com problemas sanitários, os } \\
\text { quais foram por eles } \\
\text { discutidos quanto a possíveis } \\
\text { causas e soluções. }\end{array}$ & $\begin{array}{l}\text { Contribuíram na construção cooperativa de saber, por } \\
\text { meio de reflexão (entre os sujeitos e destes com os } \\
\text { pesquisadores), na discussão de nexos causais e na busca } \\
\text { de possíveis soluções, facilitando a apropriação crescente } \\
\text { dos saberes construídos e, consequentemente, sua difusão } \\
\text { (aprendizagem social). } \\
\text { Foram importantes para produzir diagnósticos } \\
\text { participativos, denúncias de irregularidades no sistema } \\
\text { ambiente-saúde, também demandando estudos específicos } \\
\text { para questionamentos dos sujeitos, dos pesquisadores } \\
\text { ou de ambos, tais como: inquérito parasitológico, análise } \\
\text { de qualidade de água, análise de parasitos no solo, estudos } \\
\text { sobre disposição de resíduos. }\end{array}$ \\
\hline $\begin{array}{l}\text { OBSERVAÇÃO } \\
\text { PARTICIPANTE/ } \\
\text { provedora de relevantes } \\
\text { informações qualitativas } \\
\text { sobre as dinâmicas locais } \\
\text { QUESTIONÁRIOS e ENTRE- } \\
\text { VISTAS / captação dados } \\
\text { sociais, doenças mais } \\
\text { prevalentes, repre-sentações } \\
\text { sociais sobre saúde, doença } \\
\text { e ambiente. }\end{array}$ & $\begin{array}{l}\text { Forneceram evidências importantes sobre o sistema em } \\
\text { estudo, contribuindo para redirecionamento metodológico } \\
\text { e planejamento de aplicação de novos instrumentos, } \\
\text { decisões sobre a dinâmica da pesquisa. } \\
\text { georeferenciamento trouxe um importante instrumento } \\
\text { pedagógico por permitir produtos que facilitaram a } \\
\text { interpretação espacial dos fenômenos em estudo. }\end{array}$ \\
\hline
\end{tabular}




\begin{tabular}{|c|c|}
\hline $\begin{array}{l}\text { GEOREFERENCIAMENTO / } \\
\text { localização de domicílios, } \\
\text { fontes de água, depósitos de } \\
\text { resíduos, etc. }\end{array}$ & \\
\hline $\begin{array}{l}\text { ANÁLISE DE QUALIDADE } \\
\text { DE ÁGUA / coleta e análise } \\
\text { microbiológica quanto à } \\
\text { potabilidade de amostras. } \\
\text { INQUÉRITO } \\
\text { PARASITOLÓGICO } \\
\text { importante indicativo da } \\
\text { crítica condição de saúde } \\
\text { intestinal dos sujeitos. }\end{array}$ & $\begin{array}{l}\text { Forneceram respostas às indagações (sobre a qualidade } \\
\text { da água, prevalência de parasitoses intestinais) surgidas na } \\
\text { aplicação de mapas-falantes e/ou painel com fotos, } \\
\text { atendendo, portanto, demandas não só dos pesquisadores, } \\
\text { mas também dos sujeitos e, assim, contribuindo para } \\
\text { aumentar a credibilidade em relação à pesquisa. }\end{array}$ \\
\hline $\begin{array}{l}\text { CONSTRUÇÃO } \text { DE ABAIXO } \\
\text { ASSINADO / petição } \\
\text { encaminhada à } \text { FUNASA } \\
\text { solicitando providências em } \\
\text { termos de saneamento } \\
\text { básico. }\end{array}$ & $\begin{array}{l}\text { Contribuíram para a elevação da } \\
\text { autoestima, fortalecimento do grupo (empoderamento) e } \\
\text { da crença destes no potencial de transformação, por meio } \\
\text { do uso de instrumentos legais de participação para a } \\
\text { busca de soluções coletivas. }\end{array}$ \\
\hline
\end{tabular}

Legenda:

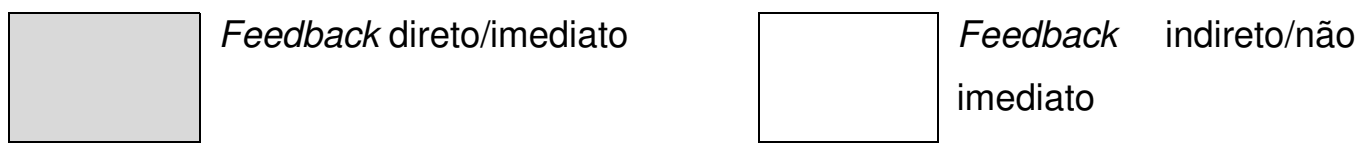

Fonte: produzido pelo autor, descrição mais completa destes e dos demais instrumentos aplicados, ver Toledo et al. (2006), Giatti et al. (2007) e Toledo et al. (2012).

Observações: As palavras e expressões em negrito no quadro 2 acima tem forte correspondência com níveis e desafios à participação e com características dinâmicas de uma pesquisa participativa (LIST 2006; THIOLLENT 2007; MORIN 2004). 
Foi possível verificar que mesmo instrumentos considerados nãodialéticos provaram ser importantes fornecedores de feedback durante o processo, pois os mesmos traziam respostas de elevada importância às interações diretas entre pesquisadores e sujeitos. Como exemplo desta situação, um processo de análise de amostras de água utilizada para abastecimento humano (instrumento não-dialético), foi empregado por demanda dos sujeitos, quando em reuniões comunitárias com aplicação de mapas falantes ficou claro o desejo de se ter confirmação sobre a qualidade de água utilizada para consumo (GIATTI et al. 2007).

A partir das experiências adquiridas na dinâmica de aplicação dos instrumentos da pesquisa e respectiva classificação enquanto retroalimentação e, também vislumbrando o objetivo maior de se alcançar o nível mais elevado de participação, é possível trilhar um percurso analítico direcionado à superação de desafios. Estes, compreendidos por sua correspondência com a evolução do processo participativo, são aqui elencados como: mobilização social, cooperação, apropriação (de conhecimentos, valores e habilidades) e desenvolvimento de postura proativa para o enfrentamento dos problemas.

Ao revelar-se como indispensável no processo de participação popular, a mobilização social é primordial. Porém, é preciso oferecer subsídios e criar condições não somente para que ela se constitua, mas, da mesma maneira, seja mantida no decorrer do processo, por meio da elevação da autoestima dos atores sociais e da confiança na sua própria capacidade de transformação da realidade, a partir do fortalecimento do poder desses indivíduos como sujeitos sociais (empoderamento), e também por meio da construção e apropriação de novos conhecimentos, valores e habilidades, os quais contribuirão para o desenvolvimento de autonomia frente os problemas (CHRISTOPHER et al. 2008).

No enfrentamento de problemas complexos, como na confluência de questões sociais, ambientais e de saúde, a participação não pode limitar-se a uma simples divulgação ou democratização de informações. Ou ainda, não pode ser reduzida a uma consulta popular. Por sua vez, um processo participativo dialógico demanda o despertar de uma postura proativa dos sujeitos no processo de tomada de 
decisões, bem como seu acompanhamento e avaliação constante. Refere-se, portanto, a um processo cíclico de intervenções que se dá, conforme List (2006) a partir do nível 6 (aprendizado interativo e colaborativo) em direção ao nível 7 (automobilização e empoderamento).

Ou seja, ao mesmo tempo em que requer a mobilização social e a construção de conhecimentos sobre o tema, ao se concretizar o processo bem sucedido de participação, é oferecida uma oportunidade de aprendizagem mútua e de fortalecimento comunitário, possibilitando assim que os atores sociais envolvidos, ao final do processo, possam "caminhar sozinhos" (autonomia/postura proativa) - mesmo diante da possibilidade de descontinuidade ou desconexão quanto a ações governamentais necessárias. Com isso, vale salientar que tal nível de participação depende não só de transformações nas formas de ação coletiva, mas também do processo de gestão e de políticas públicas, pois o saneamento básico é um componente essencial dos direitos do cidadão (TOLEDO et al. 2012).

Minkler (2010) enfatiza que em processos participativos que objetivam produzir conhecimentos coletivos indutores de políticas públicas, um pré-requisito importante é fortalecer o compromisso entre os parceiros - sujeitos e pesquisadores. Mas a efetiva solução dos problemas nem sempre estará circunscrita aos sujeitos e pesquisadores. Em lauaretê, aspectos como resistência à pesquisa, inércia da população perante alguns problemas e baixa autoestima foram identificados e considerados entraves à mobilização social. Quanto à resistência inicial à pesquisa, esta foi manifestada pelos indígenas desde o primeiro contato com as lideranças locais, quando deixaram claro sua preocupação quanto aos reais benefícios que teriam com a pesquisa. Informaram que muitos estudos já haviam sido desenvolvidos na região, porém a maioria, até aquele momento, não havia trazido melhorias efetivas para a população e nem mesmo a devolutiva dos resultados.

Estudos como os de Christopher et al. (2008) e Cochran et al. (2008) descrevem situações similares em que os indivíduos oferecem resistência, sendo estereotipados e explorados sistematicamente. Procurou-se nesta pesquisa atender essa demanda, partindo da condição inicial de que toda proposta de intervenção, seja 
ela educacional ou prática, envolvendo mudança de hábitos, tem seus limites como o da recusa clara, o da resistência camuflada ou da reinterpretação (MINAYO, 2005).

Podemos dizer que alguns avanços para enfrentar o desafio da mobilização social foram reconhecidos na forma de evidências ao longo do processo com o uso dos diferentes instrumentos. Merecem destaque aqui, resultados obtidos com o Painel com Fotos - aplicação similar ao 'Photovoice', amplamente empregado em estudos na abordagem de 'Community-Based Participatory Research' (CASTLEDEN et al. 2008; FINDHOLT et al. 2011). Na construção deste Painel com Fotos para identificar nexos causais e possíveis soluções para os problemas, no momento da apresentação destes, os indígenas fizeram breves comentários em português referentes à escrita dos cartazes, em seguida dirigiram-se diretamente aos demais presentes na língua tukano.

Obviamente, a dificuldade com o idioma - por parte dos pesquisadores impossibilitava o correto julgamento sobre as explanações, contudo, com o teor dos enunciados explicado em momentos conclusivos, foi possível compreender que ali ocorria uma reflexão sobre os problemas, causas e soluções, assim como cobranças eram feitas pelos líderes quanto às responsabilidades individuais pertinentes. Consecutivamente, os indígenas que apresentavam as explicações requisitavam ao final das mesmas que, por meio de complementação, os pesquisadores realizassem a legitimação e confirmação daquilo que eles haviam apresentado - já nesse momento, em português, idioma utilizado ao longo de todo o processo de interação entre pesquisadores e sujeitos. Desse modo, o uso deste instrumento possibilitou aos participantes refletirem sobre sua realidade e, a partir dessa reflexão, puderam ser observados discursos de alguns indígenas e incentivos à mobilização social.

Para a apropriação desses novos conhecimentos destacamos entraves associados principalmente ao pluriculturalismo local, já que estão presentes em lauaretê cerca 15 etnias, pertencentes a três grupos linguísticos, as quais mantêm inúmeras características culturais, apesar de estarem em contato crescente com a sociedade não-indígena há mais de 80 anos. Assim, prevaleciam ainda entre os indígenas de lauaretê crenças mitológicas na forma como se relacionavam entre si e 
com o ambiente, na interpretação do adoecimento e nas práticas de prevenção e cura (TOLEDO et al. 2009).

A análise por triangulação dos resultados (MINAYO et al. 2005) dos mapas-falantes, questionários, entrevistas e observação participante revelaram que os indígenas, mesmo reconhecendo situações de causa e efeito sobre os agravos à saúde a que estavam expostos, ainda não haviam incorporado esse conhecimento na vida cotidiana, ou seja, havia uma divergência entre o discurso e a prática, o que na antropologia é chamado de 'bricolage', característico de um processo de ressignificação de enunciados da sociedade envolvente quanto aos sabres e representações dos indígenas. Com isso, apesar de demonstrarem o reconhecimento de uma lógica sanitária em cadeia capaz de transmitir doenças, permanecia dentre os sujeitos a interpretação de que as doenças diarreicas, por exemplo, eram típicas de indígenas e causadas por feitiços ou por desequilíbrios nas relações entre as pessoas, o meio, a sociedade e as entidades espirituais (GIATTI et al. 2007; GARNELO e WRIGHT 2001).

Em especial, nos resultados da observação participante, foi possível o reconhecimento dessa reinterpretação baseada em lógicas míticas e, consequentemente, a necessidade de adequações metodológicas a fim de enfrentar essa realidade peculiar. Esse processo de apropriação de conhecimentos é favorecido em pesquisas participativas, principalmente pela constante troca de saberes entre pesquisadores e sujeitos do problema. Isso caracteriza um processo de aprendizagem colaborativa e interativa, já que os resultados encontrados no decorrer do processo oferecerão novos ensinamentos a todos (FLICKER 2008).

O uso de alguns instrumentos, especificamente aqueles de diagnóstico participativo, como o mapa-falante e o painel de fotos, classificados como fornecedores de feedbacks diretos/imediatos ao processo de pesquisa-ação, permitiu ainda melhor 
compreender a espiral cíclica de Lewin $(1946)^{2}$. Isto porque resultados desses instrumentos indicaram a necessidade não só de ações específicas, como a realização de intervenções educativas sobre temas como resíduos e nutrição, mas da mesma maneira, demandaram novos estudos para questionamentos tanto dos sujeitos como dos pesquisadores, como as análises da água, do solo, dos resíduos e o inquérito parasitológico.

Percebe-se, portanto, que instrumentos dialéticos e não dialéticos podem ser complementares no estudo e enfrentamento de realidades complexas. Nesse sentido, Waltner-Toews (2001) identifica, como componentes de uma abordagem ecossistêmica em saúde, tanto estudos científicos clássicos, como também a pesquisa-ação, ambos lado a lado no processo de pesquisa e intervenção. $\mathrm{Na}$ aplicação desta pesquisa em foco, teve-se a oportunidade de compreender essa combinação de estudos de distintas naturezas, contudo, ficou claro que o processo participativo dialógico pretendido, foi mais bem executado tendo como eixo condutor as intervenções participativas, aqui classificadas sob a forma de instrumentos de feedback direto. Por sua vez, os recursos de estudos científicos clássicos, foram os aplicados e classificados como instrumentos de feedback indireto. Isto constitui um processo de retroalimentação e de complementariedade à proposta de Lewin (1946), de modo a incrementar o subsídio de instrumentos científicos clássicos.

Conforme demonstrado, resultados desse processo de pesquisa-ação revelaram uma mobilização social crescente dos sujeitos do problema, a construção de novos conhecimentos, o desenvolvimento de novas habilidades e caminhos para ressignificação de valores, elementos favoráveis para o enfrentamento da complexidade da questão sanitária local. Como exemplo dessas conquistas destaca-se a elaboração de um abaixo-assinado à FUNASA, instituição a quem se atribuía, na ocasião, a responsabilidade por serviços de saneamento em terras indígenas.

\footnotetext{
${ }^{2}$ Este autor é um dos principais precursores da pesquisa participativa e publicou seus primeiros ensaios abordando e interagindo com questões de relacionamento entre grupos sociais, especialmente envolvendo minorias judaicas e população negra nos Estados Unidos. A espiral cíclica a que se refere é a aplicação continuada composta por planejamento, ação (intervenções) e estudo de evidências, com foco na qualidade da ação, base de uma metodologia de pesquisa-ação (action-research).
} 
Por outro lado, também foi possível reconhecer limites ao alcance do que List (2006) considera como o nível mais elevado de participação, ou seja, a automobilização e o empoderamento. Em lauaretê, a característica da distância física ${ }^{3}$, e a pouca interlocução com o poder público, que deveria prover a execução de ações em saneamento, ocasionaram uma significativa ruptura no processo. Ali há a necessidade de intenso movimento social reivindicando reformas politicas e administrativas quanto às terras indígenas, estimulando que sejam executadas obras de infraestrutura e que esses processos ocorram de modo a permitir o controle social por parte da comunidade indígena.

\subsection{Desafios para a ampliação da comunidade de pares: demarcando categorias de análise}

Na sequência do encontro de evidências em lauaretê, e da forma como se caracteriza a ruptura do processo de resolução dos problemas sanitários, especialmente pelo distanciamento entre os sujeitos e o poder público, foi sendo evidenciada a necessidade da construção coletiva de saberes e a busca colaborativa de soluções em uma escala ampliada. Por outro lado, há sim questões científicas a serem desbravadas, principalmente no campo das ciências sociais neste contexto de problemas sanitários. Desse modo, desvela-se o imperativo de que as práticas inerentes à pesquisa-ação teriam que se expandir para envolver gestores públicos no processo dialético. E isso, deve ocorrer na amplitude do território, pois os problemas se reproduzem nas terras indígenas do alto rio Negro, onde se encontram centenas de comunidades indígenas com os mesmos problemas sanitários.

Ou seja, enquanto o processo participativo para a promoção do empoderamento e da construção coletiva de saberes deve operar a partir do nível local, mas a questão do saneamento básico em terras indígenas impõe expandir uma

\footnotetext{
${ }^{3}$ lauaretê situa-se em uma localidade de difícil acesso. Pertence ao município de São Gabriel da Cachoeira / AM e fica a uma distância de aproximadamente $300 \mathrm{~km}$ da sede municipal, acessível, geralmente, por barcos.
} 
abordagem ao território. Evidentemente, a legitimidade de participação social em categorias espaciais ampliadas deve ser procedida por meio de legítimos representantes, para fazer correspondência a essa demanda. Nesse caso, julga-se conveniente buscar alternativas para promover a expansão da comunidade de pares, possibilitando diálogo entre academia, sociedade e gestores visando, portanto, interagir com realidades multifacetadas.

Enfatiza-se a correspondência deste caso em estudo com os pressupostos de Funtowicz e Ravetz (1993), pois: Questões antropológicas nas relações homem, ambiente e saúde são determinantes e adicionam complexidade, melhor dizendo, evidenciam a característica de uma complexidade reflexiva; A necessária ampliação da escala de intervenções para o território pressupõe 0 envolvimento ativo de gestores públicos; Por fim, as políticas públicas de saneamento e saúde se apoiam em questões científicas superadas apenas sob uma perspectiva positivista (relação causal direta, ex.: doenças de ciclo fecal-oral). Todavia, a subjetividade humana requer a superação de ações que seriam unilaterais, como a simples construção de banheiros e redes de água e esgoto, o que não garante que as representações e práticas da população possibilitem aos sujeitos se apropriem destas melhorias. Em síntese, julga-se adequado caracterizar esse arcabouço com elementos característicos da ciência pós-normal, como valores controvertidos, incertezas em jogo e riscos de sérios prejuízos à saúde e à qualidade de vida.

O programa Ecohealth, uma iniciativa do IDRC (International Development Research Centre), instituição ligada ao parlamento do Canadá, estimula e financia diversos projetos de pesquisa, principalmente em países em desenvolvimento. A abordagem proposta pelo programa Ecohealth remete à necessidade de estudar e de promover intervenções participativas para problemas complexos, compreendendo desde questões de saúde humana, a aspectos ecológicos 
e socioambientais, baseando-se nos pilares da transdisciplinaridade ${ }^{4}$, participação e equidade (LEBEL 2003). Esse tipo de enfoque que pressupõe o envolvimento de equipes multidisciplinares de pesquisadores, tratando o objeto de pesquisa de modo sistêmico e participativo, envolvendo obrigatoriamente os sujeitos das situações ou dos riscos, tem sido classificado como uma Abordagem Ecossistêmica em Saúde (WALTNER-TOEWS 2001; FREITAS et al. 2009).

Além de possibilidade comparativa entre os pressupostos da pesquisaação e da Abordagem Ecossistêmica em Saúde, um ponto de destaque para fazer avançar em questionamentos foi que, de acordo com Lebel (2003), em certo momento do avanço colaborativo no estudo e das decisões sobre problemas dos ecossistemas e da saúde, torna-se fundamental o envolvimento de representantes do poder público, ou gestores de um modo geral, em determinado nível de desenvolvimento da pesquisa participativa.

Retomando quanto à evolução do processo de empoderamento, é possível averiguar avanços quando este se inicia pela identificação de pequenos grupos que, já fortalecidos por interesses comuns, são convocados para atuar como agentes do diagnóstico da realidade na qual estão inseridos, constituindo-se um processo e não um produto, onde as pessoas envolvidas são beneficiadas desde 0 princípio do diagnóstico por meio de participação ativa. Em um segundo momento, quanto ao estabelecimento de parcerias intersetoriais entre órgãos gestores e sociedade civil iniciam-se as organizações e trabalhos comunitários, com vistas ao desenvolvimento da ação política e de uma postura proativa para com o destino da comunidade e melhoria de suas condições. Nestes trabalhos comunitários, ressalta-se a importância do reconhecimento, reflexão e discussão acerca dos mecanismos legais de participação e das leis que garantem seus direitos e deveres como cidadãos. $\mathrm{Na}$ área da saúde isto tem sido denominado de advocacia em saúde, elemento

${ }^{4}$ Utiliza-se o termo transdisciplinaridade nesta tese apenas como citação correspondente a determinado movimento ou arcabouço metodológico, como o Ecohealth, que evidencia o termo. No entanto, nesta tese se utiliza o conceito de interdisciplinaridade no estudo dos contextos socioambientais e de saúde combinado com os processos participativos, como possibilidade de avanços na compreensão e resolução dos problemas em foco. Opta-se pela interdisciplinaridade, por ser também um conceito já melhor estabelecido, com características operacionais mais bem definidas (ALVARENGA et al. 2011). 
fundamental para o empoderamento e constituição de indivíduos e grupos sociais fortalecidos (LAVERACK e WALLERSTEIN 2001; BECKER et al. 2004).

Assim, na perspectiva do desenvolvimento de uma ciência pós-normal e produção do saber com participação dos sujeitos e gestores públicos envolvidos no problema, as instituições de pesquisa têm, no desenvolvimento de etapas de um processo de empoderamento e, especialmente na prática da advocacia em saúde, uma possibilidade real e urgente de intervenção. Isso se faz valer à medida que as transformações almejadas dependem da atuação de cidadãos conscientes de seus direitos e deveres. Então, por meio de um constante diálogo entre saber técnico e saber popular, tem-se a construção de novos conhecimentos e a incorporação de novos valores necessários para o empoderamento e para o despertar de maior engajamento político.

A partir dessas reflexões em torno de uma experiência aplicada e o criticismo respectivo, espera-se poder delimitar algumas categorias de análise que sejam aplicáveis às pesquisas ou intervenções com foco em contextos socioambientais e de saúde, tendo em vista que para a sustentabilidade de ações nesse sentido é premente o envolvimento de amplos atores sociais, inclusive os sujeitos dos riscos, mas também especialistas acadêmicos, consultores, gestores públicos, etc.. Enfim, uma comunidade ampliada de pares. Desse modo, apresenta-se o Quadro 4 composto no sentido de contribuir para uma analogia a partir de dimensões e respectivas categorias de análise. As dimensões em questão se referem a: modelos de intervenção tendo como padrão mais elevado o empoderamento em processos dialógicos; escala de abrangência das intervenções; e a funcionalidade que se pretende. 
Quadro 4 - Dimensões e categorias de análise para processos participativos e promoção da ampliação de comunidade de pares.

\begin{tabular}{|c|c|}
\hline Dimensões & Categorias e enunciados \\
\hline $\begin{array}{l}\text { Aplicação de } \\
\text { instrumentos } \\
\text { participativos }\end{array}$ & $\begin{array}{l}\text { A quantidade de instrumentos não corresponde diretamente à qualidade } \\
\text { do processo de empoderamento, este por sua vez, se constrói dentro de } \\
\text { uma dinâmica de retroalimentação: assim, propõem-se três categorias: } \\
\text { - Pontual - em que se verifica apenas um instrumento de poder dialético } \\
\text { envolvendo os sujeitos; } \\
\text { - Multi-instrumentos - em que se combinam distintos instrumentos, } \\
\text { porém, sem caracterizar um processo de retroalimentação; } \\
\text { - Cíclica/continuada - uma aplicação de distintos instrumentos } \\
\text { combinados e em cadeia de retroalimentação, com elevada participação } \\
\text { crítica dos sujeitos, inclusive provendo questões a serem respondidas } \\
\text { pelo processo de pesquisa, também caracterizando o envolvimento } \\
\text { colaborativo na dinâmica ou redelineamento metodológico. }\end{array}$ \\
\hline Escala & $\begin{array}{l}\text { Seria possível estabelecer diretamente uma escala de intervenção em } \\
\text { base comunitária, contudo, deve-se verificar que alguns problemas } \\
\text { ambientais e de saúde afetam distintamente grupos que não estão } \\
\text { isolados espacialmente, como trabalhadores de determinadas atividades } \\
\text { ou mesmo minorias étnicas/culturais. Esses grupos sociais podem residir } \\
\text { dispersos espacialmente, porém compartilhando características e } \\
\text { determinados riscos. Desse modo, propõem-se as categorias: } \\
\text { - Local/dirigida - por permitir classificar os grupos de sujeitos de risco } \\
\text { por uma característica comum, seja enquanto delimitação de certo grupo } \\
\text { social (trabalhadores, indígenas ou imigrantes), seja pura e } \\
\text { simplesmente um grupo de determinada comunidade ou bairro; } \\
\text { - Ampliada - que corresponde a uma escala superior em termos } \\
\text { geográficos, podendo ser uma cidade/metrópole, uma bacia hidrográfica, } \\
\text { uma bio-região (ex.: bioma Mata Atlântica), estado/província ou país. } \\
\text { Está escala, tem como consideração de base o diferenciamento com } \\
\text { relação à categoria local/dirigida, na qual a intervenção se procede } \\
\text { diretamente com os sujeitos. Na escala ampliada a intervenção pode ser }\end{array}$ \\
\hline
\end{tabular}




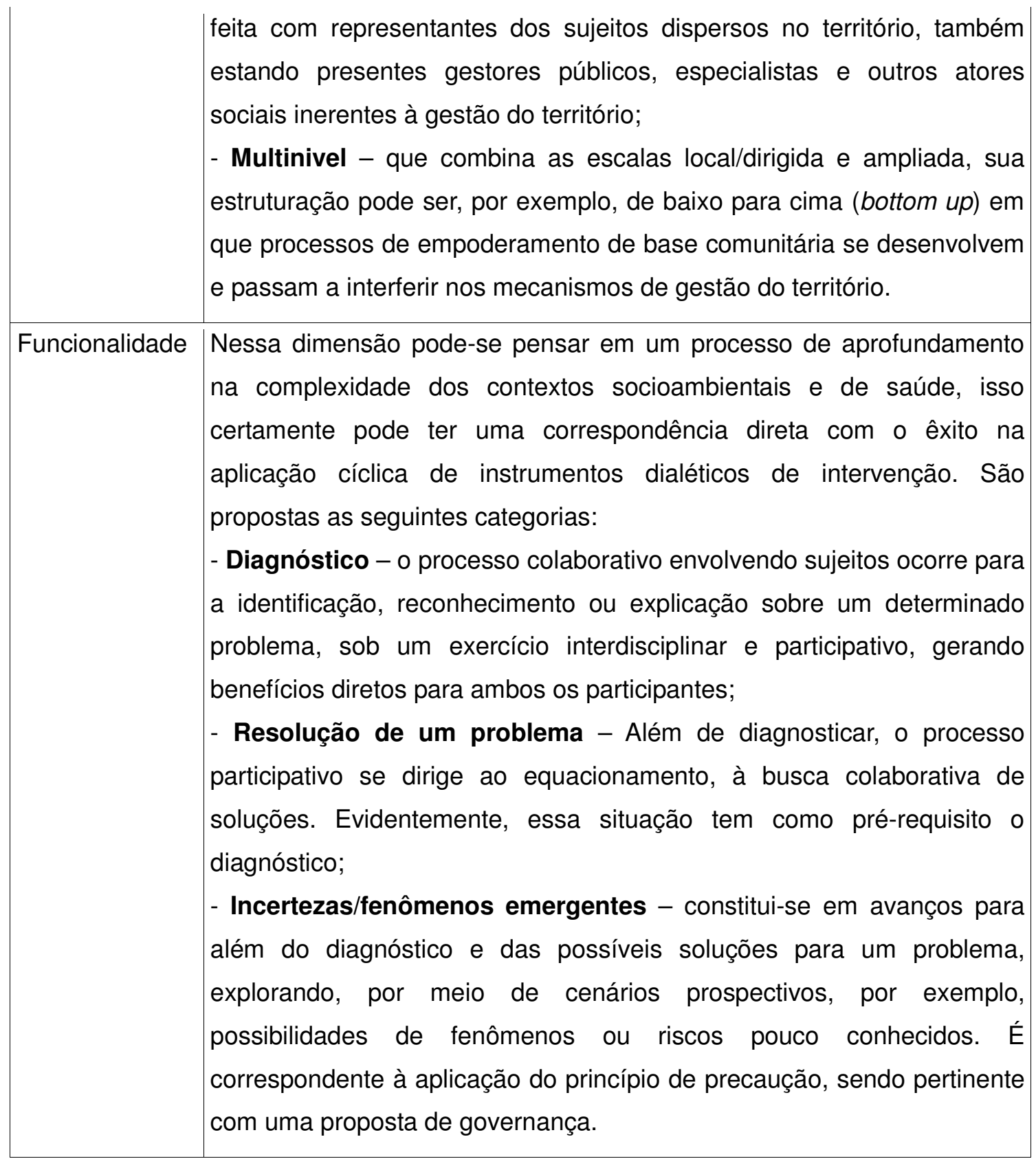

Fonte: elaborado pelo autor

Sendo que a experiência de pesquisa-ação em lauaretê ofereceu os pressupostos para essa proposta de classificação, pode-se afirmar que o referido projeto foi compreendido como: Uma abordagem cíclica/continuada - que envolveu os sujeitos sistematicamente com processos de retroalimentação pela combinação de instrumentos dialéticos e não dialéticos; Uma aplicação em escala local - pois 
embora tenha iniciado um processo no qual o empoderamento avançava para a categoria multinível, o distanciamento dos gestores públicos comprometeu essa possibilidade; e, por fim, um projeto cuja funcionalidade se dirigiu à resolução de um problema, tendo como foco a questão sanitária e o objetivo maior de promoção da saúde da população indígena, isso se refletiu em medidas individuais e coletivas de prevenção à saúde, além de reinvindicações ao poder público quanto ao direito ao saneamento básico.

Realmente, a experiência utilizada não permite justificar a proposição de todas as categorias elencadas. A referência à complementação desse quadro reside em processo de revisão bibliográfica convencional durante todo o processo de pesquisa e na produção das publicações inerentes. No capítulo 5 empreende-se uma ampla revisão bibliográfica sistemática explorando publicações que tratam de processos participativos em torno de contextos socioambientais e de saúde. Nesta sequência espera-se trazer todos os elementos complementares, justificativas e situações que ilustram essa proposta de classificação. 


\section{Uma revisão sistemática de literatura sobre pesquisa participativa e ampliação de comunidade de pares em contextos socioambientais e de saúde.}

No contexto de antecedentes de pesquisa participativa relatados e nas revisões críticas de desafios associados às intervenções envolvendo os sujeitos dos riscos, além de ampliação do referencial teórico dialogando com proposições de uma ciência Pós-normal, apresenta-se essa revisão sistemática de literatura. A amplitude deste levantamento se constitui de estudos participativos em diferentes escalas, sobre distintas orientações teóricas e metodológicas e com variado espectro em termos de funcionalidade a que se destinam. O tema das intervenções se situa na complexidade de contextos socioambientais e de saúde em que se verifiquem abordagens participativas com características dialógicas (FREIRE 1987).

\subsection{Método de revisão sistemática}

O método da revisão sistemática de literatura foi escolhido por oferecer possibilidade de desenho adequado para a seleção de publicações pertinentes para com os objetivos desta tese, bem como, pela possibilidade de se constituir rigorosa síntese a partir dos artigos elegíveis, sendo passível de reprodução e permitindo, por meio desta síntese, constituir amplo panorama (LIBERATI et. al. 2009; GALVÃO et al. 2004) quanto a pesquisas e intervenções participativas para complexos problemas que envolvem situações socioambientais e de saúde.

Para cumprir esses requisitos esta revisão sistemática foi procedida sob uma rigorosa definição de seu processo metodológico, escolha de base bibliográfica de pesquisa condizente, estabelecimento de critérios específicos para elegibilidade e para avaliação da relevância de pesquisas selecionadas (GALVÃO et al. 2004). Para o processo de síntese de informações disponíveis nas pesquisas selecionadas, foram inicialmente identificadas informações sobre questões vigentes e pertinentes ao 
propósito desta tese, considerando a possibilidade de ampla busca dentre os estudos elegíveis. Procedeu-se assim, a seleção justificada por critérios de inclusão e exclusão específicos à avaliação qualitativa dos estudos selecionados sobre aspectos metodológicos, de abrangência dos objetivos e das intervenções participativas relatadas nos respectivos artigos.

Enquanto escolha de referencial para a abordagem metodológica foram aplicados subsídios oriundos de consagrados avanços e práticas sobre revisões sistemáticas com foco a dar suporte para a prática de cuidados clínicos baseados na qualidade de evidências científicas (GALVÃO et al. 2004). Todavia, não é intuito desta revisão sistemática realizar uma síntese a partir das conclusões das publicações localizadas, como se fosse anseio apontar um método de intervenção participativa mais eficiente, ou mesmo, destacar abordagens participativas que sejam limitadas e incapazes a responder aos cenários complexos em que se desenvolvem. Na realidade, o procedimento de síntese adotado foi conduzido para produzir um panorama das publicações selecionadas classificando-as em três dimensões: da aplicação dos instrumentos metodológicos; da escala de abrangência das intervenções; e da funcionalidade da abordagem.

Assim, optou-se pelo direcionamento racional desta revisão sistemática para o enriquecimento da reflexão em torno de análise qualitativa sobre pesquisas e intervenções participativas. Após o processo de qualificação dos estudos selecionados nas dimensões citadas, foi procedida à quantificação de alguns aspectos chave conforme apresentado na seção 5.2. Resultados e discussões da revisão sistemática. No processo de síntese, diferentemente de uma revisão voltada à clínica baseada em evidências, onde se buscam melhores decisões para o tratamento de determinados agravos, utilizamos o mesmo processo de busca de informações para selecionar e avaliar os diferentes tipos de intervenção, porém, buscando também identificar a consistência das intervenções dentre estudos de diferentes formas de intervenção (MULROW, 1994) para diferentes escalas de processos participativos ou distintas funcionalidades que se objetiva, como a realização de diagnósticos participativos, resolução de determinados problemas coletivos e/ou o diálogo com problemas emergentes e com incertezas científicas dos riscos combinados de fatores 
socioambientais.

A seguir apresentam-se itens correspondentes à descrição geral sobre o processo de revisão sistemática da forma como aplicados em sequencia cronológica, descrita no fluxograma da Figura 3, em adaptação de protocolos propostos por Sampaio e Mancini (2007) e por Liberati et al. (2009).

Figura 3 - Fluxograma metodológico de etapas de revisão sistemática

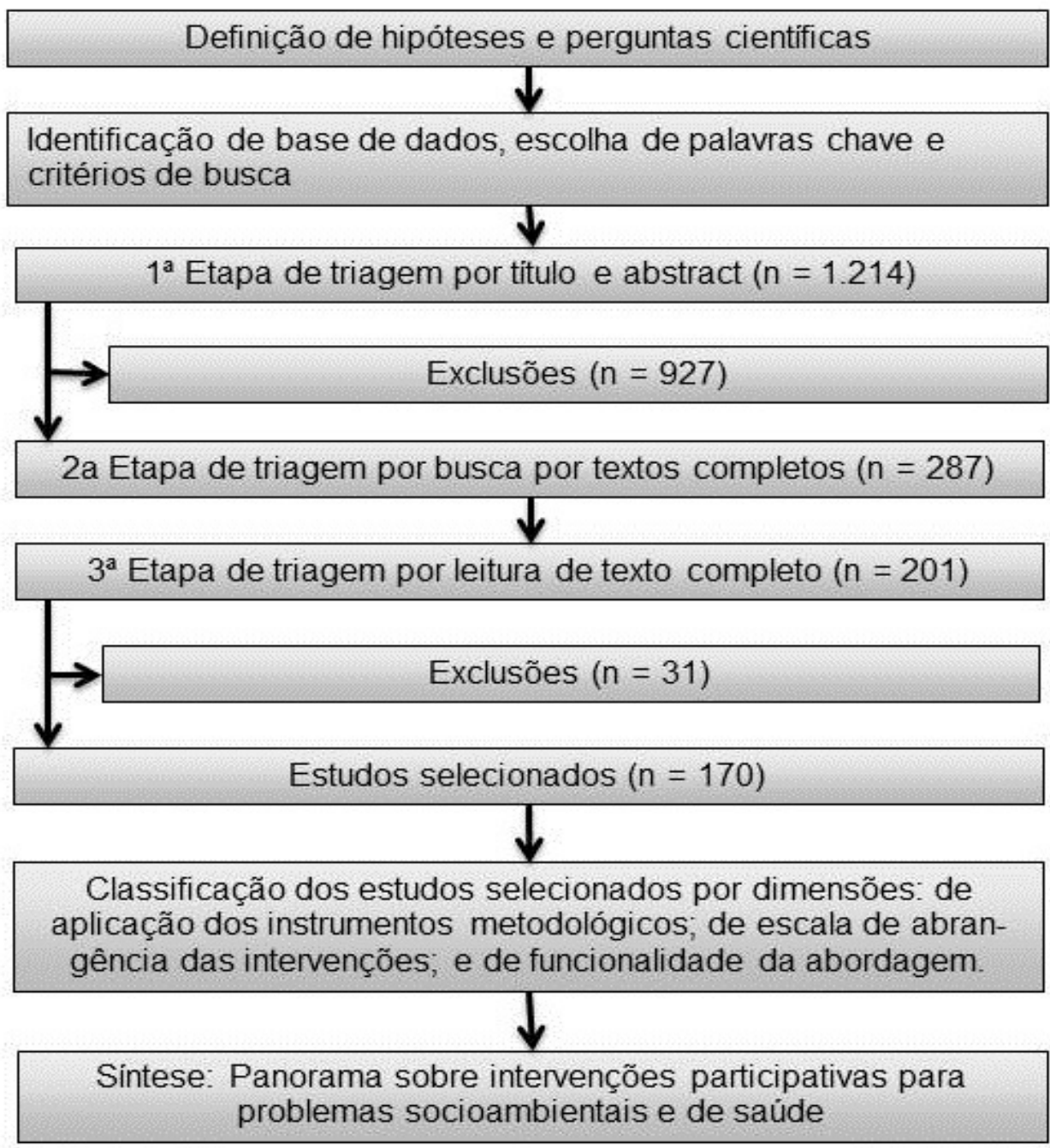

Fonte: elaborado a partir de Sampaio e Mancini (2007) e Liberati et al. (2009). 


\subsubsection{Hipóteses e perguntas da revisão sistemática}

Considerando que pesquisas participativas sobre contextos socioambientais e de saúde podem ter os mais diferentes desenhos e podem ser executadas a partir de distintos instrumentos e que os mesmos podem operar de forma combinada ou complementar, ou mesmo cíclica em processo de retroalimentação, um processo de avaliação crítica de distintas pesquisas participativas quanto ao processo de aplicação de instrumentos pode ser condizente. Desse modo, se estabelece a primeira pergunta referente a esta revisão sistemática:

- É possível classificar distintas pesquisas e intervenções participativas sobre contextos socioambientais e de saúde a partir da aplicação de seus instrumentos?

Tendo como pressuposto que problemas socioambientais com impacto na saúde afetam indivíduos pertencentes a grupos sociais como de comunidades desfavorecidas, trabalhadores em determinadas atividades ou de gênero, considerando que as respectivas cadeias causais dos fatores de risco possuem origem em processos mais abrangentes como das injustiças socioambientais que se distribuem nos territórios, e que esses contextos estão subordinados a processos globais com impactos locais, pode ser importante avaliar o modo como os processos de pesquisa e intervenções participativas promovem o diálogo entre os grupos sociais e diferentes escalas territoriais, como em municípios, em regiões metropolitanas, etc. Assim, têm-se a segunda pergunta:

- $\quad$ É viável classificar pesquisas e intervenções participativas sobre contextos socioambientais e de saúde a partir da escala de abrangência?

Em consideração à complexidade inerente aos contextos socioambientais e de saúde e à necessidade premente de processos participativos que se justificam por várias razões, como a necessidade de envolvimento dos sujeitos para a produção de saberes complementares e soluções colaborativas, ou mesmo a 
necessidade do envolvimento de múltiplos atores sociais e sujeitos dos riscos para dialogar e dirimir as incertezas científicas, pressupõe-se, desse modo, que pesquisas participativas nesse campo podem ser classificadas quanto à funcionalidade a que se dirigem, portanto, apresenta-se a terceira questão desta revisão sistemática:

- A que se dirigem as abordagens participativas sobre contextos socioambientais e de saúde? Estes estudos participativos tem sua funcionalidade focada no diagnóstico, na resolução ou gestão compartilhada, ou nas incertezas científicas inerentes?

\subsubsection{Busca de evidências}

Sendo a proposta desta pesquisa um amplo panorama sobre pesquisa participativa, optou-se pela utilização das possibilidades de busca bibliográfica do sistema Web of Science, desenvolvido e mantido pelo Institute of Scientific Information/Thomsom Scientific, Philadelphia, EUA.

Outras bases bibliográficas foram cogitadas para esse levantamento: 0 PubMed, base de pesquisa bastante tradicional em biomédicas; e Scopus, base de dados criada pelo grupo Elsevier. Se, por um lado o PubMed têm ampla tradição na área da saúde, foi decidido buscar em base multidisciplinar, pois a transversalidade das questões socioambientais e de saúde permitiria localizar artigos de interesse dentro de amplo sortimento de periódicos com respectivas áreas de conhecimento distintas. Nesse sentido, apesar de a base Scopus possuir maior número de periódicos indexados (FALAGAS et. al. 2008), o Web of Science é a base de dados bibliográficos genuinamente pan-disciplinar (JACSO 2005). Também, a possibilidade de utilização da ferramenta Endnote agregada à base do Web of Science, constituindo-se de importante auxílio para seleção e classificação de referências, favoreceu à escolha desta base de dados bibliográficos.

O Scielo Brasil também foi cogitado para a busca, mas como se 
pretendia um panorama global, considerou-se que a inserção desta base poderia promover uma proporção indevida de estudos e intervenções realizadas no Brasil. Considera-se que há periódicos do Scielo que também estão indexados no Web of Science, desse modo publicações sediadas no Brasil, favorecendo a divulgação de experiências brasileiras, também foram contempladas na busca empreendida.

Os termos escolhidos para a busca bibliográfica foram: "saúde" e "ambiente" ou "ambiental" e "participação" ou "participativo(a)" ou "governança" ou "pós-normal" ou "abordagem ecossistêmica em saúde" . Considera-se que estes termos estão devidamente representados na revisão bibliográfica componente dos capítulos anteriores e no desenvolvimento crítico de experiência de pesquisa relatada. Uma vez que o idioma de busca foi o inglês, procedeu-se a adequação dos termos nesse idioma, tendo como respaldo leituras científicas anteriores e pré-busca no Web of Science. Dessa forma a terminologia de busca em inglês é apresentada a seguir. No período entre 24/07/2012 a 07/12/2012, foi realizada a busca bibliográfica a partir do acesso via login na página eletrônica de busca do Web of Science (http://apps.webofknowledge.com/), onde foram aplicados os seguintes critérios de busca:

\section{Topic: "health" AND Topic: "environment OR environmental" AND Topic "participatory OR participative OR governance OR post- normal OR ecohealth".}

\section{Enquanto ajustes permitidos pela página de busca foram procedidos:}

\section{- $\quad$ Timespan: All years (constando registro entre 1864 e 2012 na ocasião da busca)}

\footnotetext{
${ }^{5}$ Apenas uma grande diferenciação na terminologia foi a substituição do termo "abordagem ecossistêmica em saúde" pois este termo composto em português não é frequentemente observado na literatura em língua inglesa, tendo como palavra análoga "ecohealth", que inclusive, é denominação utilizada por um programa de pesquisa e fomento do International Development Research Centre - IDRC/Canadá (www.idrc.ca), com iniciativas apoiadas em distintos continentes.
} 


\section{$-\quad$ Records per page $=\mathbf{1 0}$}

- $\quad$ Sort by $=$ Publication date - newest to oldest

- Search language: English

- $\quad$ Lemmatization $=$ off

Com esse procedimento, foram localizados 1.212 artigos, que passaram por três etapas de triagem para atingir o número final de artigos selecionados de 170 (ver Figura 3). A primeira etapa de triagem foi efetuada diretamente no Web of Science, por meio de aplicação de critérios de inclusão e exclusão apresentados no Quadro 5, aplicados aos títulos e resumos. Nesta fase os artigos selecionados foram salvos automaticamente no aplicativo EndNote, resultando em 287 registos. Posteriormente foi empreendida a segunda triagem por busca dos textos completos, disponibilizados via sistemas de acesso aberto (open access) ou por acessos permitidos pela assinatura do Periódicos CAPES, provida pela Universidade de São Paulo, esta etapa permitiu a localização de 201 artigos.

A terceira etapa de triagem foi feita por meio da leitura dos textos completos localizados, aplicaram-se, para tanto, os mesmos critérios de inclusão e de exclusão adotados para os títulos e resumos. De fato, quando em dúvida sobre a elegibilidade de determinados artigos na primeira etapa de triagem, estes foram incluídos e, após a aquisição dos textos completos, foi possível esclarecer dúvidas e efetuar, assim, nova etapa de triagem com exclusão de artigos que não contemplavam os critérios determinados. Todo processo de busca bibliográfica e aplicação de critérios de inclusão e exclusão foram procedidos pelo mesmo indivíduo, no caso, o autor desta tese. 
Quadro 5 - Critérios de inclusão e exclusão para artigos em revisão sistemática de literatura de pesquisas e intervenções participativas em contextos socioambientais e de saúde.

\begin{tabular}{|c|c|}
\hline & Critérios \\
\hline Inclusão & $\begin{array}{l}\text { - Tratar de pesquisa ou intervenção participativa/dialógica (Freire, 1987) em } \\
\text { um contexto socioambiental com possível interferência na saúde da } \\
\text { população, seja em nível local, dentre determinados grupos sociais, ou em } \\
\text { escala ampliada em determinado território. Além disso, também é } \\
\text { condicional a inclusão de subsídios ou questões científicas na } \\
\text { problematização, ou o fato de a promoção das intervenções ocorrer por parte } \\
\text { de instituições de ensino e pesquisa ou corporações, ou por meio de } \\
\text { políticas públicas sob os mesmos princípios participativos. }\end{array}$ \\
\hline Exclusão & $\begin{array}{l}\text { - Artigos de revisão ou de concepção puramente teórica; } \\
\text { - Não contemplar conjuntamente saúde (questões inerentes à saúde } \\
\text { humana), ambiente (tendo necessariamente o ambiente na condição de fator } \\
\text { de exposição a determinados riscos), e processos participativos dentro de } \\
\text { um princípio dialógico (Freire, 1987); } \\
\text { - Não apresentar clara indicação/relato de processos participativos com } \\
\text { envolvimento de sujeitos ou múltiplos atores sociais; } \\
\text { - Aplicar exclusivamente instrumentos não dialógicos que apenas envolvem } \\
\text { os sujeitos para aquisição de informações como na aplicação de } \\
\text { questionários ou entrevistas; } \\
\text { - Não apresentar descrição e aplicação de instrumentos capazes de } \\
\text { promover a participação dos sujeitos, sobre uma perspectiva dialógica; } \\
\text { - Apresentar e discutir questões de participação, governança, ou } \\
\text { abordagens ecossistêmicas em saúde (Ecohealth) ou em ciência pós-normal } \\
\text { exclusivamente na forma conclusiva no sentido de proposição para } \\
\text { solucionar ou mitigar determinado contexto que interfira na saúde humana; }\end{array}$ \\
\hline
\end{tabular}

Fonte: elaborado pelo autor 


\subsubsection{Análise crítica e classificação dos artigos incluídos}

Procedeu-se, primeiramente, a classificação qualitativa dos estudos selecionados por meio de dimensões e respectivas categorias de análise para processos participativos e promoção da ampliação da comunidade de pares. A definição destas categorias encontra-se no Quadro 4, capítulo 4.

Por meio da classificação e discussão de artigos representativos das dimensões e respectivas categorias de análise foi possível avançar por uma análise crítica da produção científica em foco, também se procedendo a discussão a partir da quantificação do número de produções referentes a cada categoria de análise utilizada. Soma-se a esse processo a classificação e contabilização dos artigos por local de intervenção relatada e, também, por periódicos de publicação.

Uma análise integrada foi executada a partir do cruzamento dos artigos pela combinação de classes atribuídas nas distintas dimensões e categorias de análise. Em conjunto, essas análises se dirigiram a averiguar um panorama sobre a produção, apontando tendência nas relações entre as categorias nas dimensões de análise, bem como desafios que prevalecem em processos de estudo e intervenção em realidades complexas que envolvem contextos socioambientais e de saúde.

\subsection{Resultados e discussão da revisão sistemática de literatura}

O número inicial de artigos localizados pela busca na base de dados selecionadas, 1214 artigos, mostra a amplitude da busca. No entanto, a revisão cuidadosa dos títulos e resumos permitiu uma seleção adequada e criteriosa com a exclusão 927 itens. Grande parte das exclusões se consumou com a combinação de critérios de exclusão nas seguintes situações:

- $\quad$ Os termos referentes à participação, governança, ciência pósnormal e abordagem ecossistêmica em saúde eram apresentados de 
forma conclusiva como uma forma de recomendação, não sendo orientação metodológica e não havendo a descrição de processos participativos/dialógicos;

- O termo ambiente não era utilizado como sendo intrínseco a processo de exposição e riscos à saúde humana, quando em muitas circunstâncias constam situações como ambiente político, ambiente de decisões ou ambiente hospitalar em situação em que o estudo analisava apenas relações interpessoais no contexto e não um processo socioambiental de implicação na saúde como, por exemplo, na expressão "clinical learning environment";

- Inúmeros papers se constituíam como revisão, sendo algumas bem objetivas quanto à proposição de processos participativos; outras, inclusive, propondo modelos de pesquisa interdisciplinar, transdisciplinar ou sistêmica com foco no envolvimento dos sujeitos.

Na realidade a busca isolada com os termos 'health' e 'environment' ou 'environmental' sem os demais filtros resultaria em uma quantidade muito grande de estudos, com mais de 100.000 registros no Web of Science. Por um lado vemos que a possibilidade de encontrar artigos em saúde ambiental, ou correlatos é imensa, porém vemos que dentre estes apenas uma pequena parcela, proporcionalmente, se identifica com os termos empregados para as relações de participação e pesquisas dialógicas, conforme empregados nesta pesquisa.

A propósito os termos empregados para as relações de participação, em combinação com 'health' e 'environment' ou 'environmental' geraram as seguintes quantidades de artigos, individualmente:

\footnotetext{
- "participatory" ou "participative": 705;

- " "governance": 510;
} 


\section{- $\quad$ "post-normal": 8; \\ - "ecohealth": 28.}

É grande a proporção dos artigos para os termos em inglês análogos à participação e à governança. Mas especialmente quanto à governança registrou-se um expressivo volume de exclusões, sendo selecionas apenas 33 a partir da primeira triagem por título e resumo. Isto decorreu principalmente como relatado acima, em situação onde o termo é apresentado na forma de uma recomendação e não como algo essencial e condutor da metodologia dos estudos. Observa-se que segundo Jacobi et al. (2012) o conceito de governança é relativamente recente, tendo sido mais utilizado na gestão de recursos naturais e problemas ambientais e, especialmente, na gestão da água a partir da década de 2000. A realização de pesquisas e/ou intervenções sob orientação da governança pode ser considerada como um grande e atual desafio, principalmente, pelo fato deste conceito ser razoavelmente recente e também em decorrência dos desafios da promoção de alianças e cooperação por meio da organização e participação de diversos atores envolvidos na gestão de situações ambientais, com suas formas de resistências, assimetrias sociais e impactos decorrentes.

Pode-se observar que a aplicação de critérios rigorosos, especialmente quanto aplicação ou não aplicação de metodologia participativa dialógica, pode denotar, por meio da elevada quantidade de artigos inelegíveis, a necessidade de melhor delimitação do que realmente pode ser considerado o envolvimento participativo de múltiplos sujeitos ou atores sociais para tratar de contextos socioambientais e de saúde. Sob outro ponto de vista, pode-se inferir que há intensa demanda por diálogo entre ciência e sociedade na resolução de problemas complexos como os que envolvem saúde e ambiente. Em uma dissertação de mestrado do Programa de Pós-Graduação em Saúde Pública, da Faculdade de Saúde Pública da Universidade de São Paulo, uma ampla revisão bibliográfica sobre a participação social na gestão ambiental municipal no Brasil, relata diversos obstáculos à participação como inerentes falta de percepção de problemas e demandas locais e também a questão do acesso à informação. Havendo premente necessidade de se promover 
meios para processos efetivos de participação, a autora ressalta que, em muitas circunstâncias, a participação social é apresentada de forma generalizada e como uma "fórmula mágica" sem ter os devidos meios para sua realização (GIARETTA 2011: p.120).

Tabela 1 - Periódicos com dois ou mais artigos selecionados em revisão sistemática

\begin{tabular}{lc}
\hline \multicolumn{1}{c}{ PERIÓDICOS } & $\begin{array}{c}\text { No de artigos } \\
\text { selecionados }\end{array}$ \\
\hline Health Education \& Behavior & 9 \\
Environmental Health Perspectives & 8 \\
Social Science \& Medicine & 8 \\
Health Promotion International & 5 \\
Journal of Urban Health: Bulletin of the New York Academy of Medicine & 4 \\
Public Health Nursing & 4 \\
American Journal of Public Health & 3 \\
Environment and Planning B: Planning and Design & 3 \\
Environment and Urbanization & 3 \\
EcoHealth & 3 \\
Health Education Research & 3 \\
Revista Panamericana de Salud Pública & 3 \\
American Journal of Community Psychology & 2 \\
BMC Health Services Research & 2 \\
Ecological Economics & 2 \\
Environmental Health & 2 \\
Environmental Impact Assessment Review & 2 \\
Environmental Research & 2 \\
Futures & 2 \\
Health \& Place & 2 \\
International Journal of Health Services & 2 \\
International Journal of Occupational and Environmental Health & 2 \\
Journal of Cleaner Production & 2 \\
Journal of Community Health & 2 \\
Journal of Exposure Science and Environmental Epidemiology & 2 \\
Maternal and Child Health Journal & 2 \\
Saúde e Sociedade & 2 \\
Society \& Natural Resources & 2 \\
Tropical Animal Health and Production & 2 \\
\hline Total de artigos & 2 \\
\hline For & 2 \\
\hline
\end{tabular}

Fonte: elaborado pelo autor 
Uma vez que se encontram poucos artigos que relatam processos participativos dialógicos sobre contextos socioambientais e de saúde, com referência a aplicação dos métodos empreendidos nesta revisão sistemática e seleção de 170 textos têm-se, por outra análise, que estes ainda não possuem um espaço delimitado de divulgação científica entre algum grupo específico de periódicos caracterizáveis por subárea de conhecimento. Esta afirmativa é respaldada pelo amplo espectro de publicação dos artigos selecionados dentre diversos periódicos, como é possível verificar na Tabela 1, onde estão ranqueados os periódicos com dois ou mais artigos encontrados, e no Quadro 6, com o amplo sortimento de periódicos onde cada qual teve apenas um artigo selecionado. Dentre o grupo com dois ou mais artigos verificase a distribuição de 90 artigos em 29 periódicos, no grupo com apenas um artigo têmse 80 artigos em 80 periódicos distintos, portanto. Pode-se, todavia, observar a intensa proximidade das áreas de conhecimento da saúde e do ambiente dentre os títulos dos periódicos com estudos selecionados.

Quadro 6 - Relação de periódicos com apenas um artigo selecionado em revisão sistemática

- Academic Emergency Medicine • Action Research • Agriculture and Food Systems - Agricultural Systems • American Journal of Industrial Medicine • American Journal of Preventive Medicine - Annals Academy of Medicine - Antipode - Aquaculture Environment Interactions • Australian Geographer • Australian Journal on Ageing • Bioinformatics and Biomedical Engineering • BMC International Health and Human Rights - Cadernos de Sáude Pública - Community Action Against Asthma - Desalination - Disaster Medicine and Public Health Preparedness • Ecological Applications • Ecological Indicators • Electronic Government • Environmental and Molecular Mutagenesis • Environmental Education Research • Environmental Management • Environmental Policy and Governance • Environment Planning A - Forestry - Frontiers in Ecology and the Environment - Geoforum - Global Environmental Change • Health and Social Care in the Community • Health Policy and Planning • International Journal of Public Health • International Journal of Urban 
and Regional Research • Irrigation and Drainage • ITS Telecommunications • Journal of Advanced Nursing • Journal of Community Psychology • Journal of Environmental Planning and Management • Journal of Environmental Psychology - Journal of General Internal Medicine - Journal of Health Care for the Poor and Underserved • Journal of Health Communication • Journal of Health Psychology • Journal of Hydrology • Journal of Immigrant and Minority Health • Journal of Law, Medicine \& Ethics • Journal of Loss Prevention in the Process Industries • Journal of Occupational and Organization Psychology • Journal of Occupational Health • Journal of Planning Education and Research • Journal of Policy Modeling • Journal of the Transportation Board • Malaria Journal • Marine Policy • Mount' Sinai Journal of Medicine - National Institutes of Health Public Access - Ocean \& Coastal Management • Organization \& Environment • Pest Management Science • Physics and Chemistry of the Earth • Policy Sciences - Preventing Chronic Disease • Qualitative Health Research - Regional Environmental Change • Resources, Conservation and Recycling • Safety Science • Scandinavian Journal of Work Science Communication - Social Indicators Research • The American Journal of Occupational • The Journal of Applied Theatre and Performance • The Journal of Primary Prevention • Transboundary and Emerging Diseases • Tropical Medicine and International Health • Urban Forestry \& Urban Greening • Wageningen Journal of Life Sciences • Water Resources Management • Wildlife Research • WIT Transactions on Ecology and the Environment - Work: A journal of Prevention, Assessment and Rehabilitation.

Fonte: elaborado pelo autor

Há uma nítida evolução no número de publicações selecionadas ao longo dos anos, de acordo com a data de publicação dos artigos (ver Gráfico 1). 0 primeiro ano a contar com um artigo que contemplou os critérios de inclusão desta revisão é de 1997, ano em que constou apenas uma publicação encontrada, assim como no ano seguinte. Uma elevação bastante evidente no número de publicações se atesta a partir de 2008, sendo que entre este ano e 2012 a média de publicações selecionadas foi de 21,6 artigos por ano. Esta média difere bastante, por exemplo, do 
primeiro quinquênio do início da década, entre 2000 e 2004 com média de 7 artigos por ano, reforçando a afirmativa quanto a progressão temporal de publicações sobre participação dialógica em contextos socioambientais e de saúde.

Gráfico 1 - Evolução temporal por ano de publicação de artigos selecionados em revisão sistemática

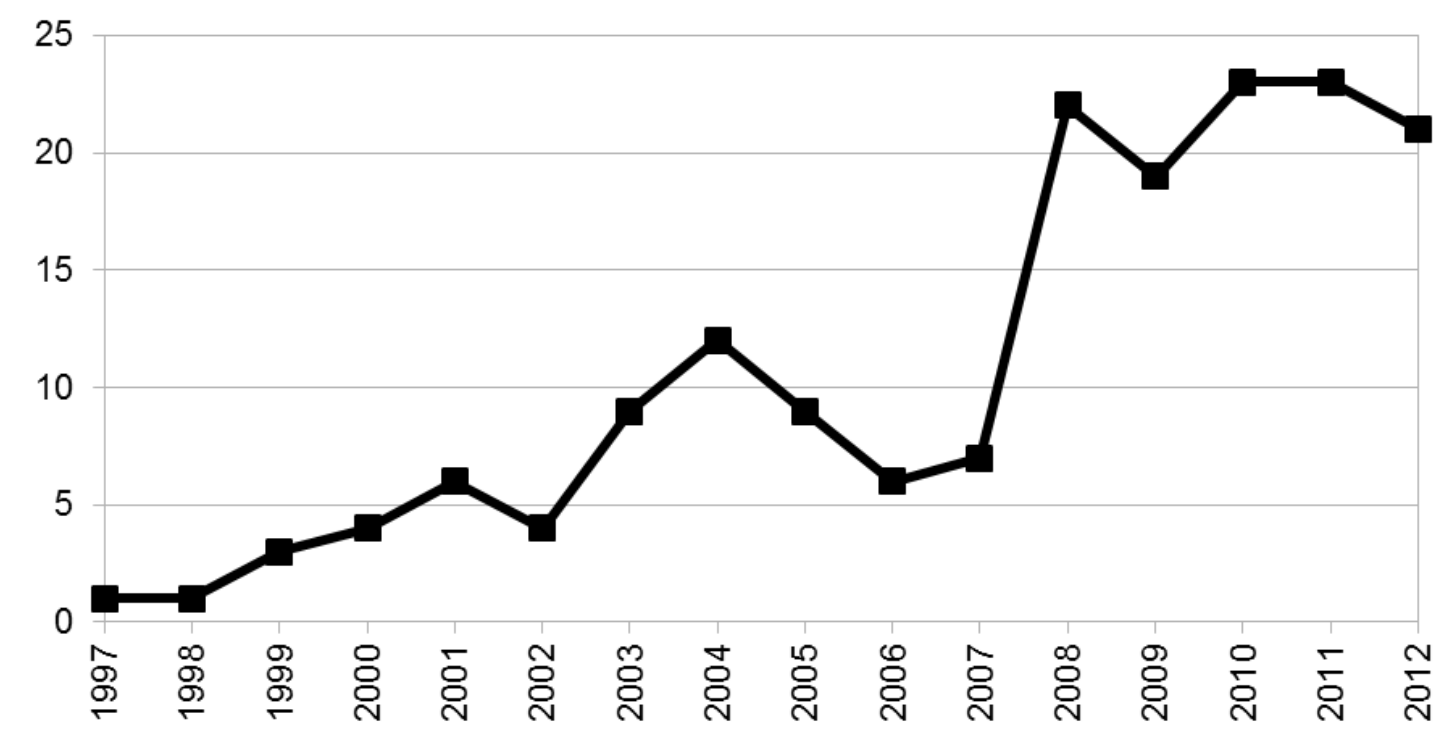

Fonte: elaborado pelo autor

\subsection{1. - Classificação e análise das publicações quanto aos instrumentos participativos dialógicos}

A proposição dessa classificação vai de encontro diretamente com os desafios de se promover processos participativos dialógicos; quanto a esse tipo de dificuldade podemos salientar diferentes situações, como: dificuldades iniciais para 0 estabelecimento de confiança entre os sujeitos e pesquisadores quando em processo de intervenção em comunidades socialmente desfavorecidas e culturalmente diferenciadas (CHRISTOPHER et al. 2008); os entraves diversos como a 
desinformação e a falta de percepção para os problemas ambientais de modo a dar suporte a maior envolvimento de atores sociais na gestão ambiental participativa (GIARETTA 2011); a necessidade de se aplicar, de modo combinado, diversos instrumentos participativos para promover a mobilização social para as questões de interesse (TOLEDO et al. 2012).

Não obstante, pode-se considerar que há diferentes níveis de participação a partir do envolvimento dos sujeitos nos processos de intervenção. Para List (2006) esse processo pode ter até 7 níveis distintos que podem ser identificados em graduação que se inicia de uma simples cooptação manipulativa, em que os sujeitos apenas interferem em diagnósticos e na compreensão de determinadas situações/problemas, até os níveis mais elevados de participação que seriam quando se efetivam o aprendizado colaborativo, a automobilização e o empoderamento. $\mathrm{Ou}$ seja, o maior anseio de um processo cíclico participativo deve ser o de permitir que os sujeitos adquiram sua autonomia para compreender os problemas em que estão inseridos, ter iniciativa para a resolução ou a mitigação desses problemas e buscar soluções colaborativas, diálogo com gestores públicos, dentre outras possibilidades de ações proativas.

Mas neste estudo não se tem o propósito de avaliar se as publicações selecionadas atingiram os níveis mais elevados de participação conforme destacados por List (op. cit.). De fato, considera-se aqui que deve haver grande diferença entre uma abordagem com apenas um instrumento de outra abordagem que conte com um processo cíclico e continuado de planejamento, ações (aplicação de instrumentos participativos), identificação de evidências (LEWIN 1946). Com base nessa perspectiva foi feita a decisão de se analisar os artigos selecionados nas três categorias quanto aos instrumentos participativos dialógicos, sendo elas: pontual - 27 artigos, multiinstrumentos - 67 artigos; e continuada/cíclica - 76 artigos, ver Gráfico 2. Nos trechos seguintes apresentam-se sínteses sobre inclusões de exemplificação, com 0 que se espera oferecer melhores subsídios quanto às diferenças dentre essas três categorias. 
Gráfico 2 - Distribuição de artigos selecionados em categorias segundo aplicação de instrumentos participativos.

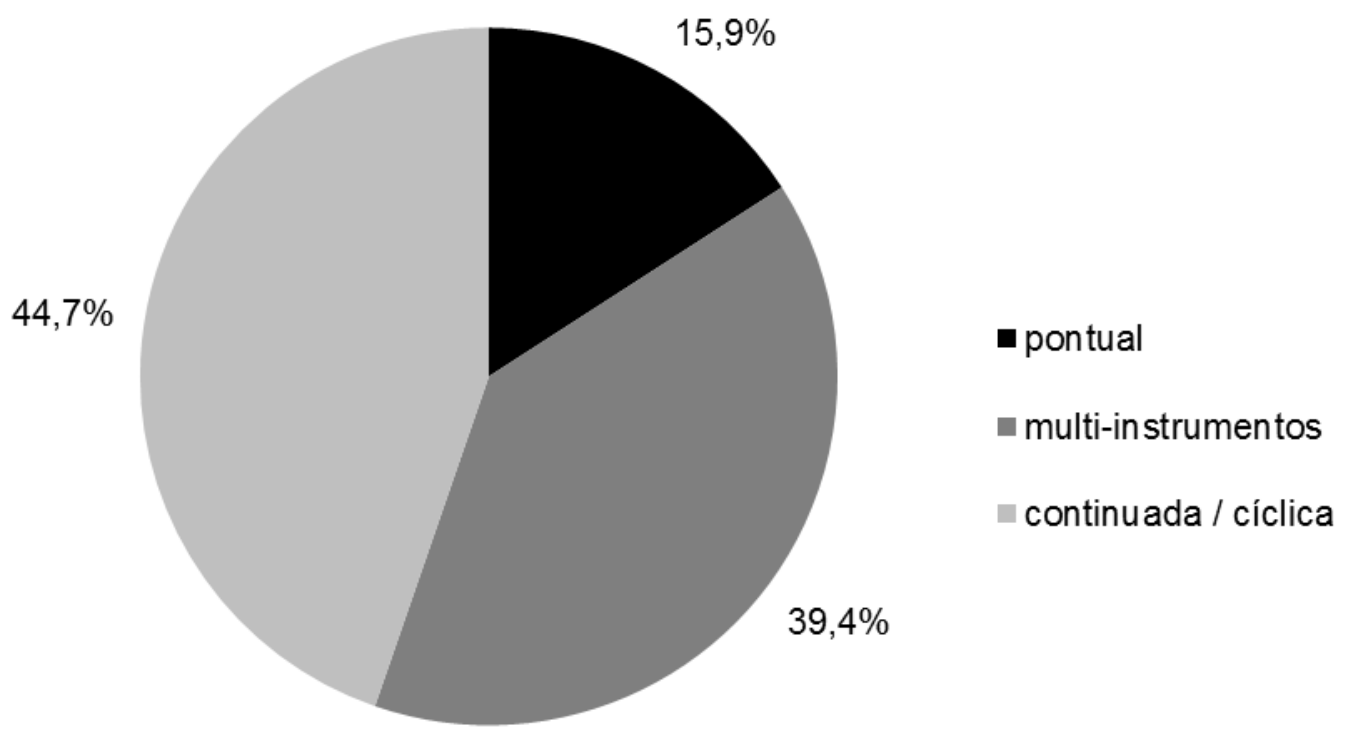

Fonte: elaborado pelo autor

Um primeiro caso a ilustrar uma abordagem pontual, ou seja, com aplicação de apenas um instrumento participativo é o caso do estudo de Nare et al (2006) sobre a participação de sujeitos em comunidades rurais no Zimbabwe, onde, por meio da aplicação de grupos focais, os autores identificam deficiências nos sistemas de monitoramento de qualidade de água, inclusive quanto a participação social nesse processo. O estudo também evidencia conhecimentos tradicionais inerentes à avaliação da qualidade da água e propõe que esses saberes sejam reconhecidos e incorporados pelos sistemas de informações públicos.

Holloman e Newman (2010) realizaram pesquisa participativa do tipo inquérito, aplicado a Afro-Americanos moradores de área costeira e com baixa renda (Virginia/EUA). A intervenção trata do consumo de frutos do mar e riscos de 
contaminação, especialmente por mercúrio. O estudo envolveu mulheres negras moradoras locais na aplicação de entrevistas, situação que permitiu a elegibilidade do estudo, pois tornou os sujeitos envolvidos enquanto pesquisadores, possibilitando que os mesmos colaborassem ativamente com análise de dados, discussões e conclusões. Como terceiro exemplo de aplicação pontual, Berbes-Blazquez (2012) relata processo de avaliação de serviços dos ecossistemas e bem-estar humano por meio de 'Photovoice' aplicado em localidade rural, em uma região de bacia hidrográfica na Costa Rica, onde predomina a monocultura e processos de degradação do meio. A metodologia aplicada é apontada como eficiente para identificar a perspectiva dos indivíduos da comunidade sobre os serviços dos ecossistemas.

Quanto a abordagens multi-instrumentos estas foram classificadas quando na aplicação de distintas ferramentas de caráter participativo, quando os mesmos não configuravam um processo de retroalimentação. Ou seja, quando o desenho se apresentava estático, como algo já delimitado e planejado sem a participação dos sujeitos nessas etapas. Esta é uma importante diferenciação, pois os estudos considerados de abordagem cíclica devem ter tido a incorporação dos sujeitos dentro da perspectiva da continuidade no planejamento, na execução de ações e na identificação de evidências. Essas evidências, em processo cíclico, devem ter importância no processo cognitivo e na execução de instrumentos ou ações subsequentes.

São exemplos de abordagens multi-instrumentos: Uma aplicação de avaliação participativa rápida (Rapid Participatory Appraisal - RAP) em Belfast/Reino Unido, em que moradores de bairros socialmente desfavorecidos contribuem com a indicação de problemas que não são desvelados pelos indicadores tradicionais e fogem ao controle das políticas públicas, tendo como chave a combinação de aspectos sociais, ambientais (equipamentos urbanos) e de acesso (como a serviços de saúde). O estudo se constitui da análise de dados oficiais sobre as áreas de estudo, aplicação de grupos focais e de questionários (LAZENBATT et al. 2001); Derrick et al. (2008) relatam abordagem que objetiva sensibilizar comunidades estuarinas afro-americanas (Richmond/EUA) a se protegerem do excessivo consumo de peixes, que se associa com exposição à tóxicos, inclusive mercúrio, via cadeia alimentar. Para isso utiliza 
método de comunicação de riscos culturalmente adaptado e posterior inquérito sobre conhecimento adquirido e hábitos auto relatados referentes à pesca.

Explorando abordagens que foram classificadas como continuadas/cíclicas, o artigo de Elkatsha e Watts (1997) constitui a primeira ilustração, apresentada aqui como um modelo bem sucedido de abordagem cíclica. Com foco no controle da esquistossomose em comunidades rurais no Egito, esta pesquisa parte de técnicas de pesquisa qualitativas de enfoque antropológico, como observação participante, grupos focais e entrevistas, mesclando-as com monitoramento de qualidade de água e de presença de caramujos (hospedeiros intermediários e fundamentais na transmissão do agente patogênico), e posterior processo de capacitação de agentes de saúde com a colaboração de sujeitos locais. Mas a principal característica da abordagem continuada da pesquisa não é meramente a quantidade e diversificação de instrumentos; de fato, essa qualidade se consagra com o processo de retroalimentação (feedbacks) que dinamiza a pesquisa e permite que a participação dos sujeitos seja muito mais ativa e crítica. Os autores assinalam no processo, por exemplo, que os saberes e interpretações dos sujeitos locais sobre a doença foram incorporados na capacitação realizada e também o monitoramento realizado contou com a participação integral de moradores locais e ainda, após o reconhecimento do importante papel das mulheres na estrutura social e em particular sua possibilidade de contribuição na prevenção da doença, estas foram inseridas de modo estratégico em todas as etapas do processo participativo.

Quigley et al. (2000) apresentam relevante projeto de intervenção com foco na assistência de comunidades de indígenas norte americanas presentes em distintos estados, as quais foram prejudicadas por exposições à radiação de testes nucleares realizados entre as décadas de 1950 e 1960. Na abordagem, também trabalham com processo educativo de comunicação de riscos culturalmente adaptado, porém, diferentemente do artigo de Derrick et al. (2008), acima classificado como multinivel, Quigley e colaboradores avançam com o envolvimento dos sujeitos na condução técnica e comunitária de um estudo, incorporando monitoramento ambiental, vigilância de doenças e uma pesquisa sobre a saúde da população local. Essa abordagem, segundo os autores, desenvolveu senso crítico e capacidade local não só 
de interpretar as consequências e os problemas, como também, possibilitou a autonomia necessária para dialogar, por exemplo, com atores governamentais em defesa de seus direitos por um ambiente livre de exposições às radiações nocivas. Essa possibilidade de defesa formal por parte da própria comunidade e com o respaldo dos pesquisadores se enquadra no princípio da advocacia (advocacy) do movimento de Promoção da Saúde (BUSS, 2003).

O exitoso envolvimento de sujeitos assim relatado em um processo colaborativo de pesquisa vem sendo denominado de epidemiologia popular (popular epidemiology), como no caso do artigo de San-Sebastián e Hurtig (2005), na região amazônica do Equador, envolvendo organizações sociais de base local na definição de agenda de pesquisa desde a formulação de hipóteses até o tratamento e disseminação dos resultados. No caso, a intervenção é focada em amplo processo de degradação ambiental e de qualidade de vida decorrente de extensos derramamentos de petróleo. Como desdobramentos do processo de empoderamento, têm-se um posicionamento que faz frente à hegemonia corporativa da exploração do petróleo e interfere diretamente em uma política pública nacional de regulação do setor.

Abordagens pontuais ou multi-instrumentos podem ser eficazes quanto aos objetivos delimitados nas pesquisas de intervenção, sendo, frequentemente associáveis a um corte transversal no tempo, em que, por meio das ações empreendidas, busca-se atingir os determinados objetivos mediante a complexidade das questões socioambientais e de saúde. Diferenciam-se com mais destaque, portanto, as abordagens continuadas/cíclicas, em que há uma dinâmica de constantes interações entre os sujeitos e pesquisadores, entre saberes locais/tradicionais e saberes técnicos científicos, junto a sequência de instrumentos interativos, configurando um processo de retroalimentação.

Como afirmado anteriormente, não é o propósito avaliar a qualidade dos estudos de intervenção e sim, diferenciá-los pela forma de aplicação e combinação de instrumentos de pesquisa e intervenção. Todavia, é nas abordagens continuadas/cíclicas que se evidencia o empoderamento e a sustentabilidade das ações, esta última característica associada à autonomia, que habilita os sujeitos sob 
forma organizacional e de apropriação de saberes e competências. Ou seja, novos problemas, que podem ser bastante diferenciados do foco das abordagens participativas, poderão ser enfrentados pelas comunidades/sujeitos. Uma importante evidência desse tipo de processo reside na ocasião de desdobramentos de ações e intervenções locais em que os sujeitos ou suas representações legítimas, como organizações de base, passam a dialogar e interferir diretamente em políticas públicas, em um legítimo processo de baixo para cima (bottom-up), conforme caracterizado por Minkler (2010) a partir ampla experiência em pesquisas participativas de base comunitária (community-based participatory research - CBPR).

\subsection{2. - Classificação e análise das publicações quanto à escala territorial de abrangência das intervenções}

$\mathrm{Na}$ seção anterior, discutindo e exemplificando quanto à classificação dos artigos por aplicação de instrumentos participativos, foram apresentados casos que se desenvolvem a partir de abordagens locais, sob a ótica da escala espacial em que se desenvolvem. Os contextos territoriais em foco compreendem comunidades de baixa renda, culturalmente diferenciadas, como no caso de indígenas, exposições ambientais negligenciadas, submissão dos sujeitos a uma condição de exclusão, tendo ocasionalmente relação direta com meios de produção ou suas externalidades incidindo sob a forma de degradação ambiental e de qualidade de vida sobre grupos desfavorecidos.

Essa é uma condição típica que se reproduz intensamente associada ao 'sucesso da modernidade' ao 'êxito da industrialização', como na ampliação e dinamização dos processos produtivos fortemente impactantes ao meio, refletindo nos insucessos do controle de suas respectivas externalidades gerando uma profusão de riscos que não são compreendidos, mitigados e evitados sob as mesmas dinâmicas da produção e bens e riqueza (BECK 2008). Analisando essa situação de causas e consequências da modernidade nós verificamos que em sociedades desiguais as maiores cargas de danos ambientais recaem sobre grupos sociais discriminados, 
populações étnicas tradicionais, bairros periféricos onde residem operários e populações marginalizadas e vulneráveis de modo geral, configurando o que se define por injustiças ambientais (PORTO 2007).

Sendo processos diretamente conectados aos sistemas produtivos, que seguem uma lógica econômica de amplitude mundial baseada na reprodução do capital, essas injustiças estão diretamente conectadas por meio de uma relação dialética global-local. Desse modo, são reflexos ou desdobramentos locais de processos que se estendem em diferentes escalas territoriais. Isso é verificável pelos processos históricos em que os meios produtivos degradadores do ambiente ou consumidores vorazes de recursos naturais são transferidos para países em desenvolvimento. Ou, por outro lado, quando indústrias migram na busca de mão de obra barata e leis trabalhistas mais permissivas. Esse tipo de mobilidade é foco de estudo da Ecologia Política, que por sua vez, estabelece um referencial crítico sobre a transferência e a mobilidade dos riscos em distintos territórios e com desdobramentos nas escalas territoriais, principalmente nas condições de desigualdade que se configuram (MARTINEZ-ALLIER 2007; PORTO 2007).

Sob esse arcabouço vemos que a sustentabilidade das ações voltadas às questões socioambientais e de saúde, exacerbadas por injustiças ambientais, não pode ser exitosa caso se restrinja ao nível local. Essa concepção permite, portanto, classificar as abordagens participativas em estudo sob a capacidade de as mesmas interagirem com escalas territoriais. Para isso, optou-se pela diferenciação em três categorias: local/dirigida - 110 artigos; ampliada - 24 artigos; e multinível - 36 artigos, ver Gráfico 3.

Os artigos que se enquadram por uma abordagem local, são tipicamente configurações de injustiças ambientas, com devida delimitação de grupo social sobre exposição e problema ambiental adstrito ao território. Mas outro tipo de situação também contribuiu com a mesma categoria de local/dirigida, refere-se, por exemplo, a comunidades constituídas por determinada classe de trabalhadores, que se caracterizam como grupo social e podem compartilhar determinadas situações de risco, as quais também são adstritas, mas não ao território basicamente e sim à 
ocupação dos sujeitos.

Gráfico 3 - Distribuição de artigos selecionados em categorias segundo classificação por escala de abordagem.

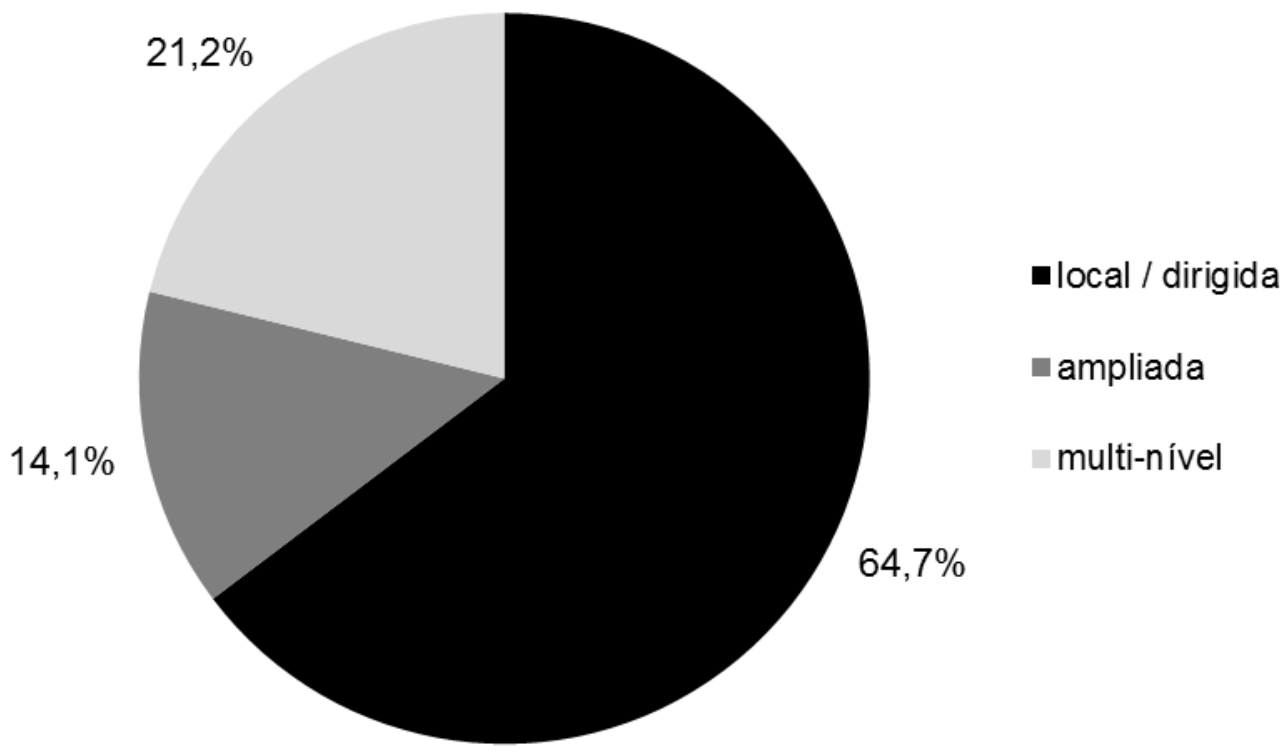

Fonte: elaborado pelo autor

Poulsen et al. (2004) trazem uma boa ilustração quanto ao estudo de intervenção cujos sujeitos são um grupo social que se identifica pela profissão, no caso, motoristas de ônibus em Copenhague, na Dinamarca. Dentre as evidências encontradas os autores trabalham sobre a perspectiva de que a maior parte dos problemas de saúde que afetam os motoristas de ônibus é fortemente condicionada pela inter-relação entre fatores inerentes ao trabalho e à vida privada dos mesmos. Outro exemplo similar é o da aplicação de um instrumento de gestão participativa para a gestão de edifícios com foco na qualidade do ar (indoor-air problems), em que são 
envolvidos enquanto sujeitos os trabalhadores de uma determinada empresa, tendo como enfoque uma abordagem psicossocial e de saúde do trabalhador (LAHTINEN et al. 2008). No Brasil, uma interessante aplicação nesse sentido, de Gouveia-Vilela et al. (2010) descreve processo de intervenções com foco na saúde do trabalhador no controle da Dengue, dentre técnicos da Superintendência de Controle de Endemias SUCEN, que trabalham em distintas localidades no Estado de São Paulo. Nesse caso, apesar da dispersão espacial evidente dos profissionais, é possível caracterizar a unidade do grupo de estudo pela atividade, justificando ser uma abordagem dirigida (local/dirigida).

Com relação às abordagens ampliadas, primeiramente estas se classificam por exclusão ao que foi apresentado como abordagens locais/dirigidas. Desde um município ou cidade, podendo se ampliar para bacias hidrográficas, estados/províncias, biomas, nações, comunidades multilaterais e, até mesmo, abordagens referentes à escala global, todas foram classificadas como ampliadas. Não se trata de definir uma categoria estratégica para incluir praticamente tudo, mas há uma diferença elementar entre uma abordagem com foco em indivíduos que compõem um determinado grupo, relativamente homogêneo e que sofrem as mesmas exposições ambientais, em que se consiste a escala local/dirigida, para uma escala diferenciada em que distintas unidades territoriais possuem as mais diferentes representatividades de interesses, atores sociais, instâncias governamentais, corporações, etc. Também, partindo das unidades enfocadas nas abordagens locais/dirigidas, os territórios ampliados serão certamente o lócus de grupos sociais heterogêneos.

Algumas referências componentes desta revisão podem elucidar melhor quanto às aplicações desta categoria: Hien et al. (2008) relatam e avaliam um programa de educação com desenvolvimento de competências para a promoção de ambientes saudáveis focado à 150 lideranças comunitárias no Vietnam. O estudo avalia por meio de grupo de intervenção e controle a efetividade das medidas para minimizar riscos ambientais, sobretudos os relativos a precário saneamento do meio. Demeter et al. (2009) descrevem a aplicação de cenários prospectivos para a indústria do leite e derivados na Holanda, incluindo questões de sustentabilidade ambiental. Os 
participantes envolvidos foram pessoas ligadas às cadeias produtivas de leite e derivados e especialistas dedicados ao setor e o estudo teve abrangência nacional.

Uma interessante abordagem ampliada associada a urbanismo é conduzida por Wolch et al. (2010) em Los Angeles / EUA. Nesta iniciativa, as intervenções participativas envolvem OnG's, acadêmicos e planejadores urbanos, com foco na sustentabilidade urbana a partir das potencialidades oferecidas pela ampla existência de becos e vielas (alleys), os quais se caracterizam como ruas de serviço subutilizadas, mas com grande potencial para promover ambientes urbanos sustentáveis, sobretudo em bairros onde predominam grupos sociais desfavorecidos como afro-americanos, asiáticos e hispânicos, localidades que carecem de áreas verdes e de espaços de lazer e socialização.

Conforme observado e discutido nos exemplos da seção anterior, quanto aos artigos ilustrando a classificação segundo aplicação de instrumentos participativos, estes partem de uma abordagem local. Todavia, alguns destes se ampliam na forma de intervenções delineadas tipicamente de baixo para cima (bottom-up). Isto ocorre especialmente pelo processo de empoderamento que possibilita que os interesses locais ou de determinados grupos sociais venham a se estabelecer, por exemplo, na forma de uma participação em políticas públicas, na gestão do território dialogando com questões ambientais e desigualdades, ou, simplesmente, confrontando sistemas produtivos cujas externalidades geram impactos e exposições ambientais.

São exemplos, portanto, de abordagens locais que passam por um processo de ampliação de escala (scalling up): estudo de Elkatsha e Watts (1997) que, no controle comunitário da esquistossomose no Egito, amplia de escala envolvendo no projeto macro gestores do saneamento e do controle de doenças no país; e a abordagem de San-Sebastián e Hurtig (2005), que a partir do envolvimento de organizações sociais de base local em regiões afetadas pela exploração irresponsável de petróleo, os sujeitos logram êxito tomando parte no processo de uma política de regulação do setor, no Equador.

Também como abordagens em escala multinível têm-se o artigo de O' 
Fallon et al. (2003) que descreve oficinas de planejamento urbano, denominadas 'Town meetings', conduzidas em algumas cidades norte americanas, com ampla participação de distintas camadas da sociedade, acadêmicos e gestores. Essas oficinas foram promovidas por um órgão governamental National Institute of Environmental Health Sciences - NIEHS/EUA, que conta com tradição em abordagens participativas para questões de saúde ambiental. E ainda, o estudo de Álvarez-Farizo et al. (2007) que relata a participação de representantes da sociedade em avaliação ambiental que consiste de um júri, no caso, discutindo importantes mudanças na gestão dos recursos hídricos providas por novas e rigorosas regulamentações fornecidas pela União Europeia. Nessas circunstâncias, os autores identificam a possibilidade de as possíveis escolhas migrarem do nível de interesse individual para o coletivo, permitindo a aplicabilidade da regulamentação restritiva, mas que objetiva a sustentabilidade no uso do recurso água.

\subsubsection{Classificação e análise das publicações quanto a funcionalidade}

Conforme tratado no capítulo 3 desta tese, os contextos socioambientais e de saúde são dotados de uma complexidade emergente ou reflexiva, isso significa que além das dinâmicas inerentes aos ecossistemas com as interações entre biota e o ambiente físico, o clima, os fluxos de energia, a biodiversidade, a ciclagem de materiais e todas as outras características altamente intrínsecas, os sistemas socioambientais também são regidos, em parte, pela subjetividade humana, pelos anseios, valores, adaptabilidade, resiliência, vulnerabilidade e todos os demais traços e capacidades dos humanos. Estes aspectos adicionam complexidade e, de fato, não procede a uma separação analítica entre sistemas naturais e sociais. Quando tratamos de estilos de vida dos humanos, os mesmos de um lado elevam as demandas produtivas, impactando os ecossistemas e seus serviços, como também, interferem direta e indiretamente exacerbando riscos à saúde que se combinam com as desigualdades sociais e com os próprios desequilíbrios dos ecossistemas (KAY 1999; PORTO 2007; RAVETZ 2004, MEA 2005). 
Retomando a experiência de pesquisa-ação em terra indígena, relatada no capítulo 4 desta tese, é de se observar que apenas um amplo diagnóstico com a combinação de distintas técnicas de pesquisa, inclusive com instrumentos participativos, e uma análise capaz de vislumbrar as diferentes faces dos problemas em foco, constituem condições de se aprofundar melhor no contexto sanitário precário em que condicionantes sociais como valores e crenças míticas se combinam com os fatores ambientais em um quadro de difícil equacionamento (GIATTI et al. 2007).

Desse modo, vislumbramos que uma abordagem de pesquisa participativa com sua funcionalidade dirigida a um diagnóstico já é, em si, um grande desafio. Mas, novamente no contexto de lauaretê, apenas o diagnóstico não significava muito perante a situação crítica de exposições às doenças inerentes aos valores e práticas humanas e precário saneamento combinados naquele núcleo de feições urbanas. Justamente o diagnóstico produzido reforçava a inegável necessidade de construção colaborativa de soluções. E o alcance do referido projeto se estendeu até o estabelecimento de um processo de mobilização social, no envolvimento dos sujeitos em várias etapas de pesquisa e intervenção. Isto possibilitou a colaboração no delineamento de dois tipos de solução: as locais, como alternativas de prevenção à saúde em base com medidas coletivas, domiciliares e individuais; e o início de um diálogo com gestores municipais na busca pelo direito às condições adequadas de saneamento básico (TOLEDO et al. 2012).

A precedente análise, dividida em duas fases, contextualiza uma diferenciação entre duas categorias empregadas nesta classificação dos estudos relativos à funcionalidade das intervenções, que são respectivamente: diagnóstico categoria contemplada com 78 artigos; e resolução de problema - que somou 76 artigos. A terceira categoria desta dimensão de análise refere-se à incertezas/fenômenos emergentes, que permitiu a classificação de 16 artigos. Ver Gráfico 4. 
Gráfico 4. Distribuição de artigos selecionados em categorias segundo classificação por funcionalidade

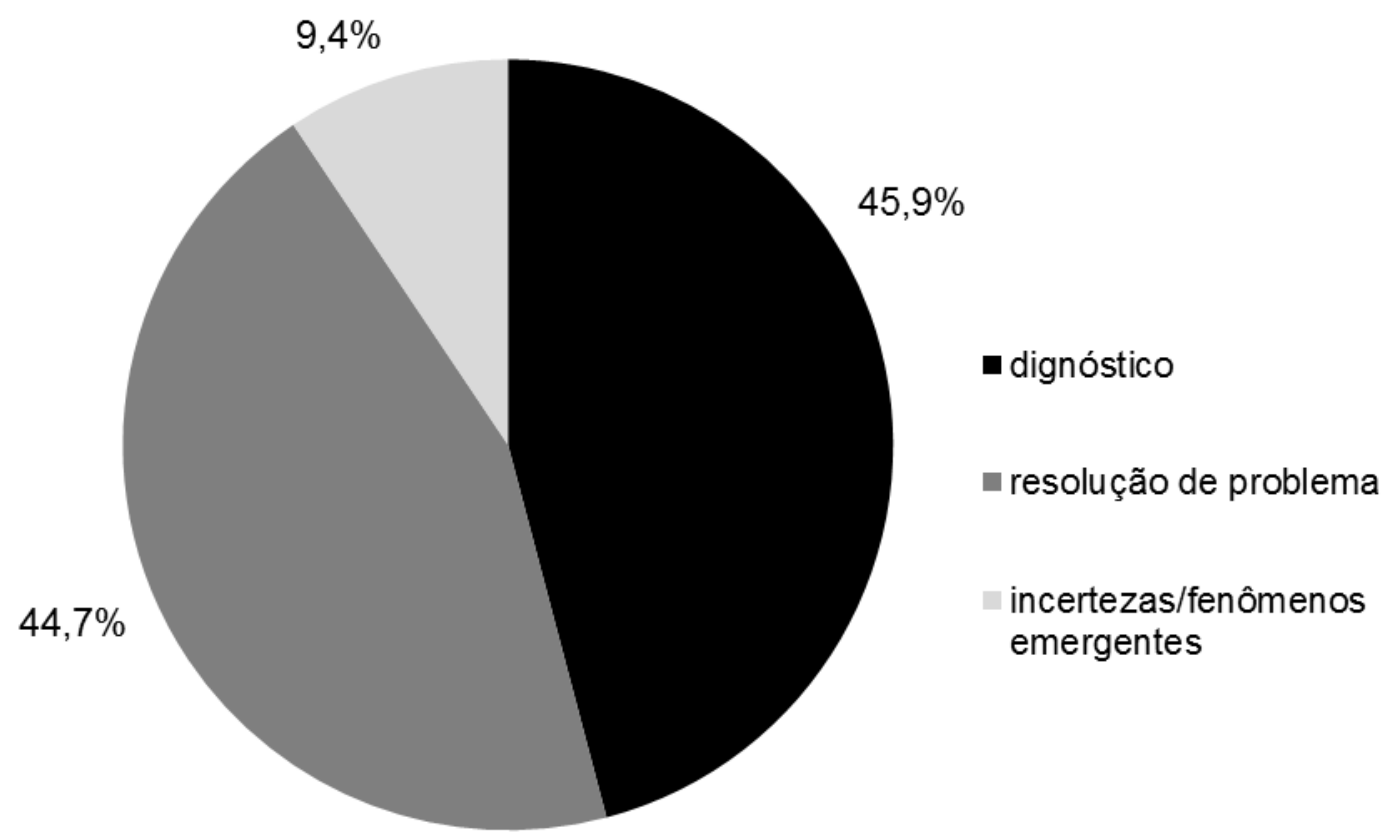

Fonte: elaborado pelo autor

Para adicionar a categoria de incertezas/fenômenos emergentes no escopo do exemplo corrente, propõe-se aqui lançar algumas situações ou eventos, associados às tendências regionais ou globais ou mesmo situações razoavelmente hipotéticas. A proposta seria pensar cenários tais como: lauaretê, terra indígena no extremo Noroeste do Estado do Amazonas, recebe significativas migrações regionais, se torna um importante polo urbano em área fronteiriça e, em médio e longo prazos, passa a sofrer fortes ameaças por eventos climáticos extremos, como chuvas que promovem deslizamentos de terra e desastres, e/ou períodos prolongados de secas. Essas situações se combinam com desigualdades urbanas, tensões sociais e um perigo iminente: uma epidemia provocada por um vírus causador de febre hemorrágica de elevada letalidade que pode 'transbordar' dos ecossistemas naturais se disseminando rapidamente entre a população. 
À primeira vista, o contexto apresentado pode parecer exageradamente pessimista, no entanto, vários elementos inseridos podem ser pertinentes, como já são é realidade em outras localidades urbanas (MCMICHAEL 2001), inclusive na Amazônia brasileira. Apenas a combinação de vários elementos como estes em uma determinada circunstância pode significar um processo de ruptura, ou uma emergente crise, com sérios danos à saúde e à qualidade de vida, particularmente, com elevada mortalidade, como em períodos epidêmicos ou na ocorrência de desastres ambientais.

Não podemos precisar as conjunturas vindouras, pois o futuro é incerto e, mesmo com as mais elevadas tecnologias e avanços científicos, sempre haverá incertezas. A complexidade emergente e reflexiva inerente aos sistemas socioambientais justifica essa primazia de imprevisibilidade, certamente. Para Godet e Durance (2009) a história não se repete, porém o comportamento humano sim. Desse modo, ocorre que o tempo passa e diante de situações críticas comparavelmente recorrentes o comportamento dos humanos se reproduz de maneira assustadoramente similar. Assim, os eventos do passado deveriam, na realidade, servir melhor ao planejamento, elaboração de planos de contingência, medidas preventivas e mitigatórias, etc.

As mudanças climáticas, como questão chave no campo das incertezas e dos riscos de nosso tempo (BECK 2008), permitem aprofundar sobre os argumentos de Godet e Durance ( $o p$ cit), pois, se de um lado a hipótese do aquecimento global se associa como causa à industrialização e a generalizada emissão de gases de efeito estufa em decorrência da ação antrópica, por outro, as consequências desse processo não vão trazer novos problemas, apenas exacerbar problemas já existentes e bem conhecidos. A variabilidade climática com distintos desdobramentos regionais, eventos extremos como chuvas intensas, secas, furacões, desastres climáticos em geral e a combinação destas situações emergentes com questões socioambientais acentuando os riscos de epidemias, grandes mortalidades, migrações, fome, guerras e conflitos decorrentes de escassos recursos naturais, são todos elementos já conhecidos da humanidade. Estas situações podem se combinar com a vulnerabilidade dos ambientes e dos grupos sociais tendo como resultando consequências ampliadas em escalas temporais e espaciais (HALES et al. 2004). 
Com base nisso, apesar da imprevisibilidade, o futuro está sendo construído a cada dia, e as variáveis independentes de elevada motricidade na configuração de cenários mais ou menos desejáveis estão em desenvolvimento desde o passado, em que podem ser estudadas em termos de seus comportamentos, como também na atualidade, em que podem ser identificadas e geridas (MARCIAL E GRUMBACH 2002). Em relação a fenômenos emergentes e possibilidades de amplas crises nos sistemas socioambientais, não faltam experiências e lições aprendidas sobre desastres, por exemplo. Por outro lado, os sistemas socioambientais e seu componente de destaque, que é a subjetividade humana, têm a oferecer elevada capacidade de adaptação e resiliência (MORAN 1994; KAY 1999).

Certamente, algo de grande relevância é que as lições e experiências com situações emergentes devem estar sendo constantemente difundidas e questionadas dentre distintos atores sociais. Godet e Durance (2009) afirmam que um dos maiores desafios para a prospectiva é conjugar ideias diferentes de distintos atores, rompendo o silêncio organizacional que frequentemente é mantido por conceitos dominantes. Nesse processo é importante superar a tendência de os indivíduos se interessarem apenas pelas informações que lhes confirmem os próprios pensamentos, sendo importante ter a sensibilidade para evidenciar sinais de alerta que são aparentemente silenciosos e não tão evidentes. Esses elementos são relevantes para um processo de gerir e promover convenientemente uma racionalidade do coletivo.

As especulações sobre condições e tendências dentro da complexidade dos contextos socioambientais e o necessário diálogo com as incertezas frente à eventos emergentes possíveis, permite identificar circunstâncias análogas a uma estratégia de resolução de problemas que Funtowicz e Ravetz (1993) denominam de ciência pós-normal. Esta consiste do pressuposto em que o controle da qualidade e avaliação crítica das questões e incertezas dos riscos associados ao ambiente não pode mais ser exclusivamente adstrito aos pares altamente especializados do meio acadêmico. É preciso, portanto, promover o envolvimento de todos os afetados pelas questões em jogo no processo de avaliação crítica e na formulação de políticas. 
Com estes subsídios e com a evolução do exemplo de intervenção em terras indígenas na Amazônia, é possível identificar um fluxo na evolução e alcance da funcionalidade das pesquisas/intervenções participativas dialógicas. Esse fluxo se inicia pelo diagnóstico de um contexto socioambiental, avança em processo de desenvolvimento colaborativo de soluções ou gestão compartilhada, e finalmente, incorpora um diálogo com incertezas e possíveis fenômenos emergentes, capazes de gerar grandes mudanças nas dinâmicas socioambientais. Compreende-se, portanto, que um estudo avançado capaz de dialogar com incertezas e fenômenos emergentes suplanta e incorpora as demais categorias. Porém, certamente que um estudo de diagnóstico pode ser conduzido de modo eficaz e ser bem sucedido para seus propósitos específicos. O que prevalece, nesse sentido, é que se é almejada uma intervenção sustentável, compreendendo todas as dimensões que implicam neste termo e também, a perspectiva de atendimento das necessidades de gerações futuras, é premente a incorporação da prospectiva sobre cenários complexos e com possibilidade de significativas mudanças e isso, deve ser realizado por meio da ampliação da comunidade de pares.

Conforme apresentado no Gráfico 4, ficou evidente que os estudos e intervenções classificados como diagnóstico ou resolução de problema somaram a grande maioria, com $90 \%$ dos artigos. De um lado, estes estudos são provavelmente mais realizáveis por focarem em objetivos mais precisos, de outro lado, é possível que a categoria de incertezas/fenômenos emergentes represente um desafio ainda pouco desbravado, talvez pela necessidade de avançar mais na interdisciplinaridade e na incorporação de um delicado tema, que é o das incertezas científicas. Somam-se a isso os obstáculos de se elaborar prognósticos e ações de médio e longo prazo para questões que, inclusive são ignoradas ou negligenciadas, como dos transgênicos, da nanotecnologia e das consequências das mudanças climáticas. Em sentido contrário, também se deve considerar que interesses hegemônicos ou mesmo certas opções políticas unilaterais tendem a ocultar riscos razoavelmente desconhecidos, que não contam com a clássica comprovação de causa e efeito. Sem dúvida alguma uma maior apropriação do princípio da precaução pode ser relevante neste contexto (RAVETZ 2004). 
Retomando a classificação dos artigos quanto à funcionalidade, temos como exemplos de diagnósticos: Nussbaum et al. (2004), por meio de um estudo do tipo epidemiologia popular, desvelam aspectos relevantes de exposição e efeitos à saúde em área contaminada por radiação nos EUA. Consta como relevante a crise na governança e o processo democrático em questão, uma vez que agências governamentais negavam a contaminação e os riscos na região do estudo; Stern et al. (2010) apresentam diagnóstico de fatores de risco para doenças não transmissíveis na África do Sul, associados à migração rural para a periferia urbana, em que a obesidade é um fator chave e por outro lado, aparece como algo relevante para os sujeitos como sendo sinal de dignidade e respeito, algo que demonstra a necessidade de estudos e intervenções mais aprofundadas; e Siqueira e Jansen (2012) descrevem estudo de condições de trabalho e riscos inerentes entre imigrantes brasileiros que trabalham em Massachusetts/EUA, os quais possuem baixa renda, e possuem problemas ligados ao fato de não terem fluência em inglês, dificultando o acesso à serviços assistenciais, por exemplo.

Para ilustrar quanto a funcionalidade dirigida à resolução de um problema: Vasquez et al (2006) descrevem como jovens do Harlem/Nova lorque/EUA fazem medições de poluição com apoio de uma universidade e, com isso, acabam interferindo em processos políticos, como a mudança de qualidade de combustível em frotas de ônibus, principais fontes do problema em foco; e Terry e Khatri (2009) descrevem uma abordagem participativa sobre gestão de recursos hídricos, em que comunidades culturalmente diferenciadas das Ilhas Fiji passam a atuar na redução da poluição gerada pela criação de suínos, que afeta rios e oceano.

Dentre os 16 estudos classificados com a funcionalidade dirigida às incertezas, uma gama de condições de inclusão para essa categoria pode ser verificada nos 5 estudos brevemente relatados a seguir:

- $\quad$ Lewin e Strauss (1999) com foco na gestão metropolitana da Cidade do Cabo, África do Sul, os autores relatam a tentativa de construção de indicadores capazes de subsidiar tomadores de decisão quanto a impactos na saúde provenientes de riscos ambientais. Consiste 
de abordagem participativa com planejadores e técnicos de municípios da metrópole e, apesar da não conclusão dos indicadores propostos, evidencia um cenário de incertezas inerentes ao andamento de reformas institucionais e políticas associadas ao fim da Apartheid;

- Berkes et al. (2001) descreve a relevante participação de população nativa do Canadá tratando de múltiplos usos e conservação de recursos naturais e incertezas inerentes à mudanças climáticas. Neste contexto os saberes tradicionais passam a ter um papel muito importante em uma política pública daquele país (The Canada Oceans Act);

- Gershon et al. (2008), valorizam a importância de abordagens participativas para a implementação de medidas de redução de risco. A abordagem em questão envolve pessoas que participaram da evacuação do World Trade Center no 11 de setembro de 2001, contribuindo para melhorar a capacidade de resposta, redução de tempo de evacuação e outros aspectos inerentes ao fenômeno emergente/desastre que se constituiu, no caso pelo atentado terrorista;

- Weik et al. (2009) apresentam a construção de cenários prospectivos por múltiplos atores sociais na Suíça, em torno das potencialidades e riscos do emprego de nanotecnologia. São indicados diferentes arranjos de aspectos contextuais, envolvendo a consciência pública, lucros potenciais e regulações legais. Cinco cenários são apresentados e analisados em referência a aplicações de mercado para nanotecnologia, em que se evidencia aspectos de governança sustentável incorporando potenciais riscos sob diferentes perspectivas, como percepção de riscos, ampliação social de riscos, atitude de consumo em aversão a riscos e tolerância a riscos;

- D’Alisa et al (2010), aplicando uma leitura de ciência pós-normal, descrevem um processo político na Itália tratando de crises e conflitos 
associados a disposição de resíduos sólidos. O artigo traz uma importante contribuição diante da necessidade de se ampliar um processo democrático na gestão dos resíduos, sobrelevando a importância da comunicação de riscos diante das irredutíveis incertezas presentes em crises de gestão de resíduos sólidos.

Nos exemplos apresentados para estudos com funcionalidade de diagnóstico ou de resolução de problema procurou-se apresentar qualidades e potencialidades dos mesmos. Ressalta-se que estes estudos são frequentemente constituídos de modo sofisticado, capazes de atingir os objetivos a que se propõem. De fato, a leitura dos textos permite identificar logros obtidos. Todavia, ressalta-se que conectar as realidades tratadas de modo transversal com um diagnóstico ou a resolução de um problema, mesmo que com empoderamento e autonomia, deixa aberta uma lacuna referente a distintas escalas temporais em que cenários futuros, repletos de incertezas, podem trazer novos riscos ou novas configurações socioambientais para os mesmos riscos.

Com essa argumentação, espera-se elucidar dois aspectos relevantes para as abordagens participativas de funcionalidade voltada à incertezas/fenômenos emergentes: Estas são avançadas do ponto de vista da sustentabilidade em médio e longo prazos, quando problemas tradicionalmente diagnosticados e geridos podem contar com uma prospecção futurística; E, estas abordagens, também são as mais desafiadoras por terem que conjugar obrigatoriamente os requisitos das outras, mais a capacidade e, porque não, o espírito desbravador, para se tratar de situações de pequena probabilidade ou eventos cujos sinais de possível ocorrência são praticamente silenciosos (GODET e DURANCE 2009), ou mesmo, silenciados por interesses conflitantes, ignorância ou incapacidade de mensuração, dentre outros fatores (RAVETZ 2004). 


\subsubsection{Análise integrada e distribuição geográfica das pesquisas}

Explorar as relações entre categorias e dimensões utilizadas na classificação de artigos selecionados consiste de uma iniciativa que pode contribuir para compreender determinadas tendências entre desenhos de estudo e intervenção, para se conceber um panorama dos desafios a serem superados em estudos com as características de elegibilidade em foco, e uma possibilidade de se verificar a consistência das classificações empreendidas, de modo a se vislumbrar tendências pertinentes.

Desse modo, apresenta-se a Tabela 2 que sintetiza as inter-relações entre as categorias de classificação aplicadas. Inicialmente, pode-se observar quanto aos maiores e menores grandezas de valores no cruzamento das categorias. Por exemplo, dentre as abordagens multinível classificadas $(\mathrm{N}=36), 69,4 \%(\mathrm{~N}=25)$ foram pesquisas / intervenções cíclicas/continuadas. Nos exemplos acima, tratando de abordagens multinível, ficou clara a relação do processo de empoderamento quando os projetos em questão se iniciam em base local e posteriormente estendem a dialógica em escala ampliada (bottom-up). Portanto, é possível inferir que a qualidade cíclica/continuada das pesquisas e intervenções, que amplia as interações entre sujeitos, pesquisadores e gestores, conduzindo aos mais elevados níveis de processos participativos (LIST 2006), pode ser de maior viabilidade para que os sujeitos locais ou de determinados grupos sociais tenham acesso e venham a interferir de modo ativo na gestão do território, nos processos políticos e nas causas de motricidade que reproduzem os problemas socioambientais condicionantes da exposição aos riscos.

$\mathrm{Na}$ relação de aplicação de instrumentos com a funcionalidade, primeiramente, observa-se que a maioria dos estudos de aplicação pontual de instrumento de intervenção ( $\mathrm{N}=27)$ foram também intervenções de funcionalidade de diagnóstico $(88,8 \%, \mathrm{~N}=24)$. Para os artigos que relatam aplicação multi-instrumentos $(\mathrm{N}=67)$, 99,4\% ( $\mathrm{N}=63$ ) corresponde a estudos ou intervenções de funcionalidade diagnóstico ou resolução de problemas. Já no caso da aplicação continuada/cíclica $(\mathrm{N}=76)$, verifica-se que sua distribuição por funcionalidade se faz da seguinte maneira: $17,1 \%(N=13)$ são diagnósticos; $69,3(\mathrm{~N}=53)$ são resolução de problema e 13,2\% 
$(\mathrm{N}=10)$ compreendem incertezas e fenômenos emergentes. Com efeito, as intervenções de abordagens cíclica/continuada representaram $62,5 \%$ do total de artigos que incorporam as questões de incertezas e fenômenos emergentes $(\mathrm{N}=16)$.

Tabela 2 - Inter-relações entre as categorias de classificação aplicadas para artigos selecionados em revisão sistemática

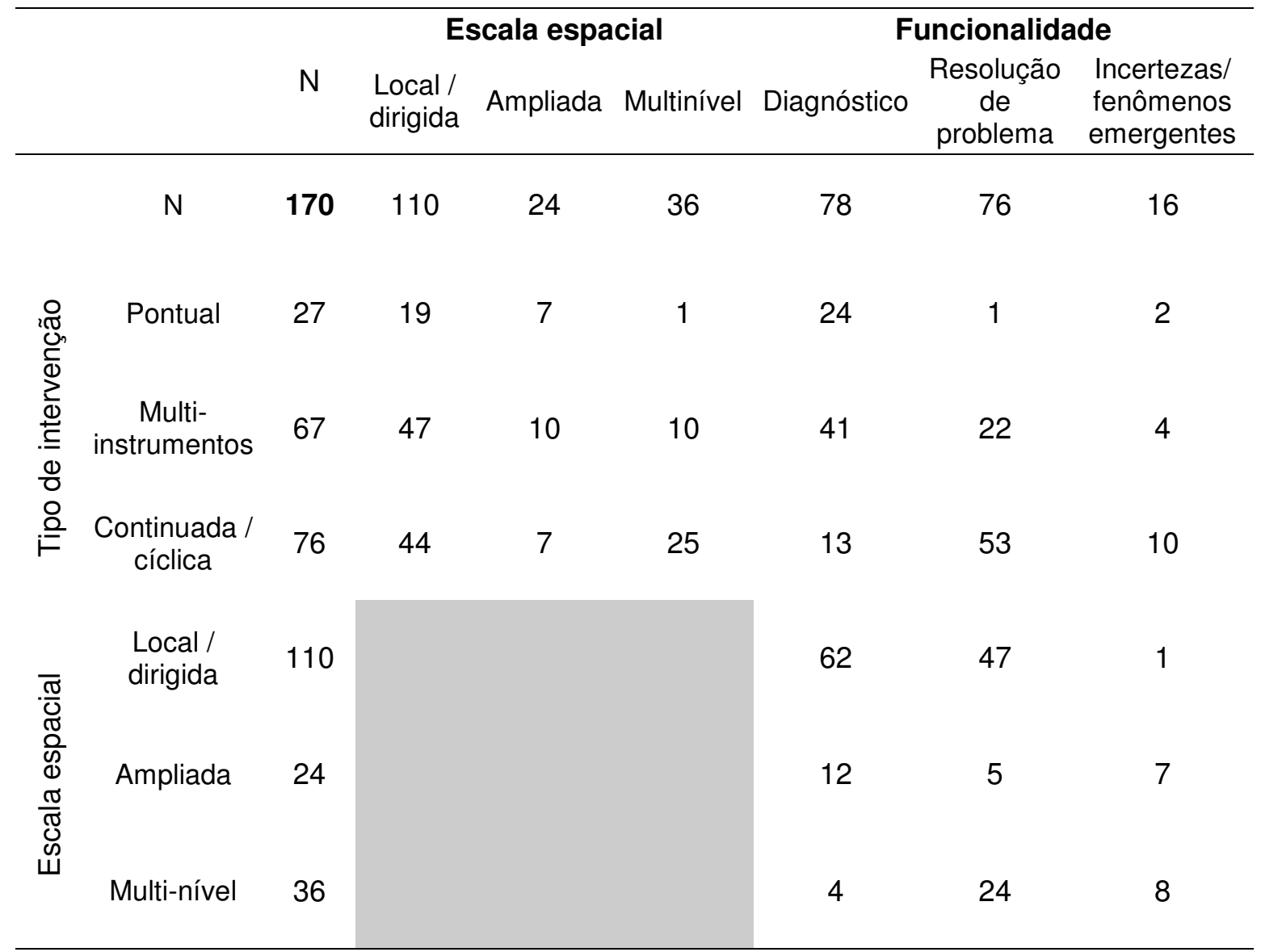

Fonte: elaborado pelo autor

Esta evolução de uma relação direta entre as proporções de classificação de artigos por funcionalidade com aplicação de instrumentos pode ser mais bem visualizada no Gráfico 5. Explorando essa tendência, temos a reforçar a afirmativa do desafio de abordagens continuadas avançando para as funcionalidades mais arrojadas de estudos e intervenções, que por sua vez seriam a partir da resolução 
de problemas com a incorporação de prospectiva futura dialogando com incertezas, fenômenos emergentes e seus riscos e desdobramentos preponderantes. A propósito, o sentido da combinação ou da incorporação de incertezas, riscos, vulnerabilidades, aplicação de abordagens continuadas, maior 'co - elaboração' entre distintos atores parece ser uma receita mais adequada à característica de uma complexidade reflexiva inerente aos sistemas socioambientais. Melhor dizendo, essa amplitude de abordagem é característica de uma Modernização reflexiva, que segundo Beck (1997: p.12) "significa a possibilidade de uma (auto)destruição criativa para toda uma era: aquela da sociedade industrial. $O$ 'sujeito' dessa destruição criativa não é a revolução, mas a vitória da modernização ocidental".

Gráfico 5 - Relação entre artigos quanto à aplicação de instrumentos e funcionalidade.

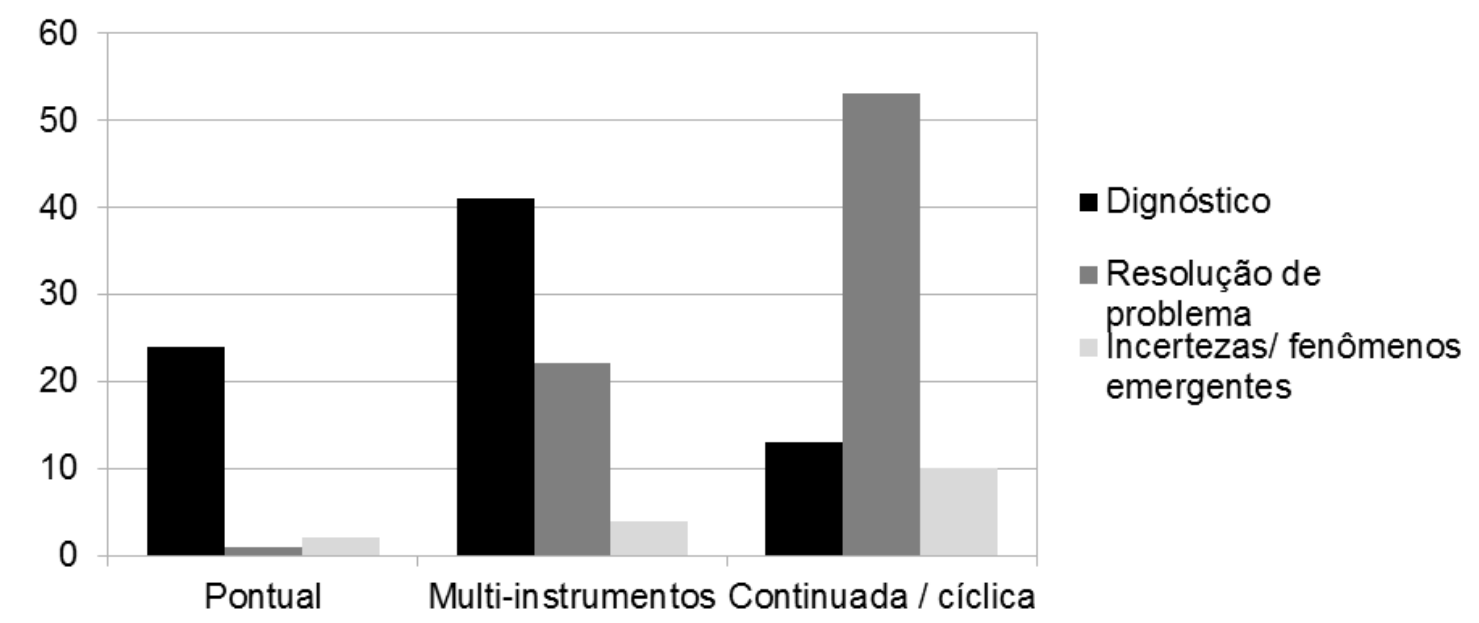

Fonte: elaborado pelo autor

Em sequência, apresenta-se a Figura 4, composta a partir de uma adaptação do diagrama proposto por Funtowicz e Ravetz (1993) para a ciência Pósnormal. Segundo esses autores a interpretação básica do diagrama é que próximo ao vértice dos eixos $x$ e y estão as práticas correspondentes à ciência pura, orientada pela 
curiosidade. Desde o vértice e em todo o primeiro segmento têm-se a predominância da ciência aplicada, com foco na clientela, nos sujeitos de interesse quanto à resolução de problemas, porém com a configuração tradicional da ciência 'normal'. Os eixos se distanciam do vértice assim como ocorre a elevação dos valores em jogo, ou em disputa (eixo y) e a elevação do grau de incertezas sistêmicas (eixo x). Portanto, o primeiro segmento próximo ao vértice representa baixos valores em disputa assim como baixo grau de incertezas, sendo passível de resolução dentro das aplicações científicas clássicas.

Porém, com a elevação do grau de incertezas sistêmicas ocorre da mesma forma a elevação do peso das apostas e disputas em jogo, deflagrando uma sequência de exacerbações das disputas dentro de um processo político, com a necessidade de reconhecimento das incertezas. No segundo segmento do diagrama Funtowicz e Ravetz (op.cit.) colocam o processo de diálogo com a relevante inserção das opiniões providas por consultores com elevada experiência para as questões em jogo. Nessa conjuntura em que se eleva a complexidade quanto às decisões, é passível se iniciar um processo em que os sujeitos dos riscos passam a oferecer contribuições no processo das decisões. Por exemplo, quando a sociedade toma certas decisões de consumo respaldada por uma percepção de riscos ou sob uma consciência de impacto global relativo à determinadas decisões.

Avançando em nível de complexidade, ao setor de mais elevado grau de incertezas sistêmicas e maior peso das decisões em jogo, situa-se o campo de operação da ciência pós-normal. Este contexto se caracteriza quando as decisões em jogo são amplamente conflitantes entre os atores sociais e quando o nível de incertezas envolve conjuntamente aspectos epistemológicos e éticos.

Sendo que esta revisão bibliográfica se caracteriza como uma possibilidade de um panorama dos processos descritos de ampliação de comunidades de pares, compreendeu-se como possível uma distribuição dos artigos selecionados e classificados por aplicação de instrumentos e funcionalidade, demonstrando como vem sendo aplicados os pressupostos da ciência pós-normal em um circuito de publicações acadêmicas de amplo reconhecimento. Assim, caracterizamos o nível mais alto de 
pesquisas de intervenção com foco em incertezas e elevados valores em disputa, incluindo os artigos em que relataram conjuntamente aplicação cíclica de instrumentos e o foco em incertezas ou fenômenos emergentes. Classificam-se, portanto, 10 artigos operantes no campo de ciência Pós-normal, dentre o total de papers selecionados nesta revisão sistemática $(\mathrm{N}=170)$.

Descendo em escala de disputas em jogo bem como de incertezas, no setor mediano do diagrama, elegem-se todos os demais artigos selecionados $(\mathrm{N}=160)$, pois estes se enquadram em pressupostos apontados nessa categoria por Funtowicz e Ravetz (op.cit), como sendo: os sujeitos passam a ter maior importância nas decisões e na garantia de qualidade do processo de interlocução entre ciência e política; a ampliação da comunidade de pares se faz necessária e plausível; um processo de legítima avaliação por parte dos sujeitos é relevante, mesmo sem que os mesmos possuam conhecimentos técnicos. Assim, todas as demais pesquisas participativas de características dialógicas foram incluídas nessa categoria.

No setor correspondente à ciência aplicada, têm-se, portanto, pesquisas sobre contextos socioambientais e de saúde que não contam com legítimos processos participativos. Na metodologia de busca de artigos desta revisão sistemática, com a busca conjunta dos termos saúde e ambiente (no caso os correspondentes em inglês aplicados - 'health' e 'environment' ou 'environmentaf'), sem os termos referentes à participação, mais de 10.000 páginas foram encontradas com 10 artigos por página. Reconhecendo que seria necessário realizar uma triagem para verificar a pertinência, mesmo sob uma posição conservadora pode-se pensar em milhares de artigos nessa condição.

Nessa análise Harper et al. (2012) tem seu estudo enquadrado no nível de aplicação de instrumentos cíclicos com a incorporação de incertezas no processo dialógico, sendo classificado, portanto, na categoria de ciência Pós-normal como aplicado na Figura 4. A partir de uma iniciativa com o povo Inuit, no Canadá, a abordagem se amplia em processo multinível, focando mudanças climáticas e suas consequências, incorporando um princípio transdisciplinar, segundo os autores. Ressalta-se nesta abordagem o forte aporte de narrativas, que permitem a 
incorporação de saberes locais com relação às mudanças culturais e impactos na saúde e qualidade de vida que ocorrem em compasso com a variabilidade climática e mudanças na disponibilidade de recursos naturais. Esse processo confere desdobramentos com o empoderamento dos sujeitos, inclusive institucionais que participam das atividades do projeto. Desse modo, o referido projeto acarreta importantes possibilidades de subsidiar os processos de gestão das questões inerentes, inclusive dos planos para redução de riscos relacionados às mudanças climáticas.

Figura 4 - Aplicação do diagrama de ciência pós-normal sobre a classificação de artigos selecionados em revisão sistemática

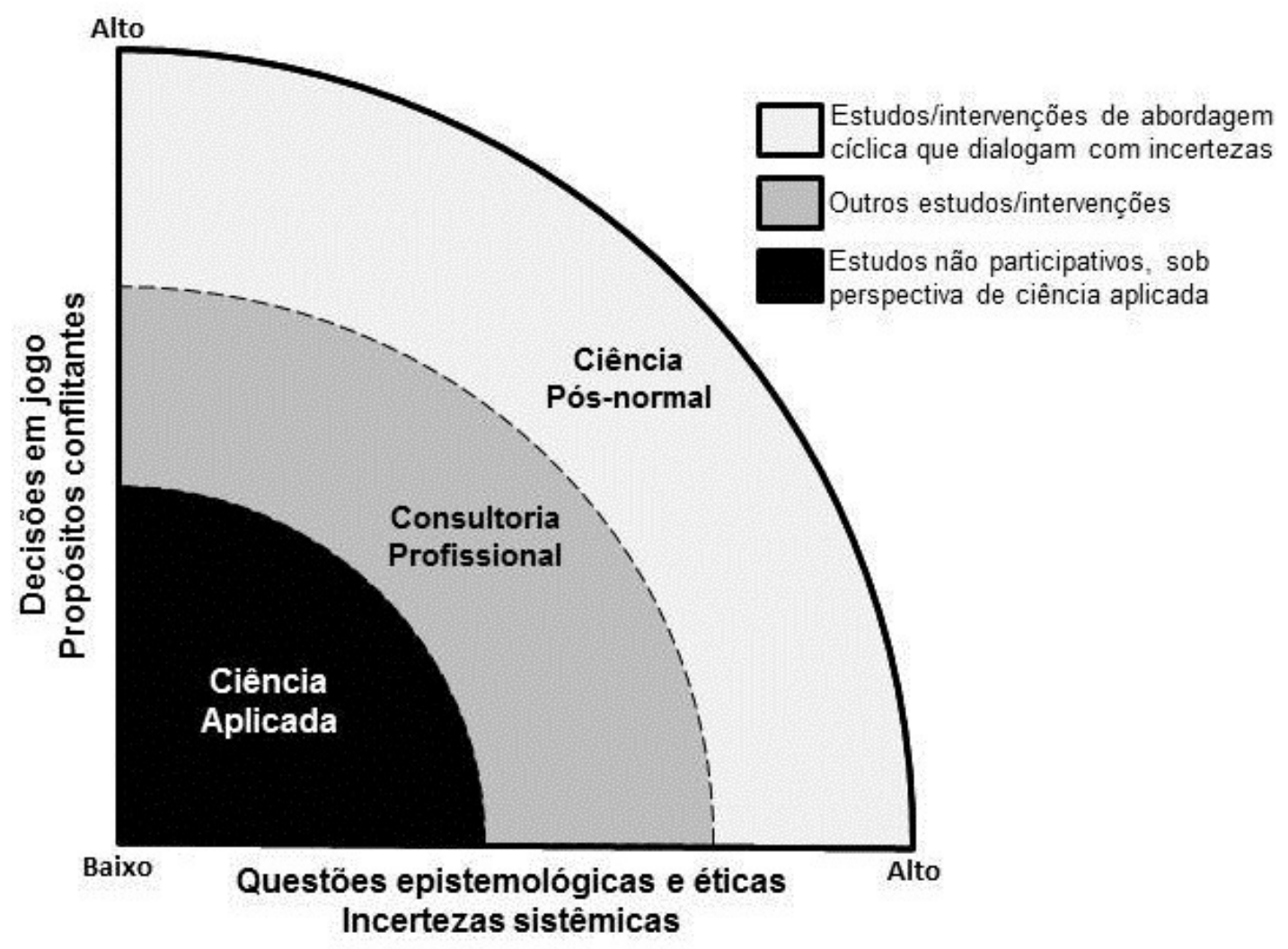

Fonte: Adaptado de Funtowicz e Ravetz (1993: p.750). 
Como em outros estudos que se iniciam, de abordagem local/dirigida, este também é valorizável por se incorporar e dialogar com políticas públicas. Desse modo, encontra-se uma correspondência com afirmativas de Lebel (2003) quanto às abordagens ecossistêmicas em saúde. Segundo esse autor, em certo momento das pesquisas sistêmicas conduzidas envolvendo saúde, sociedade (sujeitos) e ambiente, torna-se imperativo o envolvimento de gestores públicos. No caso da abordagem citada, Harper et al. (2012: p.98) denominam 'scaling up' ao processo em que a participação e as construções colaborativas migram da escala local para a territorial, dialogando também com o global, pois refere-se às consequências das mudanças climáticas.

Retrocedendo 13 anos nas datas de publicações incluídas nesta revisão, Montiel e Barten (1999) descrevem uma abordagem em promoção da saúde, dentro do movimento internacional de cidades saudáveis, em que um processo de intervenções continuadas é realizado na cidade de León, na Nicarágua, tratando de temas como saúde, pobreza e saneamento. Primeiramente, deve-se ressaltar que os autores descrevem uma análise de uma política pública implementada sob o paradigma da governança dando grande importância para o envolvimento da sociedade civil. Quanto aos desdobramentos da abordagem, afirma-se que as capacidades locais estabelecidas com as iniciativas participativas e estruturas municipais do setor da saúde, permitiram maior resiliência da cidade perante a ocorrência do furacão Mitch, ocorrido em 1998 e registrado como um dos mais severos a ocorrer em áreas costeiras do oceano Atlântico.

É pertinente recordar que dentre os critérios de inclusão para a seleção de artigos para esta revisão decidiu-se pela característica de os mesmos relatarem pesquisa ou intervenção participativa, nessa circunstância, ampla gama de artigos trazia relato de políticas públicas cujas publicações eram formas de avaliação e análise de programas, ações ou projetos. Artigos nessas condições foram, inclusive, considerados muito pertinentes, pois o interesse maior era em processos participativos e dialógicos para questões socioambientais e de saúde. Na verdade, é certamente bastante dificultoso precisar em que momento poder-se-ia classificar certas iniciativas como acadêmicas ou como política pública. De fato, não foi o intuito empreender esse 
tipo de classificação.

Por outro lado, essas conjecturas reforçam reconhecer a necessidade de maior interação entre o meio acadêmico (os pares científicos), sociedade e gestores para o enfrentamento da complexidade dos sistemas socioambientais e a saúde humana da forma como é intrínseca. Dentre os 170 artigos selecionados, 35 foram verificados como sendo análise ou avaliação de processo de política pública. Deste montante $74,3 \%(\mathrm{~N}=26)$ foram classificados como abordagem continuada/cíclica, pois com efeito, relatavam processos continuados, com participação social em momentos e situações distintas e frequentemente em médio e logo prazos, tendo em alguns casos mais de 15 anos de histórico. Do restante, foram 8 artigos classificados como abordagem multi-instrumentos e apenas 1 como abordagem pontual.

Ainda nesse grupo dos estudos sobre políticas, a distribuição dos estudos por escala foi de: 13 artigos de abordagem local/dirigida; 7 na categoria ampliada; e 15 multinível. Com relação à funcionalidade: 7 foram classificados como diagnóstico; 22 como resolução de problema; e 6 como abordagem com incertezas/fenômenos emergentes.

Os locais de intervenções relatados nos estudos selecionados são classificados através dos cinco continentes e apresentados no Gráfico 6, em que é possível ver a predominância no continente Americano com 60,7\% dos casos relatados. Nota-se que a somatória das intervenções relatadas é de 173, pois o artigo de Waltner-Toews et al. (2003) relatava estudos na Ásia, África e América, enquanto Abdel-Dayem (2006) relatava estudos na África e Ásia. 
Gráfico 6 - Distribuição das intervenções relatadas em estudos selecionados através dos cinco continentes.

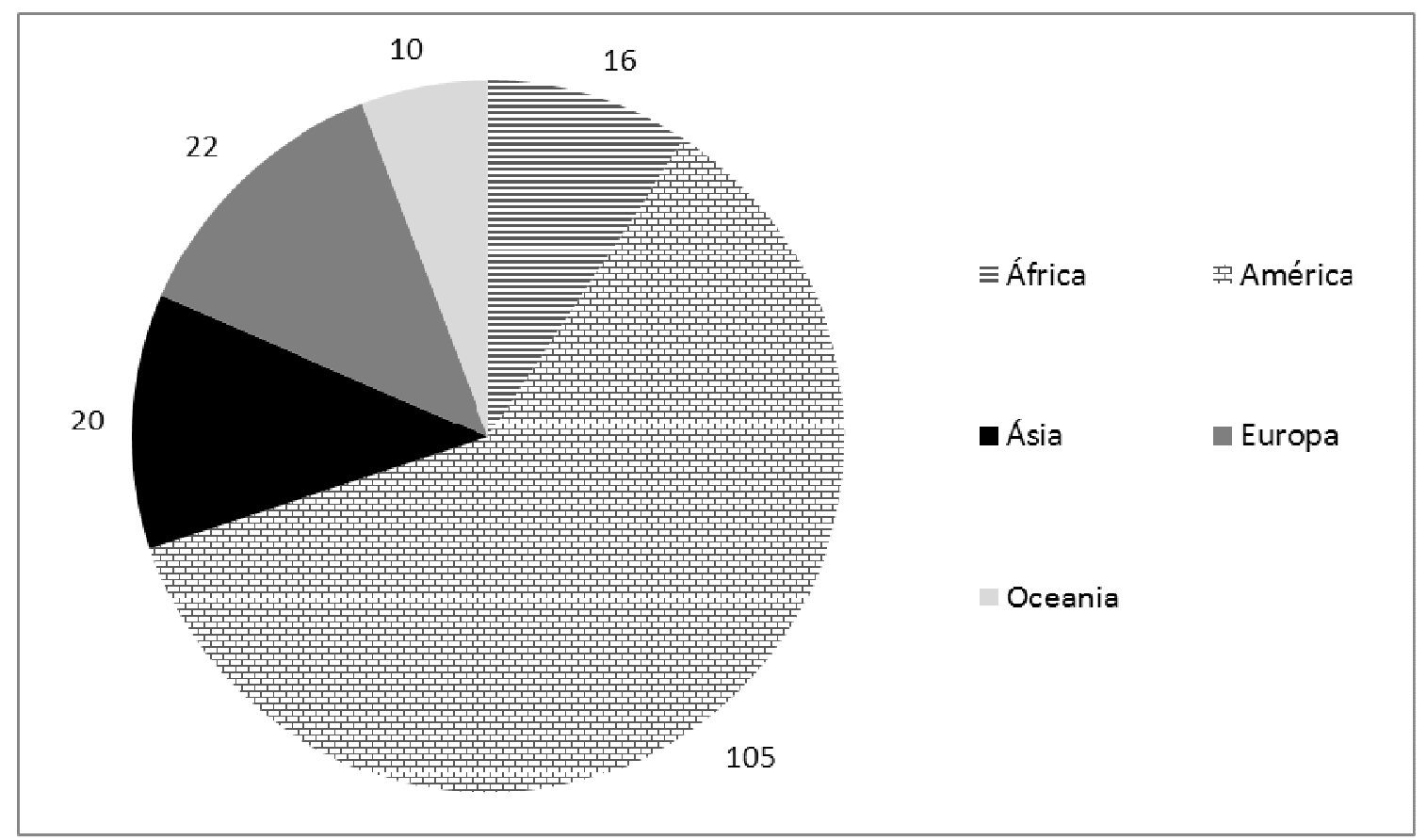

Fonte: elaborado pelo autor

A Tabela 3 apresenta a relação dos países com maior número de intervenções relatadas nos artigos selecionados. Nesta verifica-se o grande destaque de publicações nos EUA, contudo, é preciso observar que dentre as intervenções relatadas neste país, 78,4\% (N=58) se referem a abordagens locais/dirigidas e dentre estas $89,6 \%(\mathrm{~N}=52)$ tratam de grupos sociais em situação de risco por condição de injustiça ambiental. São características básicas dos grupos em estudo a exposição à contaminantes ambientais, como mercúrio, radiação ionizante, compostos orgânicos voláteis, ou maior risco de adquirir distintos tipos de morbidades associadas ao ambiente como asma e obesidade. Os grupos em estudo são diferenciáveis como minorias afro-americanas, de migrantes hispânicos, vietnamitas, brasileiros ou culturalmente diferenciados como populações indígenas, também se acrescentam populações de periferias pobres e grupos com baixos rendimentos.

Destacam-se abaixo os seis estudos de intervenção realizados nos 
EUA, de abordagem local e que se excluem da condição preponderante de injustiça ambiental como principal objetivo das abordagens:

- Gershon et al. (2008) tratam de questões relativas à evacuação do World Trade Center no atentado terrorista de 11 de setembro de 2001;

- $\quad$ Dennis et al. (2009) aplicam uma metodologia de "participatory photo mapping - PPM', que combina fotografias com técnicas acessíveis de geoprocessamento e narrativas, envolvendo jovens, que a priori, não são selecionados por conta de representarem um grupo social sobre situação de risco, exclusão social ou injustiça ambiental. O estudo se constitui de uma abordagem espacial envolvendo aspectos relevantes à saúde em meio urbano, como acesso a alimentos e hábitos respectivos;

- $\quad$ Dois estudos com similaridades, Carter e Nielsen (2011) e Flint et al (2011), apesar de envolverem comunidades indígenas do Alaska, possuem o foco na conservação de espécies, o primeiro estudo referese a uma espécie de beluga, Delphinapterus leucas ('Cook Inlet beluga'), e o segundo enfoca a conservação de uma variedade de frutas silvestres ('wild berries') que possui importância na alimentação dos nativos;

- Mendenhall et al (2011) descrevem abordagem participativa em um campus universitário como uma campanha antitabagismo;

- e Hibbard e Lurie (2002) que tratam de abordagem sobre a criação de indicadores para mensurar a gestão comunitária de recursos naturais. 
Tabela 3 - Países com dois ou mais artigos classificados por apresentarem intervenção em seu território

País $\quad \mathrm{N}$ estudos com intervenções realizadas

\begin{tabular}{cl}
\hline EUA & 74 \\
Candá & 15 \\
Austrália & 8 \\
Brasil & 5 \\
África do Sul & 4 \\
Bangladesh & 3 \\
Cuba & 3 \\
Quênia & 3 \\
Reino Unido & 3 \\
Tailândia & 3 \\
Vietnam & 3 \\
Bélgica & 2 \\
Dinamarca & 2 \\
Egito & 2 \\
Equador & 2 \\
Espanha & 2 \\
Holanda & 2 \\
Japão & 2 \\
Nepal & 2 \\
Nigéria & 2 \\
Peru & \\
\hline
\end{tabular}

Fonte: elaborado pelo autor

Nos Estados Unidos é reconhecível a importância e a prática de grupos que se dedicam à chamada 'community-based participatory research'. Mas, conforme assinalado acima, boa parte das intervenções são de abordagem local e, mudando 
quanto a dimensão de análise, dentre os artigos tratando de abordagens de funcionalidade voltada à incertezas/fenômenos emergentes, apenas 4 estudos são assim classificados, representando $5,4 \%$ do total verificado para aquele país.

Quanto aos estudos que se referem a abordagens no Canadá, segundo país com maior número de artigos selecionados, do total encontrado ( $N=15), 60 \%$ $(\mathrm{N}=9)$ são abordagens locais. Sob o aspecto da funcionalidade, $20 \%(\mathrm{~N}=3)$ são de estudos que tratam de incertezas / fenômenos emergentes.

Retomando o debate em torno dos desafios das intervenções em estudo, se por um lado as abordagens locais ou dirigidas estão frequentemente associadas a grupos sociais bem delimitados, desfavorecidos e sob condição de injustiças ambientais, por outro lado, a perspectiva de análise e intervenção ampliada/multi-instrumentos com especial atenção à incertezas e fenômenos emergentes, pode contribuir para a interpretação e ações nas causas das desigualdades e da degradação dos ecossistemas e de seus serviços que se manifestam nos territórios. Além disso, essas últimas abordagens referidas também podem ser mais proveitosas e sustentáveis pela possibilidade de aumentar a capacidade adaptativa e a resiliência perante possíveis situações críticas, reduzindo os riscos de severas rupturas nos sistemas socioambientais.

Adiciona-se melhor qualificação a esse processo, quando se reproduzem situações do tipo 'bottom-up' em que tanto os anseios como os saberes diferenciados de grupos que sistematicamente enfrentam as adversidades e injustiças ambientais, passam a fazer frente, por meio de processos multinível indicados, às dinâmicas reinantes nos territórios, influenciando ou redelineando políticas públicas. Esta configuração, perante os dilemas mais atuais da humanidade, revigora os ensinamentos de Paulo Freire da década de 1970, em plena vigência da ditadura militar no Brasil (FREIRE 1989; FREIRE 2001). Pois, quando a consciência que emerge do mundo vivido passa a fomentar um processo em que os sujeitos reelaboram o mundo por eles humanizado, estes são capazes de se ver em sua própria realidade imbricada nos contextos globais. É esta condição, certamente, que respalda um processo dialógico em que os atores se relacionam em pé de igualdade, sobrepujando 
as condições opressoras e participando ativamente da tomada de decisões, as quais passam a incorporar a propriedade de ser sustentáveis e justas.

No entanto, chama bastante a atenção o fato de a maior parte das intervenções se constituir de abordagens locais ou dirigidas a determinados grupos sociais. Mesmo que os referidos projetos sejam de elevada qualidade como por aplicação continuada/cíclica de instrumentos e evidências claras de processos de empoderamento, a falta de conexão da base local com outros níveis de organização territorial e até mesmo global, parece comprometer com relação à sustentabilidade dos processos. Pois, mesmo que os grupos que sofram a intervenção tenham, inclusive, a autonomia para lidar até mesmo com outros processos que venham a se constituir oferecendo novos riscos, isso, não garante que todas as populações no mesmo território estejam adquirindo os mesmos fatores de proteção.

Como afirmado anteriormente, é premente uma conexão global-local na análise e na gestão dos riscos que se reproduzem a partir dos insucessos da modernidade. A propósito, os riscos se reproduzem e se constituem de maneira emergente, como no caso das consequências das mudanças climáticas, ou nas inúmeras possibilidades de desdobramentos negativos em torno de novas tecnologias, como as nanotecnologias (BECK 2008). Abordagens isoladas, nesse sentido, apesar de seus desenhos sofisticados, participativos e emancipatórios, não poderiam se caracterizar como empoderadoras para o grupo social de intervenção, porém, assistencialistas quanto ao território e a relação global-local? Sim, pois, tem-se a considerar que existe uma verdadeira insuficiência destas iniciativas pelo fato de estarem desconectadas das dinâmicas mais distintas do local ao global e com todas as mediações e conflitos entre governos, governanças, interesses corporativos, oferta ou escassez de recursos naturais, crises, oportunidades e toda a gama de incertezas associadas. 


\section{Considerações finais}

Não é necessário classificar abordagens de base local ou dirigidas a determinados grupos sociais, focadas em problemas isolados, como legítimas aplicações da proposta da ciência pós-normal. Todavia, tratar questões locais, mesmo que com o mais legítimo e eficiente processo de empoderamento, não possibilita o devido equacionamento das causas complexas das injustiças ambientais. Estas, por sua vez, operam em dinâmicas do tipo global-local, têm sua motricidade atrelada à hipereficiência da modernidade, que transforma o mundo, produzindo benefícios, mas distribuindo desigualdades, impactos na biosfera, nos ecossistemas e em seus serviços e toda a possibilidade de degradação do ser humano e de sua qualidade de vida.

$\mathrm{Na}$ intensidade da força desse antagonismo da modernidade, de um lado com a oferta do conforto e de outro com a disseminação dos riscos, a proposta da ciência pós-normal encontra um amplo leque de possibilidades para atuar sobre seus pressupostos, sendo característico o contexto em torno das tensões proporcionalmente crescentes entre interesses em disputa e incertezas sistêmicas. Mas a produção científica identificada, pelos métodos aplicados neste estudo, se defronta com poucas experiências que estejam propiciando metodologia e aplicabilidade dos preceitos da ciência pós-normal. Sob o mais elevado grau entre os valores em disputa e incertezas foram classificados apenas 10 artigos que relatavam processos cíclicos de intervenção com sujeitos/atores sociais, combinando instrumentos em perspectiva dialógica, incorporando questões relativas a incertezas ou fenômenos emergentes e, ocasionalmente, caracterizando interações multinível enquanto escala.

A comparação entre esses poucos artigos encontrados nessa categoria e a abundância de artigos que envolvem saúde e ambiente, sem os pré-requisitos de participação dialógica, que são provavelmente milhares, faz a força da inferência de que o meio acadêmico está apenas se iniciando nessa nova forma de produzir ciência dialogando com problemas complexos para construir processos políticos e de governança. Procurou-se nesse estudo enfatizar que a participação dos sujeitos é indispensável para lidar com contextos socioambientais e de saúde. Entretanto, há um 
grande caminho a se percorrer nesse sentido, talvez, com a necessidade de se rediscutir o que é inovação e produto da ciência para a aplicabilidade nos problemas mais relevantes de interesse da sociedade. Não se explora aqui um novo paradigma científico, mas sim, um novo paradigma nas relações entre ciência, política, ambiente, sociedade e saúde.

Contudo, os 160 artigos descrevendo abordagens localizadas ou mesmo as ampliadas a escalas de cidades ou territórios, frequentemente associados a diagnósticos participativos e/ou resolução de problemas, também ofereceram uma relevante contribuição dentro de vários traços característicos dos pressupostos da ciência pós-normal. Isso pode ser atestado: Pela possibilidade de tais processos contribuírem com a governança; Pela oportunidade de aprofundamento do poder explicativo das pesquisas, identificação de valores e outros aspectos determinantes da subjetividade dos atores sociais; E, por fim, por permitirem o estabelecimento de plataformas locais ou dentre grupos sociais específicos que podem oferecer interessantes oportunidades de participação/intervenção em outras escalas, eventualmente.

Assim, independente das mais distintas rotulagens, seja da ciência pósnormal, da community-based paticipatory research, da abordagem ecossistêmica em saúde, da pesquisa-ação ou de outras correntes que não foram identificadas neste estudo, mas que, do mesmo modo, representam as transições atuais nos processos socioambientais na saúde e na ciência, há uma perspectiva de encontro de todas essas correntes. Isso se faz contundente por vários condicionantes contemporâneos, como: A necessidade de incorporação dos sujeitos e possível empoderamento destes para viabilizar processos legítimos de governança; As incertezas científicas que precisam ser evidenciadas e passam a ser mais uma questão de decisões mediante as disputas em jogo do que a busca de metodologias infalíveis de previsão do futuro; $E$ também, a necessária conexão entre o local e o global, na busca de sustentabilidade, especialmente no que diz respeito aos efeitos colaterais da modernidade nas desigualdades sociais combinadas com as injustiças ambientais.

A intersecção de saberes em torno dos contextos socioambientais e de 
saúde, com a necessária incorporação dos sujeitos dos riscos em processos de governança, independentemente da escala ou da funcionalidade das intervenções, constitui um movimento bastante compatível com a crítica de Santos (2009b). Constam, nesse sentido, a necessidade de romper com os limites disciplinares da ciência clássica e dialogar diretamente com o senso comum. Pois, certamente, o mais elevado grau de desenvolvimento da ciência clássica, que é uma conquista, deve, por sua vez, constituir sabedoria de vida. Ou seja, um amplo aprendizado social passível de aplicação para os dilemas da atualidade, superando a incapacidade de a ciência hiperespecializada lidar com questões complexas que demandam gestão intersetorial e participativa. 


\section{Referências}

ABDEL-DAYEM, S. An integrated approach to land drainage. Irrigation and Drainage. v. 55, n. 3. jul. 2006. Disponível em: <<Go to ISl>:/WOS:000239406800009 >.

ALVARENGA, A. T. et al. Histórico, fundamentos filosóficos e teórico metodológicos da interdisciplinaridade. In: Philippi-Jr A, Silva-Neto AJS (eds). Interdisciplinaridade em ciência, tecnologia \& inovação. Barueri/SP: Manole, 2011. p.3-68.

ALVAREZ-FARIZO, B. et al. Choice modeling at the "market stall": Individual versus collective interest in environmental valuation. Ecological Economics. v. 60, n. 4. feb. 2007. Disponível em: <<Go to ISI>://WOS:000244595100007 >.

BARBIER, R. A pesquisa-ação. Brasília, DF: Plano, 2002.

BECK, U. A reinvenção da política: rumo a uma Teoria de modernização reflexiva. In: Beck U, Giddens A, Lash S. Modernização Reflexiva: política, tradição e estética na ordem social moderna. Tradução de Magda Lopes.. São Paulo: Universidade Estadual Paulista, 1997. p. 11-73.

BECK, U. La Sociedade del Riesgo Mundial: em busca de la seguridade. Barcelona: Paidós - Estado y Sociedade 155, 2008.

BECKER, D.; EDMUNDO, K.; NUNES, N. R. Empowerment e avaliação participativa em um programa de desenvolvimento local e promoção da saúde. Ciênc Saúde Coletiva,v.9, p. 655-67. 2004.

BERBES-BLAZQUEZ, M. A Participatory Assessment of Ecosystem Services and Human Wellbeing in Rural Costa Rica Using Photo-Voice. Environmental Management, v. 49, n. 4, p. 862-875. apr. 2012. Disponível em: < <Go to ISI>://WOS:000302339300009 >.

BERKES, F.; BERKES, M.K. Ecological complexity, fuzzy logic, and holism in indigenous knowledge. Futures. v. 41, p. 6-12. 2009.

BERKES, F. et al. The Canadian Arctic and the Oceans Act: the development of participatory environmental research and management. Ocean \& Coastal Management. v. 44, n. 7-8. 2001. Disponível em: < <Go to ISI>:/WOS:000171894000001 >. 
BUSS, P. M. Uma introdução ao conceito de Promoção da Saúde. In: CZRESNIA, D. ; FREITAS, C.M. de (orgs.). Promoção da Saúde. Conceitos, reflexões, tendências. 2 ed. Rio de Janeiro: Fiocruz, 2003. p. 15-38.

BUSS, P. M. Promoção da saúde e qualidade de vida. Ciência \& Saúde Coletiva, Rio de Janeiro, v. 5, n.1, p.163-177, jan. 2000.

CÂMARA, V. M.; TAMBELINI, A.T. Considerações sobre o uso da epidemiologia nos estudos em saúde ambiental. Rev. bras. Epidemiol., v. 6, n. 2, p. 95-104. 2003.

CARR, W.; KEMMIS, S. Becoming critical: knowing through action research. Londres: Falmer Press, 1986.

CARTER, B. T. G.; NIELSEN, E. A. Exploring ecological changes in Cook Inlet beluga whale habitat though traditional and local ecological knowledge of contributing factors for population decline. Marine Policy. v. 35, n. 3, p. 299-308. may 2011. Disponível em: $<<$ Go to ISI $>$ :/WOS:000287276400003 >.

CASTLEDEN, H.; GARVIN, T.; NATION, H.-A.-A. F. Modifying Photovoice for community-based participatory Indigenous research. Social Science \& Medicine. v. 66, n. 6. mar. 2008. Disponível em: <<Go to ISI>:/WOS:000254266900013 >.

CASTRO, A. Dinâmica vetorial e suas implicações para a vigilância entomológica do dengue. In: Augusto LGS, Carneiro RM, Martins PH (orgs.). Abordagem ecossistêmica em saúde: Ensaios para o controle de dengue. Recife: Universitária da UFPE, 2005. p. 147-166.

CHRISTOPHER, S. W. et al. Building and Maintaining Trust in a Community-Based Participatory Research Partnership. American Journal of Public Health. v.98, n.8, p. 1398-1406, aug. 2008.

COCHRAN P. A. L, et. al. Indigenous Ways of Knowing: Implications for Participatory Research and Community. Am J Public Health. v. 98, p. 22-27. 2008. doi:10.2105/AJPH.2006.093641. 2008.

D'ALISA, G. et al. Conflict in Campania Waste emergency or crisis of democracy. Ecological Economics. v. 70, n. 2, p. 239-249, dec. 2010. Disponível em: < <Go to ISI>://WOS:000285128300013 >. 
DE GOUVEIA VILELA, R. A.; MALAGOLI, M. E.; MORRONE, L. C. Participative Management in Workers' Health: an experience in the vector control activity. Saude E Sociedade. v. 19 , n. 4, p. 969-980, oct-dec. 2010. Disponível em: < <Go to ISI>://WOS:000286322000022 >.

DE MARCHI, B.; RAVETZ J. R. Risk Management and Governance: a Post-Normal Science Approach. Futures. London, v. 31, n.7, p. 743-757. sep. 1999.

DEMETER, R. M. et al. Scenarios for a future dairy chain in the Netherlands. NjasWageningen Journal of Life Sciences. v. 56, n. 4, p. 301-323, jun 2009. Disponível em: $<<$ Go to ISI $>$ :/WOS:000271449400002 >.

DENNIS, S. F., JR. et al. Participatory photo mapping (PPM): Exploring an integrated method for health and place research with young people. Health \& Place. v. 15, n. 2, p. 466-473. jun 2009. Disponível em: <<Go to ISI >:/WOS:000263026500008 >.

DERRICK, C. G.; MILLER, J. S. A.; ANDREWS, J. M. A fish consumption study of anglers in an at-risk community: A community-based participatory approach to risk reduction. Public Health Nursing. v. 25, n. 4, p. 312-318, jul-aug. 2008. Disponível em: $<<$ Go to ISI $>$ :/WOS:000257571700004 >.

ELKATSHA, S.; WATTS, S. Schistosomiasis in two Nile delta villages: an anthropological perspective. Tropical Medicine \& International Health. v. 2, n. 9. sep 1997. Disponível em: <<Go to ISI>://WOS:A1997XX60000005 >.

FALAGAS, M. E. et al.Comparison of PubMed, Scopus, Web of Science, and Google Scholar: strengths and weaknesses. The FASEB Journal. v.22, n.2, Feb/2008. p. 33842, feb. 2008.

FINDHOLT, N. E.; MICHAEL, Y. L.; DAVIS, M. M. Photovoice Engages Rural Youth in Childhood Obesity Prevention. Public Health Nursing. v. 28, n. 2, p. 186-192, mar-apr. 2011. Disponível em: <<Go to ISI>:/WOS:000287740000010 >.

FLICKER, S. Who Benefits From Community-Based Participatory Research? A Case Study of the Positive Youth Project. Health Education \& Behavior. v. 35, n. 1, p. 7086. 2008.

FLINT, C. G. et al. Promoting Wellness in Alaskan Villages: Integrating Traditional Knowledge and Science of Wild Berries. Ecohealth. v. 8, n. 2, p. 199-209, jun. 2011. 
Disponível em: < <Go to ISI>://WOS:000301184000007 >.

FRANCO NETTO, G. et al. Impactos socioambientais na situação de saúde da população brasileira: Estudo de indicadores relacionados ao saneamento ambiental inadequado. Tempus - Acta de Saúde Coletiva, v. 3, n. 4, p. 53-71. 2009.

FREIRE, P. Carta de Paulo Freire aos professores. Estudos Avançados. São Paulo,

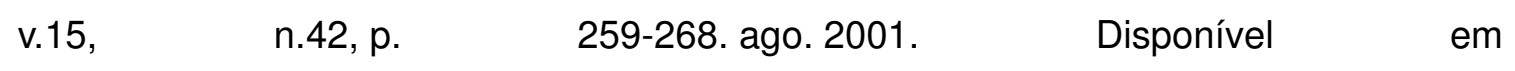
$<$ http://www.scielo.br/scielo.php?script=sci_arttext\&pid=S0103-

40142001000200013\&lng=pt\&nrm=iso $>$. acessos em 25 jan. 2013. http://dx.doi.org/10.1590/S0103-40142001000200013.

FREIRE, P. Pedagogia do oprimido. 17 ed. Rio de Janeiro: Paz e Terra, 1987.

FREITAS, C.M.; GIATTI, L.L. Sustentabilidade ambiental e de saúde na Amazônia Legal, Brasil: Uma análise através de indicadores. Série Saúde Ambiental 4. Brasília: Organização Pan-Americana da Saúde, 2010.

FREITAS, C. M.; GIATTI, L. L. Indicadores de sustentabilidade ambiental e de saúde na Amazônia Legal, Brasil. Cadernos de Saúde Pública. Rio de Janeiro, v.25, n. 6, p. 1251-1266. jun 2009. Disponívem em url: http://www.scielo.br/pdf/csp/v25n6/08.pdf.

FREITAS, C. M. et al. Enfoques ecossistêmicos em saúde - Perspectivas para sua adoção no Brasil e em países da América Latina. Série Saúde Ambiental. Brasília, n.2., Organização Pan-Americana da Saúde / Organização Mundial da Saúde / Ministério da Saúde / Fundação Oswaldo Cruz, 2009. Disponível em url: http://new.paho.org/bra/index.php?option=com content\&task=view\&id=618\&ltemid=457 ) .

FREITAS, C. M.; PORTO, M. F. Saúde, ambiente e sustentabilidade. Rio de Janeiro: Fiocruz; 2006.

FREITAS, C. M. Problemas ambientais, saúde coletiva e ciências sociais. Ciências \& Saúde Coletiva. Rio de Janeiro, v. 8, n. 1, p. 137-150. jan. 2003 . Disponível em $<$ http://www.scielo.br/scielo.php?script=sci_arttext\&pid=S1413 81232003000100011\&lng=pt\&nrm=iso $>$. Acessos em: 03 fev. 2013.

FREITAS, C. M.; DE SOUZA P. M. F.; DE GOMEZ, C. M. Acidentes químicos ampliados: um desafio para a saúde pública. Revista Saúde Pública. São Paulo, v. 29, 
n. 6, p. 503-514. dez. 1995. Disponível em url: http://www.scielosp.org/pdf/rsp/v29n6/12.pdf.

FUNTOWICZ, S.; RAVETZ, J. Ciência Pós-normal e comunidades ampliadas de pares face aos desafios ambientais. História, Ciência, Saúde. v. 4, n.2, p. 219-230. 1997.

FUNTOWICZ, S.; RAVETZ, J. R.. Science for the Post-normal age. Futures. London, v.25, n. 7, p.739-755. sep. 1993.

GALVAO, C. M.; SAWADA, N. O.; TREVIZAN, M. A. Revisão sistemática: recurso que proporciona a incorporação das evidências na prática da enfermagem. Revista LatinoAmericana de Enfermagem. Ribeirão Preto, v. 12, n.3, p. 549-556. jun. 2004.

Disponível em url <http://www.scielo.br/scielo.php?script=sci_arttext\&pid=S010411692004000300014\&Ing=pt\&nrm=iso > acessos em 19 jan. 2013. http://dx.doi.org/10.1590/S0104-11692004000300014.

GARNELO, L., WRIGHT, R. Doença, cura e serviços de saúde: representações, práticas e demandas Baníwa. Cadernos de Saúde Pública. Rio de Janeiro, v. 17, n.2, p. 273-284. abri. 2001. Disponível em url: http://www.scielo.br/pdf/csp/v17n2/4173.pdf.

GERSHON, R. R. M. et al. Participatory Action Research Methodology in Disaster Research: Results From the World Trade Center Evacuation Study. Disaster Medicine and Public Health Preparedness. v. 2, n. 3, p. 142-149. oct .2008. Disponível em: < <Go to ISI>://WOS:000207521300005 >.

GIARETTA, J. B. Z. Participação social e gestão ambiental municipal no Brasil: Desafios e Condicionantes. São Paulo 2011 [dissertação de mestrado Programa de Pós-Graduação em Saúde Pública, Faculdade de Saúde Pública da Universidade de São Paulo]. Disponível em url: http://www.teses.usp.br/teses/disponiveis/6/6134/tde24052011-161139/pt-br.php.

GIATTI, L. L.; CUTOLO, S. A. Access to water for human consumption and aspects of public health in the brasilian Amazon. In: Carolina Bilibio; Oliver Hensel; Jeferson Selbach. (Org.). Sustainable Water Management in the Tropics and Subtropics. Jaguarão, v. 3, p. 613-651. 2012a. p. p. 613-651.

GIATTI, L. L.; CUTOLO, S. A. Acesso à água para consumo humano e aspectos de saúde pública na Amazônia Legal. Ambiente e Sociedade. São Paulo, v. 15, n. 
1. abr.

2012b.

Disponível

em

url:

$<$ http://www.scielo.br/scielo.php?script=sci_arttext\&pid=S1414-

753X2012000100007\&lng=pt\&nrm=iso >. acessos em 05 fev. 2013.

GIATTI, L. L. et al. Uma interface necessária entre pesquisa em Saúde Ambiental e Promoção da Saúde. In: Maria Cecília Focesi Pelicioni; Fábio Luiz Mialhe. (Org.). Educação e Promoção da Saúde: Teoria e prática. 1ed. São Paulo: Santos, 2012. p. 699-715.

GIATTI, L. L. et al. Exposição à água contaminada: percepções e práticas em um bairro de Manaus / Estado do Amazonas, Brasil. Revista Panamericana de Salud Pública. Washington, v. 28, n.5, p. 337-43. nov. 2010. Disponível em url: http://www.scielosp.org/pdf/rpsp/v28n5/03.pdf.

GIATTI, L. L. Reflexões sobre água de abastecimento e saúde pública: um estudo de caso na Amazônia brasileira. Saúde e Sociedade. São Paulo, v. 16, n. 1, p. 134144. abr. 2007.2 Disponível em $<$ http://www.scielo.br/scielo.php?script=sci_arttext\&pid=S0104$12902007000100012 \&$ Ing=pt\&nrm=iso $>$. Acessos em 05 fev. 2013.

GIATTI, L. L. et al. Condições sanitárias e socioambientais em lauaretê, área indígena em São Gabriel da Cachoeira/AM. Ciência \& Saúde Coletiva. Rio de janeiro, v.12, n.6, p.1711-1723. dez. 2007. Disponível em url: http://www.scielo.br/pdf/csc/v12n6/v12n6a30.pdf.

GIATTI, L. L. et al. Condições de saneamento básico em Iporanga, Estado de São Paulo. Revista de Saúde Pública. São Paulo, v. 38, n. 4 p. 571-577. ago. 2004.

Disponível em $<$ http://www.scielo.br/scielo.php?script=sci_arttext\&pid=S003489102004000400014\&ln

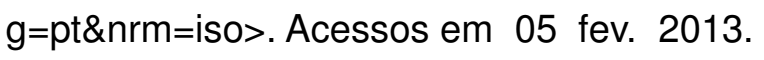

GIDDENS, A. A terceira via: Reflexões sobre o impasse político atual e o futuro da social-democracia. Rio de Janeiro: Record, 2000.

GODET, M.; DURANCE, P. A. Prospectiva estratégica para empresas e os territorios. Coord. de tradução Dias J. Cadernos do Lipsor n. 20. Paris: Laboratoire d'Inovation de Prospective Stratégique et d'Organisation; 2009. 
GRIEGER, K. D.; BAUN, A.; OWEN, R. Redifining risk research priorities for nanomaterials. Journal of Nanoparticle Research.Volume. London, v.12, n.2, p. 383392. feb. $2010 . \quad$ Disponível em url: http://download.springer.com/static/pdf/727/art\%253A10.1007\%252Fs11051-009-98291.pdf?auth66=1361319415 8f428d128944c8c01b8b001008bbf6a8\&ext=.pdf.

GUIVANT, J. S. Transgênicos e percepção pública da ciência no Brasil. Ambiente \& Sociedade. Campinas, v. 9, n. 1, p. 81-103. jun. 2006. Disponível em $<$ http://www.scielo.br/scielo.php?script=sci_arttext\&pid=S1414-

753X2006000100005\&lng=pt\&nrm=iso >. acessos em 30 jan. 2013. http://dx.doi.org/10.1590/S1414-753X2006000100005.

GUIVANT, J. S. A governança dos riscos e os desafios para a redefinição da arena pública do Brasil. Ciência, Tecnologia + Sociedade: novos modelos de governança. Brasília. dez. 2004. Disponível em: <http://www.iris.ufsc.br/pdf/A\%20governa[1]...pdf>. Acesso em: 29 mar 2013.

HA-DUONG, M. et al. Uncertainty management in the IPCC: Agreeing to disagree. Global Environmental Change. v. 17, n.1, p. 8-11. 2007. Disponível em url: http://halshs.archives-ouvertes.fr/docs/00/11/73/03/PDF/GECEditorial.pdf

HALES, S. et al. Health aspects of the Millennium Ecosystem Assessment. Ecohealth. v. 1 , n.2, p. 124-128. jun. 2004. Disponível em url: http://link.springer.com/article/10.1007\%2Fs10393-004-0085-7?LI=true\#page-1.

HARPER, S. L. et al. 'Changing Climate, Changing Health, Changing Stories' Profile: Using an EcoHealth Approach to Explore Impacts of Climate Change on Inuit Health. Ecohealth. v. 9, n. 1, p. 89-101. mar. 2012. Disponível em: < <Go to ISI>://WOS:000305678700011 >.

HARVEY, D. Condição Pós-Moderna: Uma pesquisa sobre as origens da mudança cultural. 18a ed. São Paulo: Loyola, 2009.

HIBBARD, M.; LURIE, S. Creating socio-economic measures for community-based natural resource management: a case from watershed stewardship organisations. Journal of Environmental Planning and Management. v. 55, n. 4, p. 525-544. 2012. Disponível em: <<Go to ISI>://WOS:000303571700007 >. 
HIEN, L. T. T. et al. Effectiveness of a capacity-building program for community leaders in a healthy living environment: a randomized community-based intervention in rural Vietnam. Health Promotion International. v. 23, n. 4, p. 354-364, dec. 2008. Disponível em: <<Go to ISI>://WOS:000260979900007 >.

HOLLOMAN, E. L.; NEWMAN, M. C. A community-based assessment of seafood consumption along the lower James River, Virginia, USA: Potential sources of dietary mercury exposure. Environmental Research. v. 110, n. 3, p. 213-219. apr .2010. Disponível em: <<Go to ISI>://WOS:000275943300002 >.

JACOBI, P. R; SINISGALLI, P. A. A. Governança ambiental e economia verde. Ciência \& saúde coletiva, Rio de Janeiro, v. 17, n. 6, p. 1469-1478. jun. 2012 . Disponível em <http://www.scielo.br/scielo.php?script=sci_arttext\&pid=S141381232012000600011\&lng=pt\&nrm=iso>. acessos em 04 fev. 2013. http://dx.doi.org/10.1590/S1413-81232012000600011.

JACOBI, P. R.; GUNTHER, W. M. R.; GIATTI, L. L. Agenda 21 e Governança. Estudos Avançados. São Paulo, v. 26, n. 74, 2012. Disponível em url: $<$ http://www.scielo.br/scielo.php?script=sci_arttext\&pid=S0103-

40142012000100025\&lng=en\&nrm=iso $>$ access on 22 Jan. 2013. http://dx.doi.org/10.1590/S0103-40142012000100025.

JACOBI, P. R.; TRISTAO, M.; FRANCO, M. I. G. C. A função social da educação ambiental nas práticas colaborativas: participação e engajamento. Cad. CEDES. Campinas, v. 29, n. 77, p. 63-79. abr. 2009. Disponível em $<$ http://www.scielo.br/scielo.php?script=sci_arttext\&pid=S0101-

32622009000100005\&lng=pt\&nrm=iso $>$. acessos em 30 jan. 2013. http://dx.doi.org/10.1590/S0101-32622009000100005.

JACSO P. As we may search - Comparison of major features of the Web of Science, Scopus, and Google Scholar citation-based and citation-enhanced databases. Current Science. v. $89, \quad$ n. 9 , p. 1537-47. nov. 2005. Disponível em url: http://choo.fis.utoronto.ca/FIS/courses/LIS1325/Readings/jacso.pdf.

KAY, J. J. et al. An ecosystem approach for sustaibaility: addressing the challenge of complexity. Futures. v. 31, n. 7, p. 721-742. sep. 1999. 
KUHN, T. S. A estrutura das revoluções científicas; trad. Beatriz Vianna Boeira e Nelson Boeira. São Paulo: Perspectiva, 2009.

LAHTINEN, M.; LAPPALAINEN, S.; REIJULA, K. Multiprofessional teams resolving indoor-air problems - emphasis on the psychosocial perspective. Scandinavian Journal of Work Environment \& Health, 2008. ISSN 0355-3140. Disponível em: < <Go to ISI>://WOS:000255288800007 >.

LEBEL, J. Health: an ecosystem approach. Ottawa, ON:IDRC - International Development Research Centre.

LEWIN, S.; STRAUSS, N. Planning urban environmental health information systems: a case study of Cape Town, South Africa. Environment and Urbanization. v. 11, n. 2, oct. 1999. Disponível em: <<Go to ISI>://WOS:000084096500018 >.

LEWIN, K. Action research and minority problems. Journal of Social Issues. v. 2, p. 34-46. 1946.

LIBERATI, A. et al. The PRISMA statement for reporting systematica reviews and metaanalyses of studies that evaluate healthcare interventions: explanation and elaboration. BMJ (online). jul. 2009.

LIST, D. Action research cycles for multiple futures perspectives. Futures. v. 38, n. 6, p. 673-684. aug. 2006.

MARCIAL, E. C.; GRUMBACH, R. J. S. Cenários Prospectivos - Como Construir um Futuro Melhor. Rio de Janeiro: FGV. 2002.

MARTINEZ-ALLIER, J. O ecologismo dos pobres. São Paulo: Contexto. 2007.

MATULJA, A. Capacidade adaptativa no bioma Mata Atlântica: Estudo de caso do município de São Sebastião, litoral Norte de São Paulo. 2012. Dissertação de mestrado do Programa de Pós-Graduação em Saúde Pública da Faculdade de Saúde Pública da Universidade de São Paulo. Disponível em url: http://www.teses.usp.br/teses/disponiveis/6/6134/tde-29052012-092227/pt-br.php, acesso em 30/01/2013.

MCMICHAEL, A. J. Human frontiers, environments and disease: Past patterns, uncertain futures. UK: Cambridige University Press. 2001. 
MEA - MILLENNIUM ECOSYSTEM ASSESSMENT. Ecosystems and Human Being Synthesis. Washington: Island Press. 2005.

MENDENHALL, T. et al. The SANTA Project (Students Against Nicotine and Tobacco Addiction): Using community-based participatory research to reduce smoking in a highrisk young adult population. Action Research. v. 9, n. 2, p. 199-213. jun. 2011. Disponível em: <<Go to ISI>://WOS:000291589400006 >.

MINAYO, M. C. S., et al. (orgs.). Avaliação por triangulação de métodos: abordagem de programas sociais. Rio de Janeiro: FioCruz, 2005.

MINAYO, M. C. S. Mudança: conceito-chave para intervenções sociais e para avaliação de programas. In: MINAYO, M. C. S., et al. (orgs.). Avaliação por triangulação de métodos: abordagem de programas sociais. Rio de Janeiro: FioCruz, 2005. pp 5370.

MINKLER, M. Linking Science and policy through community-based participatory research to study and address health disparities. American Journal of Public Health. v. 100, n.1, p.81-87. 2010. 100:S81-S87; doi:10.2105/AJPH.2009.165720. Disponível em url: http://ajph.aphapublications.org/doi/pdf/10.2105/AJPH.2009.165720.

MONTIEL, R. P.; BARTEN, F. Urban governance and health development in Leon, Nicaragua. Environment and Urbanization. v. 11, n. 1, apr. 1999. Disponível em: < $<$ Go to ISI >://WOS:000080654000002 >.

MORAN, E. F. Adaptabilidade humana: Uma introdução à antropologia ecológica. São Paulo: EDUSP, 1994.

MORIN, E. Ciência com consciência. 13a ed. Rio de Janeiro: Bertrand Brasil, 2010.

MORIN, A. Pesquisa-ação integral e sistêmica: uma antropopedagogia renovada. Rio de Janeiro: DP\&A, 2004.

MULROW, C. D. Rationale for systematic reviews. British Medical Journal. v. 309, n. 3, p. 597-599. sep. 1994. Disponível em url: http://www.ncbi.nlm.nih.gov/pmc/articles/PMC2541393/pdf/bmj00455-0051.pdf.

MURRAY, T.P.; SÁNCHEZ-CHOY, J. Health, biodiversity, and natural resource use on the Amazon frontier: an ecosystem approach. Cad. Saúde Pública. v. 17, suplemento, 
p. 181-191. 2001.

NARE, L.; LOVE, D.; HOKO, Z. Involvement of stakeholders in the water quality monitoring and surveillance system: The case of Mzingwane Catchment, Zimbabwe. Physics and Chemistry of the Earth. v. 31, n. 15-16. 2006. Disponível em: < <Go to ISI>://WOS:000241483000007 >.

NUSSBAUM, R. H. et al. Community-based participatory health survey of Hanford, WA, Downwinders: A model for citizen empowerment. Society \& Natural Resources. v. 17, n. 6, jul. 2004. Disponível em: <<Go to ISI>:/WOS:000221582500007 >.

O'FALLON, L. R. et al. Strategies for setting a national research agenda that is responsive to community needs. Environmental Health Perspectives. v. 111, n. 16. dec. 2003. Disponível em: <<Go to ISI>://WOS:000187034000029 >.

PATZ, J.A., et al. Climate Change and Global Health: Quantifying a growing ethical crisis. EcoHealth. v. 4, p. 397-405. 2007.

PATZ, J.A., et al. Unhealthy landscapes: Policy recommendations on land use change and infectious disease emergence. Environmental Health Perspectives. v. 112, n. 10, p.1092-8. 2004.

PORTO, M. F. S. Uma Ecologia Política dos riscos: princípios para integrarmos o local e o global na promoção da saúde e da justiça ambiental. Rio de Janeiro: Fiocruz. 2007.

PORTO, M. F. S.; FREITAS, C. M. Vulnerability and industrial hazards in industrializing countries: an integrative approach. Futures. v.35, n. 7, p. 717-736. sep. 2003.

POULSEN, K. B. The Healthy Bus project in Denmark: need for an action potential assessment. Health Promotion International. v. 19, n. 2. jun. 2004. Disponível em: < <Go to ISI>://WOS:000221295000008 >.

PRÜSS-ÜSTÜN, A.; BONJOUR, S. CORVALÁN, C. The impact of the environment on health by country: a meta-synthesis. Environmental Health. Geneva, v.7, n. 7, p. 1-10. feb. 2008.

PRÜSS-ÜSTÜN, A. CORVALÁN, C. Preventing disease through healthy environments - Towards na estimate of the environmental burden of disease. 
Geneva: World Health Organization. 2006.

QUIGLEY, D. et al. Participatory research strategies in nuclear risk management for native communities. Journal of Health Communication. v. 5, n. 4. oct-dec. 2000. Disponível em: <<Go to ISI>://WOS:000165566500003 >.

RAVETZ, J. The post-normal science of precaution. Futures. London, v.36, n. 3, p. 347357. Apr. 2004.

ROCHA L. C. R.; HORBE, A. M. C. Contaminação provocada por um depósito de lixo no aqüífero Alter do Chão em Manaus - AM. Acta Amazônica. v.36, n. 3, p. 307-12. 2006.

SAMPAIO, RF; MANCINI, MC. Estudos de revisão sistemática: um guia para síntese criteriosa da evidência científica. Revista Brasileira de Fisioterapia. São Carlos, v. 11, n. 1, feb. $2007 \quad$. $\quad$ Disponível em url: $<$ http://www.scielo.br/scielo.php?script=sci_arttext\&pid=S1413-

35552007000100013\&lng=en\&nrm=iso>. acesso em: 19 jan. 2013. http://dx.doi.org/10.1590/S1413-35552007000100013.

SAN SEBASTIAN, M.; HURTIG, A. K. Oil development and health in the Amazon basin of Ecuador: the popular epidemiology process. Social Science \& Medicine. v. 60, n. 4. feb. 2005. Disponível em: <<Go to ISI>://WOS:000226430300012 >.

SANTOS, M. A urbanização Brasileira: São Paulo: Edusp, 2009a.

SANTOS, B. S. Um discurso sobre as ciências. 6ª ed. São Paulo: Cortez, 2009b.

SIQUEIRA, C. E.; JANSEN, T. Working Conditions of Brazilian Immigrants in Massachusetts. Journal of Immigrant and Minority Health.v. 14, n. 3, p. 481-488. jun. 2012. Disponível em: <<Go to ISI ://WOS:000303525100015 >.

SLOANE, D. et al. Assessing resource environments to target prevention interventions in community chronic disease control. Journal of Health Care for the Poor and Underserved. v. 17, n. 2. may. 2006. Disponível em: $<<$ Go to ISI>://WOS:000237924600012 >.

SMITH, K. R.; EZZATI, M. How environmental health risks change with development: the epidemiologic and environmental risk transitions revisited. Annual Review 
Environmental Resources. v.30, p. 291-333. nov. 2005.

STEPHENS, C. Editorial - Indigenous Perspectives on Ecosystem Sustainability and Health. EcoHealth. v. 4, p. 369-370. 2007.

STERN, R.; PUOANE, T.; TSOLEKILE, L. An Exploration into the Determinants of Noncommunicable Diseases Among Rural-to-Urban Migrants in Periurban South Africa.

Preventing Chronic Disease. v. 7, n. 6, nov. 2010. Disponível em: $<<$ Go to |SI>://WOS:000208158900018 >.

TERRY, J. P.; KHATRI, K. People, pigs and pollution - Experiences with applying participatory learning and action (PLA) methodology to identify problems of pig-waste management at the village level in Fiji. Journal of Cleaner Production. v. 17, n. 16, p. 1393-1400. nov. 2009. Disponível em: <<Go to ISI>://WOS:000270162400002 >.

THIOLLENT, M. Metodologia da Pesquisa-ação. 15ª ed. São Paulo: Cortez. 2007.

TOLEDO, R. F.; GIATTI, L. L.; PELICIONI, M. C. F. Social Mobilization in Health and Sanitation in an Action Research Process in an Indigenous Community in Northwestern Amazon. Saúde e Sociedade. São Paulo, v.21, n.1, p. 206-218. mar. 2012. Disponível em url: <http://www.scielo.br/scielo.php?script=sci_arttext\&pid=S010412902012000100020\&lng=en\&nrm=iso $>$ 0104-1290. http://dx.doi.org/10.1590/S0104-12902012000100020.

TOLEDO, R. F.; GIATTI, L. L.; PELICIONI, M. C. F. Desafios da Promoção da Saúde em diferentes contextos amazônicos. Revista de Estudos Universitárias. Sorocaba, v.36, p.77-93. 2010.

TOLEDO, R. F.; GIATTI, L. L.; PELICIONI, M. C. F. 2009. Urbanidade rural, território e sustentabilidade: relações de contato em uma comunidade indígena no noroeste amazônico. Ambiente \& Sociedade. Campinas, v. 12, n. 1, p. 173-188. 2009. Disponível em url: http://www.scielo.br/pdf/asoc/v12n1/v12n1a12.pdf.

TOLEDO, R. F. et al. Comunidade indígena na Amazônia: metodologia da pesquisaação em educação ambiental. O Mundo da Saúde. v.30 n. 4, p. 559-569. dez. 2006.

VAN DEN HOVE, S. A rationale for science-policy interfaces. Futures. v. 39, n. 7, p. 807-826. sep. 2007. Disponível em: <<Go to ISI>://WOS:000247248600003 >. 
VASQUEZ, V. B.; MINKLER, M.; SHEPARD, P. Promoting environmental health policy through community based participatory research: A case study from Harlem, New York. Journal of Urban Health-Bulletin of the New York Academy of Medicine. v. 83, n. 1. jan. 2006. Disponível em: <<Go to ISI>://WOS:000237227300010 >.

WALTNER-TOEWS, D. et al. Perspective changes everything: managing ecosystems from the inside out. Frontiers in Ecology and the Environment. v. 1, n. 1, feb. 2003. Disponível em: <<Go to ISI>://WOS:000221789300016 >.

WALTNER-TOEWS, D. An ecossystem approach to health and its applications to tropical and emergin diseases. Cadernos de Saúde Pública. Rio de Janeiro, v.17, p. 7-36. 2001. Disponível em url: http://www.scielo.br/pdf/csp/v17s0/3878.pdf.

WIEK, A.; GASSER, L.; SIEGRIST, M. Systemic scenarios of nanotechnology: Sustainable governance of emerging technologies. Futures. v. 41, n. 5, p. 284-300. jun. 2009. Disponível em: <<Go to ISI ://WOS:000266317900005 >.

WOLCH, J. et al. The forgotten and the future: reclaiming back alleys for a sustainable city. Environment and Planning A. v. 42, n. 12, p. 2874-2896. dec. 2010. Disponível em: $<<$ Go to ISI ://WOS:000287260600007 >.

ZIELINSKI-GUTIERREZ, E. C.; HAYDEN, M. H. A model for defining West Nile virus risk perception based on ecology and proximity. Ecohealth. v. 3, n. 1, mar. 2006. Disponível em: <<Go to ISI>://WOS:000238180800004 >. 


\section{Anexo - Lista completa de referências utilizadas em revisão sistemática}

ABDEL-DAYEM, S. An integrated approach to land drainage. Irrigation and Drainage, v. 55, n. 3, Jul 2006. ISSN 1531-0353. Disponível em: <<Go to ISI>://WOS:000239406800009 >.

ADAMS, K. et al. Use of participatory research and photo-voice to support urban Aboriginal healthy eating. Health \& Social Care in the Community, v. 20, n. 5, Sep 2012. ISSN 0966-0410. Disponível em: <<Go to ISI>://WOS:000307382400004 >.

ADGATE, J. L. et al. Allergen levels in inner city homes: baseline concentrations and evaluation of intervention effectiveness. Journal of Exposure Science and Environmental Epidemiology, v. 18, n. 4, p. 430-440, Jul 2008. ISSN 1559-0631. Disponível em: <<Go to ISI>://WOS:000256832600009 >.

ALI, M.; STEVENS, L. Integrated approaches to promoting sanitation: A case study of Faridpur, Bangladesh. Desalination, v. 248, n. 1-3, p. 1-7, Nov 15 2009. ISSN 0011-9164. Disponível em: < <Go to ISI>://WOS:000271141200001 >.

ALKON, A. H. Reflexivity and Environmental Justice Scholarship: A Role for Feminist Methodologies. Organization \& Environment, v. 24, n. 2, p. 130-149, Jun 2011. ISSN 1086-0266. Disponível em: < <Go to ISI>://WOS:000292917600002 >.

ALLEN, N. E. et al. "Changing the Text": Modeling Council Capacity to Produce Institutionalized Change. American Journal of Community Psychology, v. 49, n. 3-4, p. 317-331, Jun 2012. ISSN 0091-0562. Disponível em: <<Go to ISI>://WOS:000303800600002 >.

ALVAREZ-FARIZO, B. et al. Choice modeling at the "market stall": Individual versus collective interest in environmental valuation. Ecological Economics, v. 60, n. 4, Feb 1 2007. ISSN 0921-8009. Disponível em: $<<$ Go to ISI : //WOS:000244595100007 >.

ARONSON, R. E. et al. Neighborhood mapping and evaluation: A methodology for participatory community health initiatives. Maternal and Child Health Journal, v. 11, n. 4, Jul 2007. ISSN 1092-7875. Disponível em: <<Go to ISI : //WOS:000246184700009 >.

ATKINSON, J.-A. M. et al. Community participation for malaria elimination in Tafea Province, Vanuatu: Part I. Maintaining motivation for prevention practices in the context of disappearing disease. Malaria Journal, v. 9, Apr 12 2010. ISSN 1475-2875. Disponível em: <<Go to ISI>://WOS:000278297600001 >.

AZAROFF, L. S. et al. Results of a Community-University Partnership to Reduce Deadly Hazards in Hardwood Floor Finishing. Journal of Community Health, v. 36, n. 4, p. 658-668, Aug 2011. ISSN 00945145. Disponível em: <<Go to ISI>:/WOS:000292513300022 >.

BERBES-BLAZQUEZ, M. A Participatory Assessment of Ecosystem Services and Human Wellbeing in Rural Costa Rica Using Photo-Voice. Environmental Management, v. 49, n. 4, p. 862-875, Apr 2012. ISSN 0364-152X. Disponível em: < <Go to ISI>:/WOS:000302339300009 >.

BERKES, F. et al. The Canadian Arctic and the Oceans Act: the development of participatory environmental research and management. Ocean \& Coastal Management, v. 44, n. 7-8, 20012001. ISSN 0964-5691. Disponível em: <<Go to ISI>:/WOS:000171894000001 >.

BETIANG, L. Theatre of rural empowerment: the example of Living Earth Nigeria Foundation's Community Theatre Initiative in Cross River State, Nigeria. Ride-the Journal of Applied Theatre and Performance, $v$. 15, n. 1, p. 59-78, 2010 2010. ISSN 1356-9783. Disponível em: < <Go to ISI>://WOS:000279055900005 >.

BEYER, K. M. M.; COMSTOCK, S.; SEAGREN, R. Disease Maps as Context for Community Mapping: A Methodological Approach for Linking Confidential Health Information with Local Geographical Knowledge for Community Health Research. Journal of Community Health, v. 35, n. 6, p. 635-644, Dec 2010. ISSN 0094-5145. Disponível em: <<Go to ISI>://WOS:000284780200010 >.

BLAKENEY, A. B.; MARSHALL, A. Water Quality, Health, and Human Occupations. American Journal of 
Occupational Therapy, v. 63, n. 1, p. 46-57, Jan-Feb 2009. ISSN 0272-9490. Disponível em: < <Go to ISI >://WOS:000262795300005 >.

BRENNER, B. L.; MANICE, M. P. Community Engagement in Children's Environmental Health Research. Mount Sinai Journal of Medicine, v. 78, n. 1, p. 85-97, Jan-Feb 2011. ISSN 0027-2507. Disponível em: < $<$ Go to ISI ://WOS:000287017300007 >.

BROWN, P. et al. Clearing the air and breathing freely: The health politics of air pollution and asthma. International Journal of Health Services, v. 34, n. 1, 2004 2004. ISSN 0020-7314. Disponível em: < <Go to ISI : //WOS:000220457700005 >.

BRYAN, B. A.; KANDULU, J. M. Designing a Policy Mix and Sequence for Mitigating Agricultural Non-Point Source Pollution in a Water Supply Catchment. Water Resources Management, v. 25, n. 3, p. 875-892, Feb 2011. ISSN 0920-4741. Disponível em: < <Go to ISI>://WOS:000287328500006 >.

BUIKSTRA, E. et al. THE COMPONENTS OF RESILIENCE-PERCEPTIONS OF AN AUSTRALIAN RURAL COMMUNITY. Journal of Community Psychology, v. 38, n. 8, p. 975-991, Nov 2010. ISSN 00904392. Disponível em: <<Go to ISI>://WOS:000283959300004 >.

BUYKX, P. et al. How do small rural primary health care services sustain themselves in a constantly changing health system environment? Bmc Health Services Research, v. 12, Mar 26 2012. ISSN 1472 6963. Disponível em: <<Go to ISI>://WOS:000303990600002 >.

CARTER, B. T. G.; NIELSEN, E. A. Exploring ecological changes in Cook Inlet beluga whale habitat though traditional and local ecological knowledge of contributing factors for population decline. Marine Policy, v. 35, n. 3, p. 299-308, May 2011. ISSN 0308-597X. Disponível em: < <Go to ISI>://WOS:000287276400003 $>$.

CASTLEDEN, H.; GARVIN, T.; NATION, H.-A.-A. F. Modifying Photovoice for community-based participatory Indigenous research. Social Science \& Medicine, v. 66, n. 6, Mar 2008. ISSN 0277-9536. Disponível em: <<Go to ISI>://WOS:000254266900013 >.

CHEADLE, A. et al. The Impact of a Community-Based Chronic Disease Prevention Initiative: Evaluation Findings From Steps to Health King County. Health Education \& Behavior, v. 38, n. 3, p. 222-230, Jun 2011. ISSN 1090-1981. Disponível em: <<Go to ISI>:/WOS:000290618300002 >.

CLARK, M. J. et al. Involving communities in community assessment. Public Health Nursing, v. 20, n. 6, Nov-Dec 2003. ISSN 0737-1209. Disponível em: <<Go to ISI>:/WOS:000186236900006 >.

COHEN, A. et al. Our Environment, Our Health: A Community-Based Participatory Environmental Health Survey in Richmond, California. Health Education \& Behavior, v. 39, n. 2, p. 198-209, Apr 2012. ISSN 1090-1981. Disponível em: < <Go to ISI>://WOS:000302284700010 >.

CUNNINGHAM, T. et al. Understanding Water Perceptions in Limpopo Province: A Photovoice Community Assessment. 2009. 5990-5993 ISBN 978-1-4244-2901-1. Disponível em: <<Go to ISI>://WOS:000286342803129 >.

CURTIS, A.; LOCKWOOD, M. Landcare and catchment management in Australia: Lessons for statesponsored community participation. Society \& Natural Resources, v. 13, n. 1, Jan-Feb 2000. ISSN 08941920. Disponível em: <<Go to ISI>:/WOS:000085048900005 >.

D'ALISA, G. et al. Conflict in Campania Waste emergency or crisis of democracy. Ecological Economics, v. 70, n. 2, p. 239-249, Dec 15 2010. ISSN 0921-8009. Disponível em: < <Go to ISI>://WOS:000285128300013 >.

DE GOUVEIA VILELA, R. A.; MALAGOLI, M. E.; MORRONE, L. C. Participative Management in Workers' Health: an experience in the vector control activity. Saude E Sociedade, v. 19, n. 4, p. 969-980, Oct-Dec 2010. ISSN 0104-1290. Disponível em: <<Go to ISI ://WOS:000286322000022 >.

DEJOY, D. M. et al. Assessing the impact of healthy work organization intervention. Journal of 
Occupational and Organizational Psychology, v. 83, n. 1, p. 139-165, Mar 2010. ISSN 0963-1798. Disponível em: <<Go to ISI ://WOS:000276631800008 >.

DEMETER, R. M. et al. Scenarios for a future dairy chain in the Netherlands. Njas-Wageningen Journal of Life Sciences, v. 56, n. 4, p. 301-323, Jun 2009. ISSN 1573-5214. Disponível em: <<Go to ISI>://WOS:000271449400002 >.

DENNIS, S. F., JR. et al. Participatory photo mapping (PPM): Exploring an integrated method for health and place research with young people. Health \& Place, v. 15, n. 2, p. 466-473, Jun 2009. ISSN 1353-8292. Disponível em: <<Go to ISI>://WOS:000263026500008 >.

DERRICK, C. G.; MILLER, J. S. A.; ANDREWS, J. M. A fish consumption study of anglers in an at-risk community: A community-based participatory approach to risk reduction. Public Health Nursing, v. 25, n. 4, p. 312-318, Jul-Aug 2008. ISSN 0737-1209. Disponível em: < <Go to ISI>://WOS:000257571700004 >.

DOWNS, T. J. et al. Participatory testing and reporting in an environmental-justice community of Worcester, Massachusetts: a pilot project. Environmental Health, v. 9, Jul 6 2010. ISSN 1476-069X. Disponível em: < <Go to ISI>://WOS:000282289300002 >.

Complexities of holistic community-based participatory research for a low income, multi-ethnic population exposed to multiple built-environment stressors in Worcester, Massachusetts. Environmental Research, v. 109, n. 8, p. 1028-1040, Nov 2009. ISSN 0013-9351. Disponível em: < <Go to ISI>://WOS:000271296900012 >.

ELKATSHA, S.; WATTS, S. Schistosomiasis in two Nile delta villages: an anthropological perspective. Tropical Medicine \& International Health, v. 2, n. 9, Sep 1997. ISSN 1360-2276. Disponível em: < <Go to ISI>://WOS:A1997XX60000005 >.

ENGLISH, K. C. et al. A socioecological approach to improving mammography rates in a tribal community. Health Education \& Behavior, v. 35, n. 3, Jun 2008. ISSN 1090-1981. Disponível em: < <Go to ISI>://WOS:000255570700007 >.

ENSIGN, J.; GITTELSOHN, J. Health and access to care: Perspectives of homeless youth in Baltimore City, USA. Social Science \& Medicine, v. 47, n. 12, Dec 1998. ISSN 0277-9536. Disponível em: < <Go to ISI>://WOS:000077985900021 >.

FAM, I. M.; NIKOOMARAM, H.; SOLTANIAN, A. Comparative analysis of creative and classic training methods in health, safety and environment (HSE) participation improvement. Journal of Loss Prevention in the Process Industries, v. 25, n. 2, p. 250-253, Mar 2012. ISSN 0950-4230. Disponível em: < <Go to ISI>://WOS:000300865700003 >.

FINDHOLT, N. E.; MICHAEL, Y. L.; DAVIS, M. M. Photovoice Engages Rural Youth in Childhood Obesity Prevention. Public Health Nursing, v. 28, n. 2, p. 186-192, Mar-Apr 2011. ISSN 0737-1209. Disponível em: $<<$ Go to ISI ://WOS:000287740000010 >.

FLINT, C. G. et al. Promoting Wellness in Alaskan Villages: Integrating Traditional Knowledge and Science of Wild Berries. Ecohealth, v. 8, n. 2, p. 199-209, Jun 2011. ISSN 1612-9202. Disponível em: <<Go to ISI ://WOS:000301184000007 >.

FORDE, M. et al. Strengthening integrated research and capacity development within the Caribbean region. Bmc International Health and Human Rights, v. 11, Nov 8 2011. ISSN 1472-698X. Disponível em: $<<$ Go to ISI $>$ :/WOS:000303918400007 >.

FREEDMAN, D. A.; BESS, K. D. Food Systems Change and the Environment: Local and Global Connections. American Journal of Community Psychology, v. 47, n. 3-4, p. 397-409, Jun 2011. ISSN 0091-0562. Disponível em: <<Go to ISI>://WOS:000288165100015 >.

FREITAS SETTI, A. F.; BOGUS, C. M. Community Participation in an Intervention Program Developed in a Protected Area. Saude E Sociedade, v. 19, n. 4, p. 946-960, Oct-Dec 2010. ISSN 0104-1290. Disponível em: $<<$ Go to ISI $>$ :/WOS:000286322000020 >. 
GERSHON, R. R. M. et al. Participatory Action Research Methodology in Disaster Research: Results From the World Trade Center Evacuation Study. Disaster Medicine and Public Health Preparedness, v. 2, n. 3, p. 142-149, Oct 2008. ISSN 1935-7893. Disponível em: <<Go to ISI>://WOS:000207521300005 >.

GETZNER, M. Uncertainties and the precautionary principle in cost-benefit environmental policies. Journal of Policy Modeling, v. 30, n. 1, Jan-Feb 2008. ISSN 0161-8938. Disponível em: < <Go to ISI>://WOS:000252783800001 >.

GIBBON, M.; CAZOTTES, I. Working with women's groups to promote health in the community using the health analysis and action cycle within Nepal. Qualitative Health Research, v. 11, n. 6, Nov 2001. ISSN 1049-7323. Disponível em: <<Go to ISI>://WOS:000171857700004 >.

GONZALEZ, P. A. et al. Community-Based Participatory Research and Policy Advocacy to Reduce Diesel Exposure in West Oakland, California. American Journal of Public Health, v. 101, p. S166-S175, 2011 2011. ISSN 0090-0036. Disponível em: <<Go to ISI>://WOS:000297141000027 >.

GRACE, D. et al. Participatory probabilistic assessment of the risk to human health associated with cryptosporidiosis from urban dairying in Dagoretti, Nairobi, Kenya. Tropical Animal Health and

Production, v. 44, Sep 2012. ISSN 0049-4747. Disponível em: < <Go to ISI>:/WOS:000308552400006 >.

GRANT, J. Coastal communities, participatory research, and far-field effects of aquaculture. Aquaculture Environment Interactions, v. 1, n. 2, p. 85-93, 2010 2010. ISSN 1869-215X. Disponível em: <<Go to ISI>://WOS:000292391000001 >.

GREIG, S.; PARRY, N.; RIMMINGTON, B. Promoting sustainable regeneration: learning from a case study in participatory HIA. Environmental Impact Assessment Review, v. 24, n. 2, Feb 2004. ISSN 0195-9255. Disponível em: <<Go to ISI>://WOS:000222610200014 >.

GUTBERLET, J. Empowering collective recycling initiatives: Video documentation and action research with a recycling co-op in Brazil. Resources Conservation and Recycling, v. 52, n. 4, Feb 2008. ISSN 09213449. Disponível em: <<Go to ISl>:/WOS:000253134600009 >.

HADI, A. A participatory approach to sanitation: experience of Bangladeshi NGOs. Health Policy and Planning, v. 15, n. 3, Sep 2000. ISSN 0268-1080. Disponível em: < <Go to ISI>://WOS:000089390600013 $>$.

HANSEN-KETCHUM, P. A. et al. Strengthening access to restorative places: Findings from a participatory study on engaging with nature in the promotion of health. Health \& Place, v. 17, n. 2, p. 558-571, Mar 2011. ISSN 1353-8292. Disponível em: <<Go to ISI>://WOS:000289339000019 >.

HARPER, S. L. et al. 'Changing Climate, Changing Health, Changing Stories' Profile: Using an EcoHealth Approach to Explore Impacts of Climate Change on Inuit Health. Ecohealth, v. 9, n. 1, p. 89-101, Mar 2012. ISSN 1612-9202. Disponível em: < <Go to ISI>://WOS:000305678700011 >.

HARRIS, N.; GROOTJANS, J. The application of ecological thinking to better understand the needs of communities of older people. Australasian Journal on Ageing, v. 31, n. 1, p. 17-21, Mar 2012. ISSN 1440-6381. Disponível em: <<Go to ISI>:/WOS:000301481900005 >.

HAYNES, E. N. et al. Developing a Bidirectional Academic-Community Partnership with an AppalachianAmerican Community for Environmental Health Research and Risk Communication. Environmental Health Perspectives, v. 119, n. 10, p. 1364-1372, Oct 2011. ISSN 0091-6765. Disponível em: < <Go to ISI>://WOS:000295402400018 >.

HEIDEMANN, I. T. S. B.; ALMEIDA, M. C. P. Friere's Dialogic Concept Enables Family Health Program Teams to Incorporate Health Promotion. Public Health Nursing, v. 28, n. 2, p. 159-167, Mar-Apr 2011. ISSN 0737-1209. Disponível em: <<Go to ISI>://WOS:000287740000007 >.

HEISKANEN, E. et al. Designed to travel? Transition management encounters environmental and innovation policy histories in Finland. Policy Sciences, v. 42, n. 4, p. 409-427, Nov 2009. ISSN 0032-2687. 
Disponível em: <<Go to ISI>://WOS:000272180200007 >.

HIBBARD, M.; LURIE, S. Creating socio-economic measures for community-based natural resource management: a case from watershed stewardship organisations. Journal of Environmental Planning and Management, v. 55, n. 4, p. 525-544, 2012 2012. ISSN 0964-0568. Disponível em: < <Go to ISI>://WOS:000303571700007 >.

HIEN, L. T. T. et al. Effectiveness of a capacity-building program for community leaders in a healthy living environment: a randomized community-based intervention in rural Vietnam. Health Promotion International, v. 23, n. 4, p. 354-364, Dec 2008. ISSN 0957-4824. Disponível em: <<Go to ISI>://WOS:000260979900007 >.

HOLLOMAN, E. L.; NEWMAN, M. C. A community-based assessment of seafood consumption along the lower James River, Virginia, USA: Potential sources of dietary mercury exposure. Environmental Research, v. 110, n. 3, p. 213-219, Apr 2010. ISSN 0013-9351. Disponível em: < <Go to ISI>://WOS:000275943300002 >.

INMUONG, U. et al. Participatory health impact assessment for the development of local government regulation on hazard control. Environmental Impact Assessment Review, v. 31, n. 4, p. 412-414, Jul 2011. ISSN 0195-9255. Disponível em: <<Go to ISI>:/WOS:000291778200004 >.

ISRAEL, B. A. et al. Engaging urban residents in assessing neighborhood environments and their implications for health. Journal of Urban Health-Bulletin of the New York Academy of Medicine, v. 83, n. 3, May 2006. ISSN 1099-3460. Disponível em: < <Go to ISI>://WOS:000238355600016 >.

JACOBS, N.; KISTING, S.; BRAUN, L. Collaborative research, participatory solutions: Research on asbestos in Kuruman, South Africa. International Journal of Occupational and Environmental Health, v. 10, n. 2, Apr-Jun 2004. ISSN 1077-3525. Disponível em: <<Go to ISI>://WOS:000222131400015 >.

JAMES, P. et al. Towards an integrated understanding of green space in the European built environment. Urban Forestry \& Urban Greening, v. 8, n. 2, p. 65-75, 2009 2009. ISSN 1618-8667. Disponível em: < $<$ Go to ISI ://WOS:000265431700001 >.

JARVELA, M.; RINNE-KOISTINEN, E. M. Purity and dirt as social constructions: Environmental health in an urban, Shantytown of Lagos. International Journal of Urban and Regional Research, v. 29, n. 2, Jun 2005. ISSN 0309-1317. Disponível em: <<Go to ISI>:/MOS:000231028300008 >.

JERNIGAN, V. B. B. et al. Addressing food insecurity in a Native American reservation using communitybased participatory research. Health Education Research, v. 27, n. 4, Aug 2012. ISSN 0268-1153. Disponível em: <<Go to ISI>://WOS:000306647900008 >.

JEWITT, S.; BAKER, K. Risk, wealth and agrarian change in India. Household-level hazards vs. latemodern global risks at different points along the risk transition. Global Environmental Change-Human and Policy Dimensions, v. 22, n. 2, p. 547-557, May 2012. ISSN 0959-3780. Disponível em: < <Go to ISI ://WOS:000304290100024 >.

JONSSON, J. B.; APPEL, P. W. U.; CHIBUNDA, R. T. A matter of approach: the retort's potential to reduce mercury consumption within small-scale gold mining settlements in Tanzania. Journal of Cleaner Production, v. 17, n. 1, p. 77-86, 2009 2009. ISSN 0959-6526. Disponível em: <<Go to ISI>://WOS:000260189300008 >.

JUAREZ, $\mathrm{H}$. et al. Water and health at the household level in Eastern Lima, Peru: an urban ecosystem approach. In: GOSPODINI, A. B. C. A. (Ed.). Sustainable City V: Urban Regeneration and Sustainability, v.117, 2009. p.567-575. (WIT Transactions on Ecology and the Environment). ISBN 17433541

978-1-84564-128-3.

JUDD, N. L. et al. Framing scientific analyses for risk management of environmental hazards by communities: Case studies with seafood safety issues. Environmental Health Perspectives, v. 113, n. 11, Nov 2005. ISSN 0091-6765. Disponível em: <<Go to ISI>:/WOS:000232916700030 >. 
KANG'ETHE, E. K. et al. A trans-disciplinary study on the health risks of cryptosporidiosis from dairy systems in Dagoretti, Nairobi, Kenya: study background and farming system characteristics. Tropical Animal Health and Production, v. 44, Sep 2012. ISSN 0049-4747. Disponível em: < <Go to ISI>://WOS:000308552400002 >.

KEIL, R.; ALI, H. Governing the sick city: Urban governance in the age of emerging infectious disease. Antipode, v. 39, n. 5, Nov 2007. ISSN 0066-4812. Disponível em: <<Go to ISI>:/MOS:000251384700005 $>$.

KEIRNS, C. C. Asthma Mitigation Strategies Professional, Charitable, and Community Coalitions. American Journal of Preventive Medicine, v. 37, n. 6, p. S244-S250, Dec 2009. ISSN 0749-3797. Disponível em: <<Go to ISI ://WOS:000272770000010 >.

$\mathrm{KEITH}, \mathrm{M}$. M. et al. Identifying and prioritizing gaming workers' health and safety concerns using mapping for data collection. American Journal of Industrial Medicine, v. 39, n. 1, Jan 2001. ISSN 0271-3586. Disponível em: <<Go to ISI>://WOS:000166239700004 >.

KEUNE, $\mathrm{H}$. et al. Opening the research agenda for selection of hot spots for human biomonitoring research in Belgium: a participatory research project. Environmental Health, v. 9, Jul 6 2010. ISSN 1476069X. Disponível em: < <Go to ISI>://WOS:000282289300001 >.

KOBAYASHI, Y. et al. Effects of a Worker Participatory Program for Improving Work Environments on Job Stressors and Mental Health among Workers: A Controlled Trial. Journal of Occupational Health, v. 50, n. 6, p. 455-470, Nov 2008. ISSN 1341-9145. Disponível em: < <Go to ISI>://WOS:000261661500002 >.

KREUTER, M. W. et al. The impact of implementing selected CBPR strategies to address disparities in urban Atlanta: a retrospective case study. Health Education Research, v. 27, n. 4, Aug 2012. ISSN 02681153. Disponível em: <<Go to ISI $>: /$ WOS:000306647900015 >.

KRIEGER, J. et al. Using community-based participatory research to address social determinants of health: Lessons learned from Seattle partners for healthy communities. Health Education \& Behavior, v. 29, n. 3, Jun 2002. ISSN 1090-1981. Disponível em: < <Go to ISI>:/MOS:000175673400006 >.

LAHTINEN, M.; LAPPALAINEN, S.; REIJULA, K. Multiprofessional teams resolving indoor-air problems emphasis on the psychosocial perspective. Scandinavian Journal of Work Environment \& Health, 2008 2008. ISSN 0355-3140. Disponível em: <<Go to ISI>:/MOS:000255288800007 >.

LANE, R. et al. 'Committing to Place' at the local scale: the potential of youth education programs for promoting community participation in regional natural resource management. Australian Geographer, v. 36, n. 3, Nov 2005. ISSN 0004-9182. Disponível em: < <Go to ISI ://WOS:000235183000006 >.

LATOWSKY, G. Report: Community-based, participatory research in Lawrence, Massachusetts, flags environmental health hazards and fuels education and action. Science Communication, v. 25, n. 2, Dec 2003. ISSN 1075-5470. Disponível em: <<Go to ISI>:/MOS:000186830000007 >.

LAURIAN, L. Public input in toxic site cleanup decisions: the strengths and limitations of Community Advisory Boards. Environment and Planning B-Planning \& Design, v. 32, n. 3, May 2005. ISSN 02658135. Disponível em: <<Go to ISI>:/WOS:000230087800008 >.

LAZENBATT, A.; LYNCH, U.; O'NEILL, E. Revealing the hidden 'troubles' in Northern Ireland: the role of participatory rapid appraisal. Health Education Research, v. 16, n. 5, Oct 2001. ISSN 0268-1153. Disponível em: < <Go to ISI>://WOS:000171582500005 >.

LEVENTON, J.; ANTYPAS, A. Multi-level Governance, Multi-level Deficits: The Case of Drinking Water Management in Hungary. Environmental Policy and Governance, v. 22, n. 4, Jul-Aug 2012. ISSN 1756932X. Disponível em: <<Go to ISI>://WOS:000307475700003 >.

LEWIN, S.; STRAUSS, N. Planning urban environmental health information systems: a case study of Cape Town, South Africa. Environment and Urbanization, v. 11, n. 2, Oct 1999. ISSN 0956-2478. Disponível 
em: $<<$ Go to ISI $>/ /$ WOS:000084096500018 >.

LEWIS, T. C. et al. Identification of gaps in the diagnosis and treatment of childhood asthma using a community-based participatory research approach. Journal of Urban Health-Bulletin of the New York Academy of Medicine, v. 81, n. 3, Sep 2004. ISSN 1099-3460. Disponível em: <<Go to ISI>:/WOS:000223152200014 >.

LEYS, A. J.; VANCLAY, J. K. Stakeholder engagement in social learning to resolve controversies over landuse change to plantation forestry. Regional Environmental Change, v. 11, n. 1, p. 175-190, Mar 2011. ISSN 1436-3798. Disponível em: <<Go to ISI>://WOS:000287596900014 >.

MAANTAY, J. Zoning law, health, and environmental justice: What's the connection? Journal of Law Medicine \& Ethics, v. 30, n. 4, Win 2002. ISSN 1073-1105. Disponível em: <<Go to ISI>:/WOS:000180463200011 >.

MANOTHUM, A. et al. A Participatory Model for Improving Occupational Health and Safety: Improving Informal Sector Working Conditions in Thailand. International Journal of Occupational and Environmental Health, v. 15, n. 3, p. 305-314, Jul-Sep 2009. ISSN 1077-3525. Disponível em: <<Go to ISI>:/WOS:000268362600010 >.

MASUDA, J. R. et al. Out of our inner city backyards: Re-scaling urban environmental health inequity assessment. Social Science \& Medicine, v. 75, n. 7, Oct 2012. ISSN 0277-9536. Disponível em: <<Go to ISI>:/WOS:000307697600012 >.

MAY, M. L. et al. Embracing the local: Enriching scientific research, education, and outreach on the TexasMexico border through a participatory action research partnership. Environmental Health Perspectives, v. 111, n. 13, Oct 2003. ISSN 0091-6765. Disponível em: < <Go to ISI>:/WOS:000185940800020 >.

MENDENHALL, T. et al. The SANTA Project (Students Against Nicotine and Tobacco Addiction): Using community-based participatory research to reduce smoking in a high-risk young adult population. Action Research, v. 9, n. 2, p. 199-213, Jun 2011. ISSN 1476-7503. Disponível em: < <Go to ISI>://WOS:000291589400006 >.

MIKKELSEN, A.; SAKSVIK, P. O. Impact of a participatory organizational intervention on job characteristics and job stress. International Journal of Health Services, v. 29, n. 4, 1999 1999. ISSN 0020-7314.

Disponível em: <<Go to ISI>://WOS:000084117400012 >.

MILLARD, J. e-Government strategies: Best practice reports from the European front line. In: TRAUMULLER, R. e LENK, K. (Ed.). Electronic Government, Proceedings, v.2456, 2002. (Lecture Notes in Computer Science). ISBN 0302-9743

3-540-44121-2.

MINKLER, M. et al. Si Se Puede: Using Participatory Research to Promote Environmental Justice in a Latino Community in San Diego, California. Journal of Urban Health-Bulletin of the New York Academy of Medicine, v. 87, n. 5, p. 796-812, Sep 2010. ISSN 1099-3460. Disponível em: < <Go to ISI>://WOS:000281726100007 >.

Promoting environmental justice through community-based participatory research: The role of

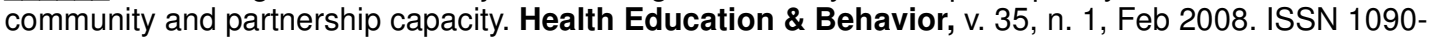
1981. Disponível em: <<Go to ISI>:/WOS:000252744200007 >.

MOCTEZUMA, P. Community-based organization and participatory planning in south-east Mexico City. Environment and Urbanization, v. 13, n. 2, Oct 2001. ISSN 0956-2478. Disponível em: < <Go to ISI>://WOS:000172217000009 >.

MOGLIA, M. et al. Application of the Water Needs Index: Can Tho City, Mekong Delta, Vietnam. Journal of Hydrology, v. 468, Oct 25 2012. ISSN 0022-1694. Disponível em: < <Go to ISI>://WOS:000310415200019 >.

MONCADA, S. et al. CC.OO. ("Comisiones Obreras") - ISTAS (Union Institute of Work, Environment and 
Health) participatory action plan for a healthier work organization: A case study. Safety Science, v. 49, n. 4, p. 591-598, Apr 2011. ISSN 0925-7535. Disponível em: <<Go to ISI>://WOS:000288975900007 >.

MONTIEL, R. P.; BARTEN, F. Urban governance and health development in Leon, Nicaragua. Environment and Urbanization, v. 11, n. 1, Apr 1999. ISSN 0956-2478. Disponível em: < <Go to ISI>:/WOS:000080654000002 >.

MOODIE, S. M.; TSUI, E. K.; SILBERGELD, E. K. Community- and family-level factors influence care-giver choice to screen blood lead levels of children in a mining community. Environmental Research, v. 110, n. 5, p. 484-496, Jul 2010. ISSN 0013-9351. Disponível em: <<Go to ISI>://WOS:000279128700013 >.

MUNOZ, G. et al. Ecosystem approach to promoting appropriate antibiotic use for children in indigenous communities in Ecuador. Revista Panamericana De Salud Publica-Pan American Journal of Public Health, v. 30, n. 6, p. 566-573, Dec 2011. ISSN 1020-4989. Disponível em: < <Go to ISI>://WOS:000300352800012 >

NADER, M. R.; SALLOUM, B. A.; KARAM, N. Environment and sustainable development indicators in Lebanon: A practical municipal level approach. Ecological Indicators, v. 8, n. 5, p. 771-777, Sep 2008. ISSN 1470-160X. Disponível em: < <Go to ISI>:/WOS:000255625200035 >.

NAMPANYA, S. et al. Improvement in Smallholder Farmer Knowledge of Cattle Production, Health and Biosecurity in Southern Cambodia between 2008 and 2010. Transboundary and Emerging Diseases, v. 59, n. 2, p. 117-127, Apr 2012. ISSN 1865-1674. Disponível em: < <Go to ISI>:/MOS:000301122700003 >

NARE, L.; LOVE, D.; HOKO, Z. Involvement of stakeholders in the water quality monitoring and surveillance system: The case of Mzingwane Catchment, Zimbabwe. Physics and Chemistry of the Earth, v. 31, n. 15-16, 2006 2006. ISSN 1474-7065. Disponível em: < <Go to ISI>://WOS:000241483000007 >.

NELSON, J. W. et al. A New Spin on Research Translation: The Boston Consensus Conference on Human Biomonitoring. Environmental Health Perspectives, v. 117, n. 4, p. 495-499, Apr 2009. ISSN 0091-6765. Disponível em: <<Go to ISI>://WOS:000264704500020 >.

NGUYEN, M. N.; OTIS, J. Evaluating the fabreville heart health program in Laval, Canada: A dialogue between two paradigms, positivism and constructivism. Health Promotion International, v. 18, n. 2, Jun 2003. ISSN 0957-4824. Disponível em: <<Go to ISI>://WOS:000182955800006 >.

NUSSBAUM, R. H. et al. Community-based participatory health survey of Hanford, WA, Downwinders: A model for citizen empowerment. Society \& Natural Resources, v. 17, n. 6, Jul 2004. ISSN 0894-1920. Disponível em: <<Go to ISI ://WOS:000221582500007 >.

O'FALLON, L. R. et al. Strategies for setting a national research agenda that is responsive to community needs. Environmental Health Perspectives, v. 111, n. 16, Dec 2003. ISSN 0091-6765. Disponível em: < $<$ Go to ISI >:/WOS:000187034000029 >.

ONYANGO-OUMA, W.; AAGAARD-HANSEN, J.; JENSEN, B. B. The potential of schoolchildren as health change agents in rural western Kenya. Social Science \& Medicine, v. 61, n. 8, Oct 2005. ISSN 02779536. Disponível em: <<Go to ISI>:/WOS:000231462700009 >.

OUDSHOORN, F. W.; SORENSEN, C. A. G.; DE BOER, I. J. M. Economic and environmental evaluation of three goal-vision based scenarios for organic dairy farming in Denmark. Agricultural Systems, v. 104, n. 4, p. 315-325, Apr 2011. ISSN 0308-521X. Disponível em: <<Go to ISI>:/WOS:000290194200003 >.

PALIS, F. G. et al. Can humans outsmart rodents? Learning to work collectively and strategically. Wildlife Research, v. 38, n. 7, p. 568-578, 2011 2011. ISSN 1035-3712. Disponível em: <<Go to ISI>://WOS:000297518200005 >.

PARKER, E. A. et al. Application of health promotion theories and models for environmental health. Health Education \& Behavior, v. 31, n. 4, Aug 2004. ISSN 1090-1981. Disponível em: <<Go to ISI>://WOS:000222816100005 >. 
Community Organizing Network for Environmental Health: Using a Community Health

Development Approach to Increase Community Capacity around Reduction of Environmental Triggers. Journal of Primary Prevention, v. 31, n. 1-2, p. 41-58, Apr 2010. ISSN 0278-095X. Disponível em: <<Go to ISI>://WOS:000281506900005 >.

Evaluation of community action against asthma: A community health worker intervention to improve children's asthma-related health by reducing household environmental triggers for asthma. Health Education \& Behavior, v. 35, n. 3, Jun 2008. ISSN 1090-1981. Disponível em: <<Go to ISI>://WOS:000255570700006 >.

Community action against asthma - Examining the partnership process of a community-based participatory research project. Journal of General Internal Medicine, v. 18, n. 7, Jul 2003. ISSN 08848734. Disponível em: < <Go to ISI>:/WOS:000184042500008 >.

PAYNE-STURGES, D. C.; SCHWAB, M.; BUCKLEY, T. J. Closing the research loop: A risk-based approach for communicating results of air pollution exposure studies. Environmental Health Perspectives, v. 112, n. 1, Jan 2004. ISSN 0091-6765. Disponível em: < <Go to ISI>://WOS:000187914500036 >.

PETROKOFSKY, G. et al. A participatory process for identifying and prioritizing policy-relevant research questions in natural resource management: a case study from the UK forestry sector. Forestry, v. 83, n. 4, p. 357-367, Oct 2010. ISSN 0015-752X. Disponível em: <<Go to ISI>:/WOS:000282432800002 >.

PINTO, R. M.; DA SILVA, S. B.; SORIANO, R. Community Health Workers in Brazil's Unified Health System: A framework of their praxis and contributions to patient health behaviors. Social Science \& Medicine, v. 74, n. 6, p. 940-947, Mar 2012. ISSN 0277-9536. Disponível em: < <Go to ISI>://WOS:000302522600019 >.

PLESCIA, M.; HERRICK, H.; CHAVIS, L. Improving health behaviors in an African American community: The Charlotte racial and ethnic approaches to community health project. American Journal of Public Health, v. 98, n. 9, p. 1678-1684, Sep 2008. ISSN 0090-0036. Disponível em: <<Go to ISI>://WOS:000258476400031 >.

PLUMMER, P. et al. Making epidemiologic studies responsive to the needs of participants and communities: The Carolina Breast Cancer Study experience. Environmental and Molecular Mutagenesis, v. 39, n. 2-3, 2002 2002. ISSN 0893-6692. Disponível em: < <Go to ISI>://WOS:000174494000004 >

POSTMA, J. Elucidating empowerment in El Proyecto Bienestar (the Well-Being Project). Journal of Advanced Nursing, v. 62, n. 4, May 2008. ISSN 0309-2402. Disponível em: < <Go to ISI>://WOS:000255714600004 >.

POTVIN, L. et al. Implementing participatory intervention and research in communities: lessons from the Kahnawake Schools Diabetes Prevention Project in Canada. Social Science \& Medicine, v. 56, n. 6, Mar 2003. ISSN 0277-9536. Disponível em: <<Go to ISI>://WOS:000181540300013 >.

POULSEN, K. B. The Healthy Bus project in Denmark: need for an action potential assessment. Health Promotion International, v. 19, n. 2, Jun 1 2004. ISSN 0957-4824. Disponível em: < <Go to ISI>://WOS:000221295000008 >.

QUIGLEY, D. et al. Participatory research strategies in nuclear risk management for native communities. Journal of Health Communication, v. 5, n. 4, Oct-Dec 2000. ISSN 1081-0730. Disponível em: <<Go to ISI>://WOS:000165566500003 >.

RAHMAN, M. H.; LUND, T.; BRYCESON, I. Salinity effects on food habits in three coastal, rural villages in Bangladesh. Renewable Agriculture and Food Systems, v. 26, n. 3, p. 230-242, Sep 2011. ISSN 17421705. Disponível em: <<Go to ISI>://WOS:000294120900007 >.

RAINE, K. D. et al. Reflections on community-based population health intervention and evaluation for obesity and chronic disease prevention: the Healthy Alberta Communities project. International Journal of 
Public Health, v. 55, n. 6, p. 679-686, Dec 2010. ISSN 1661-8556. Disponível em: < <Go to ISI>://WOS:000284652200022 >.

REED, M. S.; DOUGILL, A. J.; BAKER, T. R. Participatory indicator development: What can ecologists and local communities learn from each other? Ecological Applications, v. 18, n. 5, p. 1253-1269, Jul 2008. ISSN 1051-0761. Disponível em: <<Go to ISI>://WOS:000257719600013 >.

ROSENTHAL, J. K. et al. Links between the built environment, climate and population health: Interdisciplinary environmental change research in New York City. Annals Academy of Medicine Singapore, v. 36, n. 10, Oct 2007. ISSN 0304-4602. Disponível em: <<Go to ISI>://WOS:000250988600009 >.

ROWE, J. Voices From the Inside: African American Women's Perspectives on Healthy Lifestyles. Health Education \& Behavior, v. 37, n. 6, p. 789-800, Dec 2010. ISSN 1090-1981. Disponível em: < <Go to ISI >:/WOS:000285005100003 >.

RUDTANASUDJATUM, K.; IEEE. Road Traffic Accidents Management Model: The Successful Application of Stakeholder Involvement in Chon Buri, Thailand. 2008. ISBN 978-1-4244-2857-1. Disponível em: <<Go to ISI>://WOS:000264749600038 >.

SAN SEBASTIAN, M.; HURTIG, A. K. Oil development and health in the Amazon basin of Ecuador: the popular epidemiology process. Social Science \& Medicine, v. 60, n. 4, Feb 2005. ISSN 0277-9536. Disponível em: <<Go to ISI>://WOS:000226430300012 >.

SANCHEZ, L. et al. A community education strategy to promote participation in dengue prevention in Cuba. Revista Panamericana De Salud Publica-Pan American Journal of Public Health, v. 24, n. 1, p. 61-69, Jul 2008. ISSN 1020-4989. Disponível em: <<Go to ISI>://WOS:000258505200008 >.

Community participation in the control of Aedes aegypti: opinions of the population in one section of Havana, Cuba. Revista Panamericana De Salud Publica-Pan American Journal of Public Health, v. 15, n. 1, Jan 2004. ISSN 1020-4989. Disponível em: < <Go to ISI ://WOS:000227068400004 >.

SANCHEZ, Y. A. et al. Research needs for community-based risk assessment: findings from a multidisciplinary workshop. Journal of Exposure Science and Environmental Epidemiology, v. 20, n. 2, p. 186-195, Mar-Apr 2010. ISSN 1559-0631. Disponível em: <<Go to ISI >:/WOS:000274649700010 >.

SCHELL, L. M. et al. Health disparities and toxicant exposure of Akwesasne Mohawk young adults: A partnership approach to research. Environmental Health Perspectives, v. 113, n. 12, Dec 2005. ISSN 0091-6765. Disponível em: < <Go to ISI>://WOS:000233713200061 >.

SCHLOSSBERG, M.; BREHM, C. Participatory Geographic Information Systems and Active Transportation Collecting Data and Creating Change. Transportation Research Record, n. 2105, p. 83-91, 20092009. ISSN 0361-1981. Disponível em: <<Go to ISI>:/WOS:000271410500011 >.

SCHROEDER, P. C. et al. The Gulf of Maine Environmental Information Exchange: participation, observation, conversation. Environment and Planning B-Planning \& Design, v. 28, n. 6, Nov 2001. ISSN 0265-8135. Disponível em: <<Go to ISI>://WOS:000172859600005 >.

SCHULZ, A.; NORTHRIDGE, M. E. Social determinants of health: Implications for environmental health promotion. Health Education \& Behavior, v. 31, n. 4, Aug 2004. ISSN 1090-1981. Disponível em: < <Go to $|S|>: / /$ WOS:000222816100003 >.

SCHULZ, A. J. et al. Social and physical environments and disparities in risk for cardiovascular disease: The Healthy Environments Partnership conceptual model. Environmental Health Perspectives, v. 113, n. 12, Dec 2005. ISSN 0091-6765. Disponível em: <<Go to ISI>://WOS:000233713200060 >.

SCHWEIGMANN, N. et al. Information, knowledge, and perception of dengue risk in Argentina: two intervention experiments to generate local control strategies. Cadernos De Saude Publica, v. 25, p. S137S148, 2009 2009. ISSN 0102-311X. Disponível em: < <Go to ISI>://WOS:000264201300013 >. 
SIQUEIRA, C. E.; JANSEN, T. Working Conditions of Brazilian Immigrants in Massachusetts. Journal of Immigrant and Minority Health, v. 14, n. 3, p. 481-488, Jun 2012. ISSN 1557-1912. Disponível em: <<Go to ISI>://WOS:000303525100015 >.

SLOANE, D. et al. Assessing resource environments to target prevention interventions in community chronic disease control. Journal of Health Care for the Poor and Underserved, v. 17, n. 2, May 2006. ISSN 1049-2089. Disponível em: < <Go to ISI>://WOS:000237924600012 >.

SLOANE, D. C. et al. Improving the nutritional resource environment for healthy living through communitybased participatory research. Journal of General Internal Medicine, v. 18, n. 7, Jul 2003. ISSN 08848734. Disponível em: <<Go to ISI>:/WOS:000184042500009 >.

SNIDER, C. E. et al. Community-based Participatory Research: Development of an Emergency Department-based Youth Violence Intervention Using Concept Mapping. Academic Emergency Medicine, v. 17, n. 8, p. 877-885, Aug 2010. ISSN 1069-6563. Disponível em: < <Go to ISI>://WOS:000280449500013 >.

SPIEGEL, J. M. et al. Promoting health in response to global tourism expansion in Cuba. Health Promotion International, v. 23, n. 1, Mar 2008. ISSN 0957-4824. Disponível em: <<Go to ISI>://WOS:000253490500008 >.

STERN, R.; PUOANE, T.; TSOLEKILE, L. An Exploration into the Determinants of Noncommunicable Diseases Among Rural-to-Urban Migrants in Periurban South Africa. Preventing Chronic Disease, v. 7, n. 6, Nov 2010. ISSN 1545-1151. Disponível em: <<Go to ISI ://WOS:000208158900018 >.

SULLIVAN, J. et al. Theatre of the oppressed and environmental justice communities: a transformational therapy for the body politic. Journal of Health Psychology, v. 13, n. 2, Mar 2008. ISSN 1359-1053. Disponível em: <<Go to ISI>://WOS:000255167200003 >.

TAKANO, T.; NAKAMURA, K. Participatory research to enhance vision sharing for Healthy Town initiatives in Japan. Health Promotion International, v. 19, n. 3, Sep 2004. ISSN 0957-4824. Disponível em: <<Go to ISI>://WOS:000223826200004 >.

TERRY, J. P.; KHATRI, K. People, pigs and pollution - Experiences with applying participatory learning and action (PLA) methodology to identify problems of pig-waste management at the village level in Fiji. Journal of Cleaner Production, v. 17, n. 16, p. 1393-1400, Nov 2009. ISSN 0959-6526. Disponível em: <<Go to ISI>://WOS:000270162400002 >.

TITZ, A.; DOELL, P. Actor modelling and its contribution to the development of integrative strategies for management of pharmaceuticals in drinking water. Social Science \& Medicine, v. 68, n. 4, p. 672-681, Feb 2009. ISSN 0277-9536. Disponível em: <<Go to ISI>://WOS:000264041300012 >.

TRUDEL, L. et al. The adverse effects of psychosocial constraints at work: A participatory study to orient prevention to mitigate psychological distress. Work-a Journal of Prevention Assessment \& Rehabilitation, v. 34, n. 3, p. 345-357, 2009 2009. ISSN 1051-9815. Disponível em: < <Go to ISI>://WOS:000273753600012 >.

TSCHAKERT, P.; SINGHA, K. Contaminated identities: Mercury and marginalization in Ghana's artisanal mining sector. Geoforum, v. 38, n. 6, Nov 2007. ISSN 0016-7185. Disponível em: <<Go to ISI>://WOS:000250859000021 >.

TSEVRENI, I. Towards an environmental education without scientific knowledge: an attempt to create an action model based on children's experiences, emotions and perceptions about their environment. Environmental Education Research, v. 17, n. 1, p. 53-67, 2011 2011. ISSN 1350-4622. Disponível em: < $<$ Go to ISI>://WOS:000287318600004 >.

VAN DEN HOVE, S. A rationale for science-policy interfaces. Futures, v. 39, n. 7, p. 807-826, Sep 2007. ISSN 0016-3287. Disponível em: <<Go to ISI>://WOS:000247248600003 >.

VAN OOSTROM, S. H. et al. Development of a workplace intervention for sick-listed employees with 
stress-related mental disorders: Intervention Mapping as a useful tool. Bmc Health Services Research, v. 7, Aug 15 2007. ISSN 1472-6963. Disponível em: <<Go to ISI>://WOS:000250053800001 >.

VASQUEZ, V. B.; MINKLER, M.; SHEPARD, P. Promoting environmental health policy through community based participatory research: A case study from Harlem, New York. Journal of Urban Health-Bulletin of the New York Academy of Medicine, v. 83, n. 1, Jan 2006. ISSN 1099-3460. Disponível em: < <Go to ISI ://WOS:000237227300010 >.

WALTNER-TOEWS, D. et al. Perspective changes everything: managing ecosystems from the inside out. Frontiers in Ecology and the Environment, v. 1, n. 1, Feb 2003. ISSN 1540-9295. Disponível em: <<Go to ISI : //WOS:000221789300016 >.

WANG, C. C.; PIES, C. A. Family, maternal, and child health through photovoice. Maternal and Child Health Journal, v. 8, n. 2, Jun 2004. ISSN 1092-7875. Disponível em: <<Go to ISI >://WOS:000226627000007 >.

WELLS, N. M. Our housing, our selves: A longitudinal investigation of low-income women's participatory housing experiences. Journal of Environmental Psychology, v. 25, n. 2, Jun 2005. ISSN 0272-4944. Disponível em: <<Go to ISI>://WOS:000232192200006 >.

WHITTINGTON, D. et al. Designing a "neighborhood deal" for urban sewers: A case study of Semarang, Indonesia. Journal of Planning Education and Research, v. 19, n. 3, Spr 2000. ISSN 0739-456X. Disponível em: <<Go to ISI>://WOS:000087114900008 >.

WIEK, A.; GASSER, L.; SIEGRIST, M. Systemic scenarios of nanotechnology: Sustainable governance of emerging technologies. Futures, v. 41, n. 5, p. 284-300, Jun 2009. ISSN 0016-3287. Disponível em: < <Go to $|S|>: /$ WOS:000266317900005 >.

WILLIAMS, A. et al. Knowledge translation strategies in a community-university partnership: Examining local Quality of Life (QoL). Social Indicators Research, v. 85, n. 1, Jan 2008. ISSN 0303-8300. Disponível em: $<<$ Go to ISI $>/ /$ WOS:000250627200008 >.

WING, S. et al. Integrating epidemiology, education, and organizing for environmental justice: Community health effects of industrial hog operations. American Journal of Public Health, v. 98, n. 8, p. 1390-1397, Aug 2008. ISSN 0090-0036. Disponível em: <<Go to ISI ::/WOS:000257940800013 >.

WOLCH, J. et al. The forgotten and the future: reclaiming back alleys for a sustainable city. Environment and Planning A, v. 42, n. 12, p. 2874-2896, Dec 2010. ISSN 0308-518X. Disponível em: < <Go to ISI>://WOS:000287260600007 >.

WRIDT, P. A qualitative GIS approach to mapping urban neighborhoods with children to promote physical activity and child-friendly community planning. Environment and Planning B-Planning \& Design, v. 37, n. 1, p. 129-147, Jan 2010. ISSN 0265-8135. Disponível em: < <Go to ISI >:/WOS:000275483200009 >.

WUSTENBERGHS, $\mathrm{H}$. et al. A dual indicator set to help farms achieve more sustainable crop protection. Pest Management Science, v. 68, n. 8, Aug 2012. ISSN 1526-498X. Disponível em: < <Go to ISI>://WOS:000306496300004 >.

ZIELINSKI-GUTIERREZ, E. C.; HAYDEN, M. H. A model for defining West Nile virus risk perception based on ecology and proximity. Ecohealth, v. 3, n. 1, Mar 2006. ISSN 1612-9202. Disponível em: < <Go to ISI>://WOS:000238180800004 >. 